EGG-IS-5806

March 1982

\title{
MUON-CATALYZED FUSION EXPERIMENT \\ TARGET AND DETECTOR SYSTEMS \\ PRELIMINARY DESIGN REPORT
}

\section{MASTER}
S. E. Jones
K. D. Watts
A. J. Caffrey
J. B. Waiter

\section{U.S. Department of Energy}

\section{Idaho Operations Office • Idaho National Engineering Laboratory}

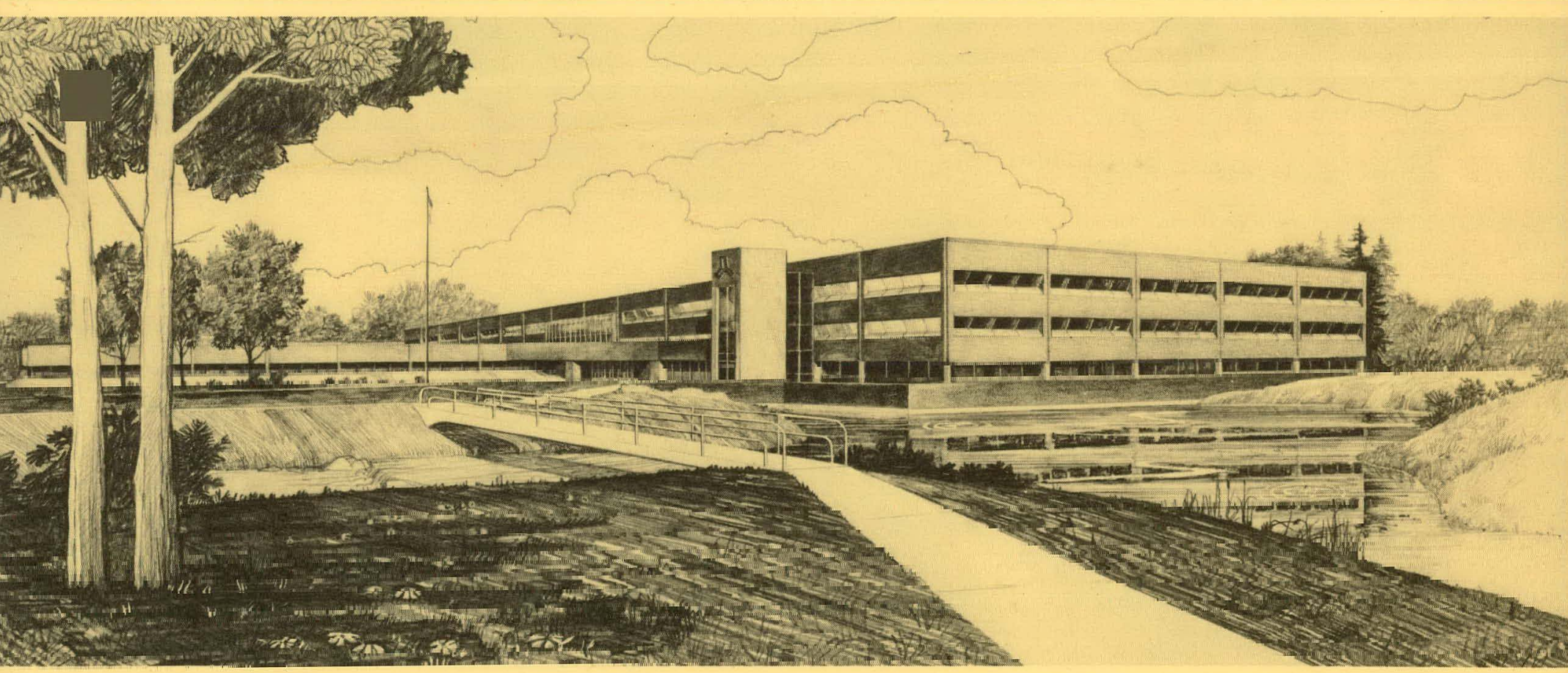

This is an informal report intended for use as a preliminary or working document

Prepared for the

U.S. Department of Energy

Idaho Operations office

Under DOE Contract No. DE-ACO7-76IDO1570 


\section{DISCLAIMER}

This report was prepared as an account of work sponsored by an agency of the United States Government. Neither the United States Government nor any agency Thereof, nor any of their employees, makes any warranty, express or implied, or assumes any legal liability or responsibility for the accuracy, completeness, or usefulness of any information, apparatus, product, or process disclosed, or represents that its use would not infringe privately owned rights. Reference herein to any specific commercial product, process, or service by trade name, trademark, manufacturer, or otherwise does not necessarily constitute or imply its endorsement, recommendation, or favoring by the United States Government or any agency thereof. The views and opinions of authors expressed herein do not necessarily state or reflect those of the United States Government or any agency thereof. 


\section{DISCLAIMER}

Portions of this document may be illegible in electronic image products. Images are produced from the best available original document. 


\section{DISCLAIMER}

This book was prepared as an account of work sponsored by an agency of the United States Government. Neither the United States Government nor any agency thereof, nor any of their employees, makes any warranty, express or implied, or assumes any legal liability or responsibility for the accuracy, completeness, or usefulness of any information, apparatus, product or process disclosed, or represents that its use would not infringe privately owned rights. References herein to any specific commercial product, process, or service by trade name, trademark, manufacturer, or otherwise, does not necessarily constitute or imply its endorsement, recommendation, or favoring by the United States Government or any agency thereof. The views and opinions of authors expressed herein do not necessarily state or reflect those of the United States Government or any agency thereof. 


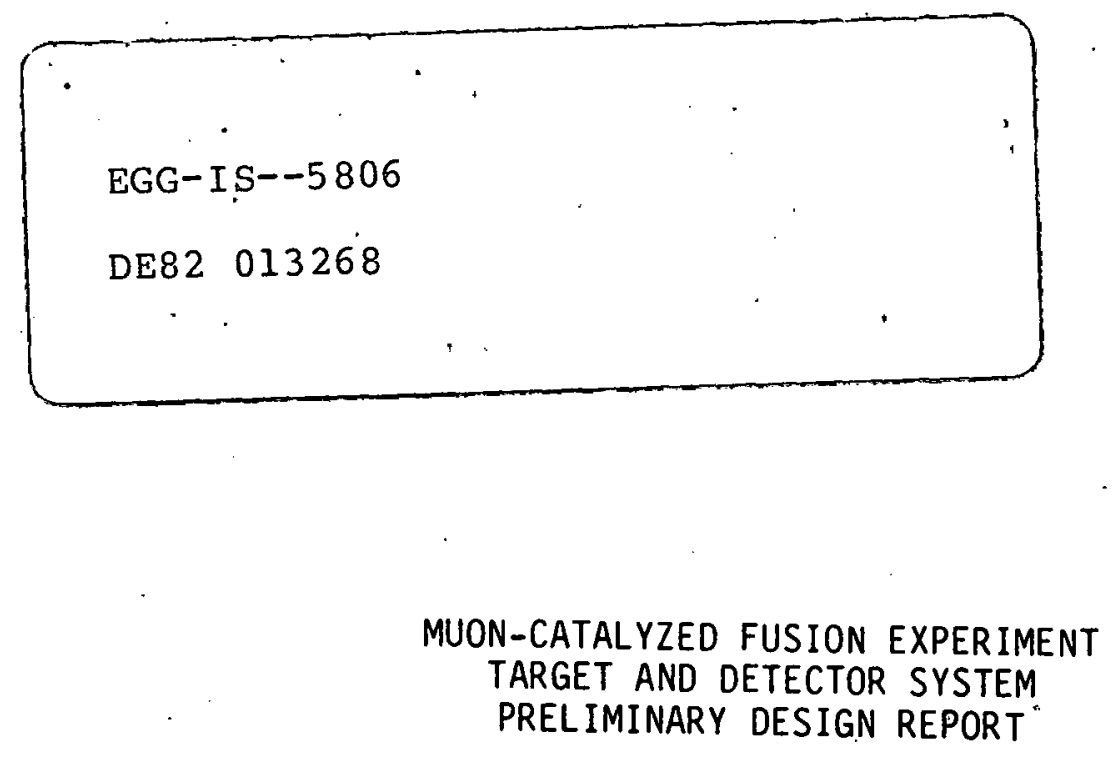

EGG-IS-5806

$\cdots \cdots$

S. E. Jones

K. D. Watts

A. J. Caffrey

J. B. Walter

i

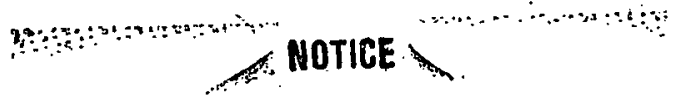

Published March 1982

PORTIOHS OF THIS NEPORT ARE ILIEGIBLE:

li has been reprowuget fron ing best suailable

copy to permit the brasdes! possible availaibility.

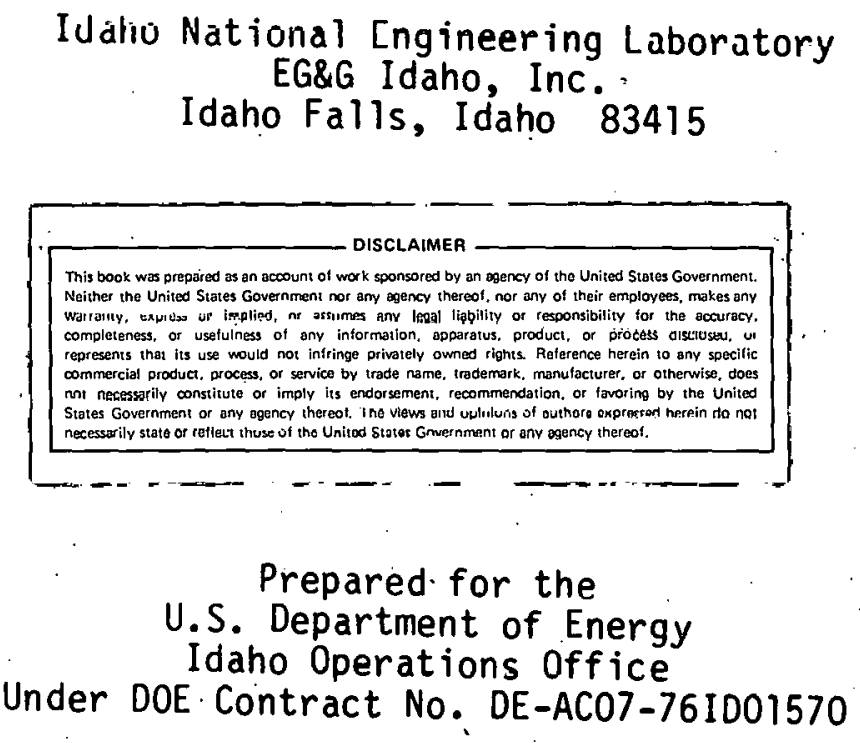

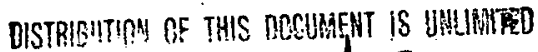


We present detailed plans for the target and particle detector systems for the muon-catalyzed fusion experiment. Requirements imposed on the target vessel by experimental conditions and safety considerations are delineated. Preliminary designs for the target vessel capsule and secondary containment vessel have been developed which meet these requirements. In addition, the particle detection system is outlined, including associated fast electronics and on-line data acquisition. Computer programs developed to study the target and detector system designs are described. 
The authors gratefully acknowledge the assistance of the following persons:

E. G. Grafwallner, R. C. Greenwood, R. L. Heath, J. M: Hoggan, L. 0. Johnson, C. W. Reich and J. R. Smith of the Physics Division, EG\&G Idaho, Inc.; L. S. Masson and L. G. Miller of the Fusion Technology Division, FG\&G Idaho, Inc.; D. F. Holland of the Fusion Reactor Safety Research Program, EG\&G Idaho, Inc.; R. C. Peel and R. S. McPherson of the Mechanical Engineering Division, EG\&G Idaho, Inc.; D. V. Herrera of the Text Processing Branch, EG\&G Idaho, Inc.; J. C. Culley, Scientific Computing Division, EG\&G Idaho, Inc.;

D. Coffin of the Los Alamos National Laboratory; and R. L. Levin of the Johns Hopkins University Physics Department. 


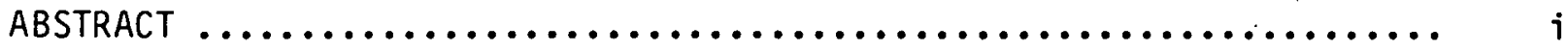

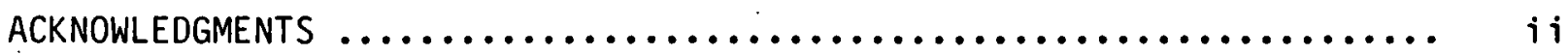

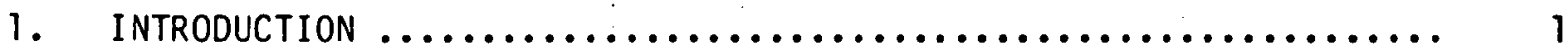

2. TARGET VESSEL DESIGN REQUiREMENTS $\ldots \ldots \ldots \ldots \ldots \ldots \ldots \ldots \ldots \ldots \ldots \ldots$

3. TARGET VESSEL DESIGN DESCRIPTION $\ldots \ldots \ldots \ldots \ldots \ldots \ldots \ldots \ldots \ldots \ldots \ldots, 18$

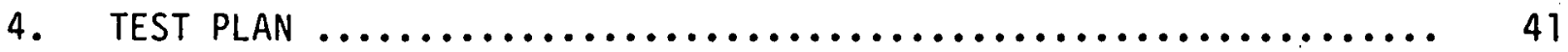

5. SAFETY CONSIDERATIONS $\ldots \ldots \ldots \ldots \ldots \ldots \ldots \ldots \ldots \ldots \ldots \ldots \ldots . \ldots \ldots \ldots$

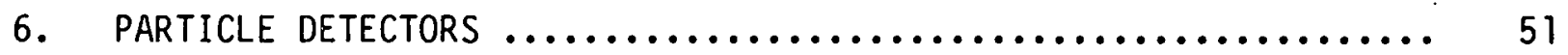

7. FAST ElECTRONICS $\ldots \ldots \ldots \ldots \ldots \ldots \ldots \ldots \ldots \ldots \ldots \ldots \ldots \ldots \ldots \ldots . \ldots \ldots$

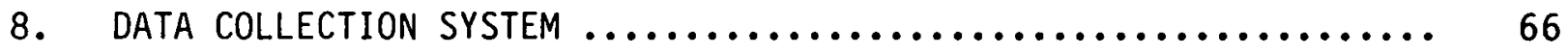

APPENDIX A--COMPUTER PROGRAM SIMUT: MUON BEAM DEGRADATION

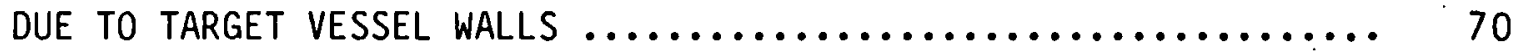

APPENDIX B--COMPUTER PROGRAM SOLANG: MONTE CARLO CALCULATION

OF AVERAGE SOLID ANGLE SUBTENDED BY CYLINDRICAL DETECTORS ...... 77

APPENDIX C--PRESSURE-VOLUME-TEMPERATURE RELATIONS FOR HIGH-DENSITY

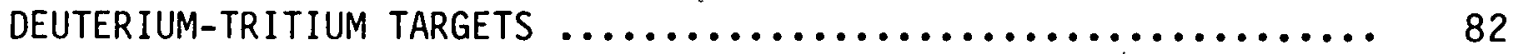

APPENDIX D--COMPUTER PROGRAM TMAP: TRITIUM PERMEATION AND WALL LOADING IN TARGET VESSEL

APPENDIX E--COMPUTER PROGRAM GRACE: MONTE CARLO PROGRAM FOR CALCULATING NEUTRON DETECTION EFFICIENCIES ................... 92

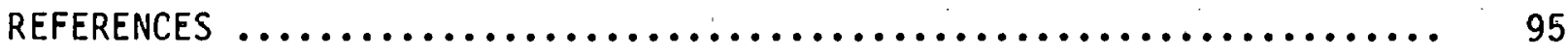




\section{INTRODUCTION}

We have proposed to measure the efficiency of the muon-catalyzed fusion reaction:

$\mu-+d+t+\mu-+{ }^{4} \mathrm{He}+n+17.6 \mathrm{MeV}$

That is, we plan to determine the average number of reaction cycles a muon will induce, as a function of deuterium-tritium ratio, fluid density, and temperature. This measurement is important for accurate assessments of muon catalysis as a fusion energy source. 2,3 we will also measure quantities which affect the efficiency of muon catalysis, increasing our understanding of the process.

Table 1 displays some of the physics quantities which we plan to measure during the experiment. Only one experiment to date has investigated muon reactions in deuterium-tritium mixtures. 10 Consequently, a great deal of original research remains to be performed, as shown on Table 1 .

The planned experiment will be performed using deuterium-tritium targets at elevated densities, temperatures and tritium concentrations. Figure 1 graphically depicts the proposed range of experimental conditions, and shows that these complement conditions selected for previous 10 and planned ${ }^{11}$ experiments in this field. It has been observed that:

Experiments at high mixture densities and tritium concentrations make it possible to measure the sticking coefficient $\left[W_{S}\right]$ as well as determine directly the maximum number of catalysis cycles $\left[\eta_{\mu, \max }\right]$ that can be effected by a single $\mu$-meson. 12

The proposed experiment meets these conditions.

The purpose of this report is to describe the target and particle detection systems in some detail. Computer programs developed to analyze these systems are also described. Our goals are: 
TABLE 1. MAJOR PHYSICS QUANTITIES TO BE MEASURED

Efficiency of muon catalys is of $d-t$ fusion Reactions:

$n_{\mu, \max }$

$\sim 100$

Concentration of Tritium in $d-t$ mixtures for which $\eta_{\mu}$ is maximum:

$\begin{array}{llll}C_{t, \text { opt }} & 50 \% & - & 3,8\end{array}$

Probability of muon capture and retention by helium ion produced during fusion:

$W_{S} \quad 0.0091 \quad-\infty \quad 6$

Deuterium-tritium meso-molecule formation rate:
$\lambda_{d t \mu}$
$3 \times 10^{4} \mathrm{~s}^{-1}$
$10^{8} \mathrm{~s}^{-1}$
$3,9,10$
$0.94 \times 10^{8} \mathrm{~s}^{-1 *}$
(lower limit)

Tritium-tritium meso-molecule formation rate:

$\lambda_{t} t_{\mu}$

$3 x^{5} 10^{-1} s$

11

* Resonance production mechanism prediction. 


\section{COMPARISON OF $\mu d t$ EXPERIMENTS}

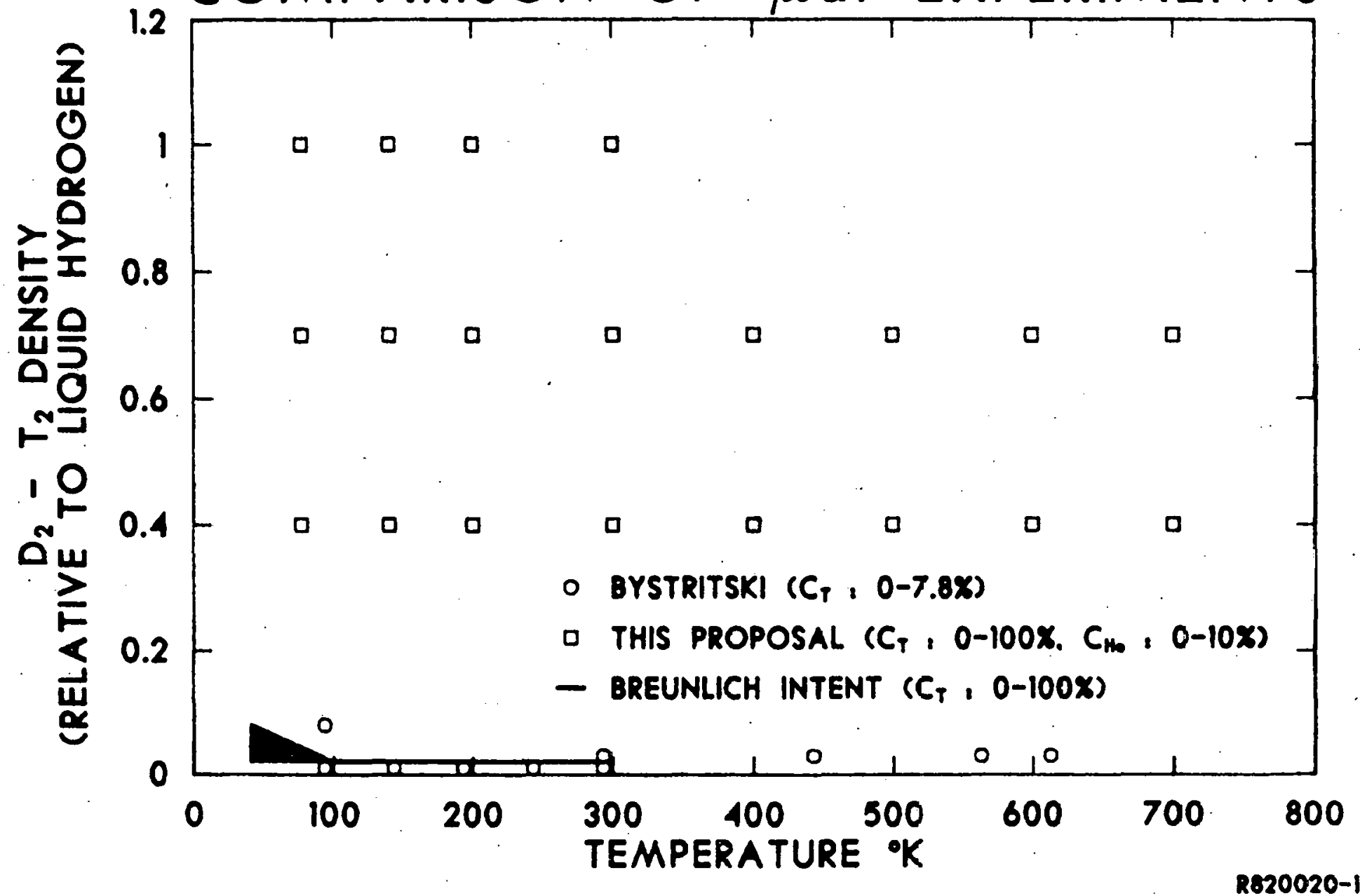

Figure 1. Experimental conditions for muon catalysis experiments. 
1) to establish the feasibility of the proposed experiment; and

2) to provide the basis for discussions with collaborators so that the designs can be finalized.

In parallel with this effort, Group MP-3 at the Los Alamos Meson Physics Facility (LAMPF) is performing studies regarding muon beam parameters and background levels achievable at the Biomedical Channel at LAMPF where this experiment may be performed. 


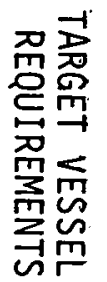




\section{TARGET DESIGN REQUIRCMLNTS}

The Muon Catalyzed Fusion Experiment Mechanical System is to functionally provide the proper environmental conditions for a deuterium/tritium mixture to allow fusion by a muon source. The mechanical system will maintain the mixture at a range of temperatures and pressures that are desired for the experiment.

The mechanical system shall be configured to allow for filling and removing the mixture from a small capsule where the fusion reaction is intended to take place. A secondary containment shall be provided to contain any leakage from the tritium containing components.

A method shall be provided to control the temperature of the capsule from cryogenic temperatures $(=80 \mathrm{~K})$ to elevated temperatures $(\simeq 700 \mathrm{~K})$. Instrumentation and controls will be provided to monitor and control the temperature.

A method shall be provided for mounting and aligning the capsule to the muon beam. This implies mounting and aligning of the secondary containment.

\subsection{Target Vesse 1 Geometry}

Several factors must be weighed in choosing the dimensions of the target vessel. The following considerations suggest the use of a small target (volume $\sim 1 \mathrm{~cm}^{3}$ ).

1. Volume $\sim r^{3}$

The volume of the vessel, and thus the amount of tritium needed to fill it, increases approximately as the cube of the target radius (since the target chamber approximates a sphere). In the reference design (see Figure 2 and Section 3.3) the volume is:

$$
V=2 / 3 \pi r^{3}+\pi r^{2} h=2 / 3 \pi(0.5 \mathrm{~cm})^{3}+\pi(0.5 \mathrm{~cm})^{2} 1.0 \mathrm{~cm}=1.05 \mathrm{~cm}^{3}
$$




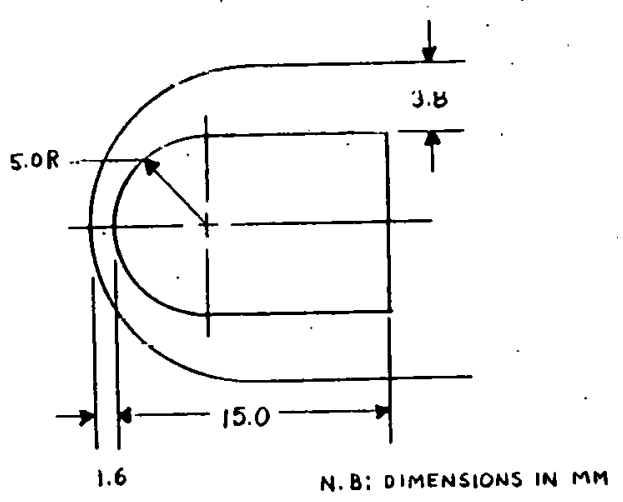

Figure 2. Target vessel diagram used in discussion of shape and size requirements.

This leads to a maximum tritium inventory in a target vesse 1 (at $70 \%$ of liquid hydrogen density) of :

$$
\begin{aligned}
\max T_{2} & =1.05 \mathrm{~cm}^{3} \times 0.7 \times 0.0353 \mathrm{~mole} / \mathrm{cm}^{3} \times 6 \mathrm{gm} / \mathrm{mole} \\
& =0.155 \mathrm{gms}
\end{aligned}
$$

which is equivalent to $\sim 1600$ curies of tritium (maximum).

\section{Muon window thickness $(t) \sim r$}

The thickness of the tip of the vessel increases 1 inearly with the vesse 1 radius. For the reference design,

$t=1.6 \mathrm{~mm}(0.9 \mathrm{~mm}$ for $40 \%$ liquid hydrogen density target only)

The required thickness decreases with the yield strength of the vesse 1 material so that high-strength steel is chosen. Also, the spherical shape of the muon entry window minimizes the thickness needed. On the other hand, the required thickness of the vessel increases with pressure (see Section 3.3.1). Yet the physics requires high target densities and temperatures which lead to high pressures (Figure 1). We seek a reasonable compromise in defining the reference design and experimental parameters. 


\section{Muon beam scatter $\sqrt{\text { thickness }} \sqrt{r}$}

The scattering angle of the beam increases weakly with the thickness of the muon entry window. However, muon scattering is sufficiently significant that it limits the effective length of the $d-t$ target. The cylindrical shape of the target chamber beyond the front window allows for considerable spreading of the beam. In the reference design, approximately as many high-momentum muons scatter into the sides of the vessel as enter the back wall $15 \mathrm{~mm}$ from the window due to straggling, so that increasing the vessel length benefits little. (This assumes $\sim 8 \%$ momentum bite on the muon beam. For more details, see Appendix $A_{\text {.) }}$ ) We note in passing that the gold plating inside the vessel serves to capture muons which scatter, straggle or diffuse to the walls so that they do not decay and are therefore rejected by event criteria.

\section{Allowable momentum bite decreases with thickness}

Figure 3 shows the dependence of acceptable momentum bite on muon entry window thickness, assuming $\sim 70 \%$ of muons stop in the $d-t$ target (see Appendix A.). Since a tight momentum bite may be difficult to obtain, a thin window is indicated. The reference design allows a momentum bite of $\sim 8 \% \mathrm{FWHM}$ at muon momentum $=50.3 \mathrm{MeV} / \mathrm{C}$ with muon losses in target vessel walls of $\sim 30 \%$ for $d-t$ fluid density of $70 \% 1$ iquid hydrogen density $(\phi=0.7)$.

\section{Geometrical neutron detection efficiency}

It becomes increasingly difficult to maintain high geometrical efficiency of detectors $\left(n_{g}\right.$ ) and low $\delta n_{g} / n_{g}$ (due to finite target size) as the target vessel size increases. For the reference design, we find (see Appendix $B$ ):

$n_{g} \simeq 68 \%$

$\delta n_{g} / n_{g} \sim 0.2 \%$ 


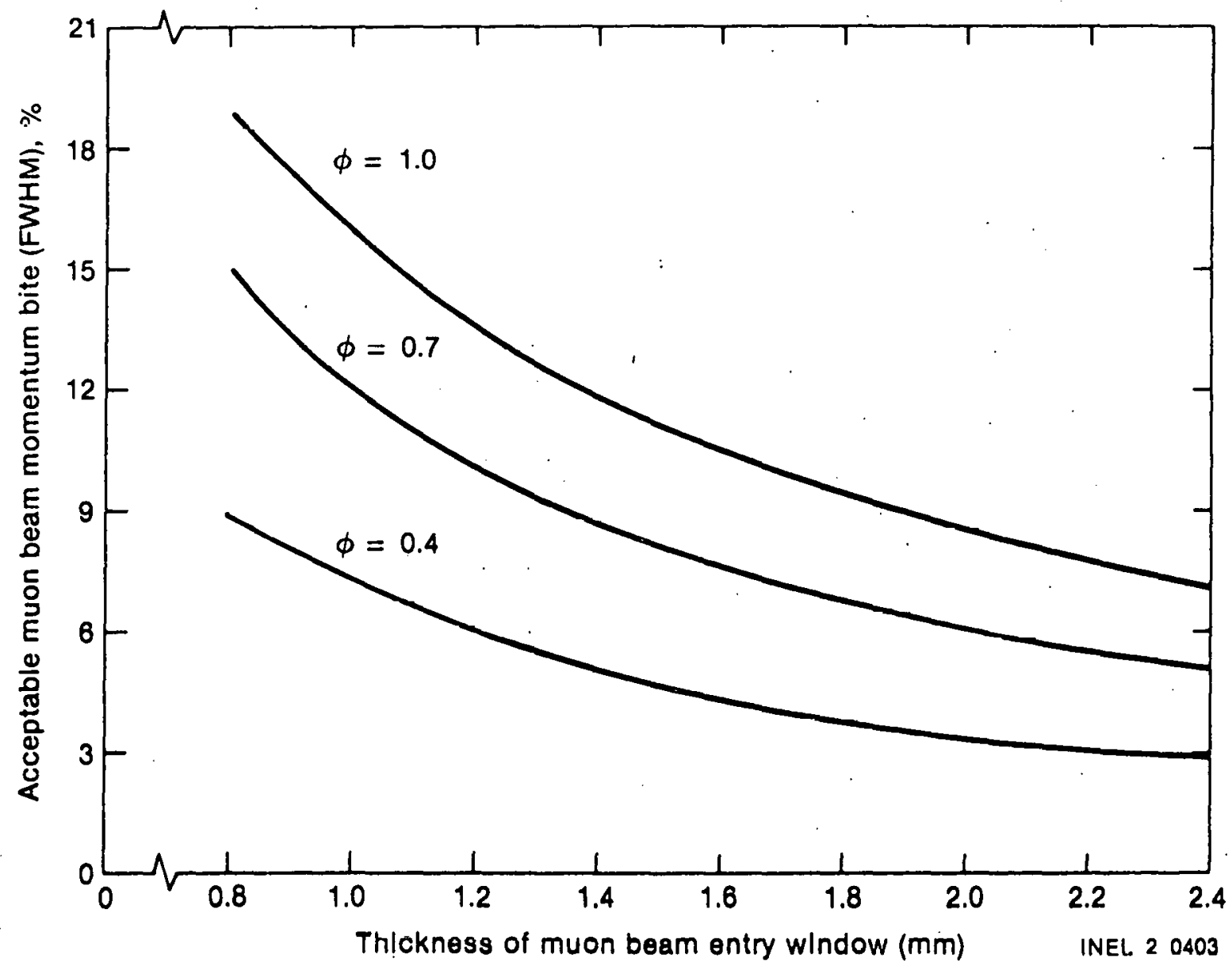

Figure 3. Dependence of acceptable muon beam momentum bite on muon entry window thickness. 
By contrast, a target vessel twice the size with the same detectors would imply:

$\eta_{g} \simeq 51 \%$

$\delta n_{g} / n_{g} \sim 2.1 \%$

A larger vessel, on the other hand, would admit a beam of larger cross-section, and collimating the beam to a small spot undoubtedly increases background radiation. However, a number of techniques minimize this problem:

1- Place collimators as far upstream from the target as possible (particularly before a bending magnet).

2- Use low-z collimators to minimize neutron background.

3- Use veto counters near the target to detect charged halo particles.

In the reference design, a spot size of $\sim 6 \mathrm{~mm}$ FWHM is required. If the beam is converging (e.g., by the use of a collimator with a cone-shaped hole), a somewhat larger spot would be acceptable.

Finally, we observe that the vessel parameters depend heavily on available muon beam parameters. The reference design (Figure 2) accomodates the following beam characteristics:

Type of beam: $\mu^{-}$

Momentum range: $45-55 \mathrm{MeV} / \mathrm{C}$

Beam spot size: $\sim 6 \mathrm{~mm}$ FWHM ( $\sigma=\operatorname{radius} / 2)$ 
Momentum bite: $\sim 8 \%$ FWHM ( $~ 70 \%$ of $\mu^{-}$stop in target)

Beam intensity: $\sim 10^{3} \mu^{-} / \mathrm{sec}$ (yielding $\sim 20$ events/sec)

If a lower quality beam is used, e.g., one with a significantly larger momentum bite, then either fewer muons will stop in the target, or a larger target may be required with attendent difficulties enumerated above.

\subsection{Design and Operational Requirements}

\subsubsection{Primary System}

The primary system encompasses the tritium-containing components and their related instrumentation and controls.

2.2.1.1 Operating Pressure. The primary system maximum operating pressure is 30,000 psig internal (with a vacuum external). The internal pressure will vary with temperature from $=7860 \mathrm{psig}$ maximum at $80 \mathrm{~K}$ to 30,000 psig at $700 \mathrm{~K}$.

2.2.1.2 Design Pressure. The primary system maximum design pressure shall be $45,000 \mathrm{psig}$ at $700 \mathrm{~K}$.

2.2.1.3 Pressure Test. The primary system shall be pressure tested to $125 \%$ of the maximum operating pressure.

2.2.1.4 Design Temperature. The maximum design temperature is $700 \mathrm{~K}$ and the minimum design temperature is $70 \mathrm{~K}$. The capsule temperature shall be variable over the range. The maximum pressure occurs at the maximum temperature and likewise the minimum pressure will occur at the minimum temperature. (Temperature verse pressure data is included as Appendix C.) 
2.2.1.5 Heater. A heater shall be provided to heat the capsule containing deuterium and tritium from $70 \mathrm{~K}$ to $700 \mathrm{~K}$. The temperature shall be controllable within $\pm 10 \mathrm{~K}$. The heater capacity shall be based on. heating the capsule from $70 \mathrm{~K}$ to $700 \mathrm{~K}$ in 30 minutes.

2.2.1.6 Thermocouples. Redundant thermocouples shall be provided on the capsule to measure the temperature. The range shall be $70 \mathrm{~K}$ to $700 \mathrm{~K}$ with accuracy to $10 \mathrm{~K}$.

\subsubsection{Leakage. The maximum allowable total leak rate from the} primary system due to leakage and permeation shall not exceed $1 \times 10^{-7}$ $\mathrm{scc} / \mathrm{sec}$ deuterium/tritium. The system integrity shall be verified by means of a standard helium leak check. The leak shall not exceed $1 \times 10^{-7}$ $\mathrm{scc} / \mathrm{sec}$ helium. Leakage in excess of $1 \times 10^{-7} \mathrm{scc} / \mathrm{sec}$ may be accommodated by a makeup and collection system if desired.

2.2.1.8 Capsule Filling. There shall be provisions in the design for filling and emptying the capsule and related piping with deuterium and tritium five times. The filling will be accomplished by the LANL Tritium Handling System. This operation will be followed by sealing the primary system internal volume per the requirements of 2.2.1.7.

2.2.1.9 Primary System Internal Volume. the internal volume of the capsule shall be approximately $1 \mathrm{cc}$. The internal volume of the primary piping shall be maintained at a minimum to maintain tritium inventory at a minimum.

2.2.1.10 Primary System Mounting. A means shail be provided to easily mount the primary system to the secondary containment while allowing for expansion and alignment.

2.2.1.11 Thermal Cycling. The capsule shall be designed for 5 thermal cycles from $70 \mathrm{~K}$ to $700 \mathrm{~K}$ to $70 \mathrm{~K}$. this implies pressure cycling from 7800 psig to 30,000 psig. The cycle shall be $>2$ hours. 
2.2.1.12 Capsule Cooling. The capsule shall be designed to allow for cooling (in $30 \mathrm{~min}$. ) to room temperture after having been elevated in temperature $(700 \mathrm{~K})$. This cooling shall be accomplished without opening the secondary containment.

2.2.1.13 Capsule Cavity Configuration. The front wall and side wall of the capsule shall be designed to the minimum thickness to allow muon and neutron penetration and still meet the requirements of 2.2.1.2.

2.2.1.14 Gold Plating. The interior of the capsule shall be coated with 0.002 inches (50 microns) of gold. (See Section 3.3.3.)

2.2.1.15 Degassing. Prior to filling the primary system with deuterium and/or tritium, the internal volume shall be vacuum/thermally $\left(400^{\circ} \mathrm{F}\right)$ degassed at $1 \times 10^{-6}$ torr for 4 hours.

\subsubsection{Secondary Containment}

The secondary containment provides a boundary around the primary system to contain any leaking tritium and to provide a thermal barrier.

2.2.2.1 Operating Pressure. The internal operating pressure shall be vacuum and the external operating pressure shall be atmospheric for the secondary containment.

2.2.2.2 Design Pressure. The secondary containment design pressure shall be $150 \%$ of the operating differential pressure.

2.2.2.3 Penetrations. The secondary containment shall provide for instrument, electrical and piping penetrations as required. Organic sealants (tefion, viton, rubber, etc.) shall not be used, due to the possible presence of tritium, which chemically attacks organics.

2.2.2.4 Leakage The maximum allowable leak rate of the secondary containment shall be $1 \times 10^{-6} \mathrm{scc} / \mathrm{sec}$ helium. 
2.2.2.5 Muon Entry Window. The front face of the secondary containment shall have a window to allow for muon passage. This window shall be made of a low cross-section material (aluminum) and shall be as thin as possible and still meet the pressure and sealing requirements.

2.2.2.6 Mounting. A means shall be provided for mounting the secondary containment and aligning it to the muon beam.

2.2.2.7 Volume. The internal volume of the secondary containment shall be sufficiently large to prevent internal positive pressurization of the containment if the contents of the primary system are released.

2.2.2.8 Vacuum Connection. A vacuum connection (flange) shall be provided on the outside of the secondary containment to provide for pulling a vacuum on the containment.

\subsection{Interface Requirements}

\subsubsection{Filling System}

The MCFE mechanical system shall interface with the LANL deuterium/tritium fill system. (See 2.2.1.8)

\subsubsection{Muon Source}

The capsule must be properly aligned and positioned for the muons from the LAMPF to properly interface with the deuterium and tritium in the capsule.

\subsubsection{Electron and Neutron Detectors.}

The capsule/secondary containment shall accommodate the electron and neutron detectors provided by EG\&G Idaho, Inc., (See Section 6.) The distance from the capsule to the detectors should be as short as practical within the physical constraints. 


\subsubsection{Vacuum System}

The secondary containment shall interface with the LANL-supplied vacuum pump used for attaining a negative pressure on the secondary containment.

\subsubsection{Temperature and Pressure Recorders/Controllers}

The instrument penetrations (connectors) shall interface to the temperature and pressure recorder/controller cables at the secondary containment wall. The recorders and controllers will be supplied by EG\&G Idaho, Inc. and will be remotely located.

\subsection{Fabrication Requirements}

\subsubsection{Cleaning}

The cleaning and cleanliness requirements for the fabrication and assembly of the MCFE mechanical system shall conform to EG\&G Standard 7022. Surfaces which come in contact with the working fluid shall be cleaned to cleanliness Level C. Components and surfaces which do not come in contact with the working fluid-containing equipment shall allow for vacuum distillation cleaning at elevated temperature after assembly.

\subsubsection{Marking}

Component marking shall be in accordance with EG\&G Standard 7006 (acid etching).

\subsubsection{Shipping}

Subsystems shall be shipped per EG\&G Standard 7020, Class II. 


\subsubsection{Radiographic Evaluation}

All pressure containing welds in the primary system shall be radiographed to the requirements of the ASME Code Section III, Class 2.

\subsubsection{Material Certification}

Material certification shall be required for all pressure-containing parts in the primary system.

\subsubsection{Stress Relieving}

Stress relieving fabricated parts shall be considered as required.

\subsubsection{Pressure Testing}

The primary system tritium-containing components shall be pressure tested per the ASME Code Section III, Class 2 and as indicated in 2.2.1.3.

\subsubsection{Leak Testing}

The primary and secondary subsystems shall be leak checked per the ASME Code Section III, Class 2 and as indicated in 2.2.1.7 and 2.2.2.4.

\subsubsection{Weld Samples}

Five acceptable capsule weld (nose to capsule body) samples shall be submitted to EG\&G for approval prior to making the capsule weld. EG\&G shall approve all weld and braze procedures prior to welding or brazing on the system.

\subsubsection{Manufacturing Process}

EG\&G shal1 approve the manufacturing sequence and processes prior to fabrication of the primary system. 


\subsection{Maintenance and Operation}

The MCFE Mechanical System shall be designed for ease of maintenance and operation.

\subsection{Quality and Safety Provisions}

\subsubsection{Quality and Safety Manual}

The EG\&G Quality and Safety Manuals shall be the guiding documents when considering quality and safety in the design of the system, along with LANL quality and safety criteria.

\subsubsection{Quality Levels}

The MCFE mechanical system shall have the following EG\&G quality levels:
A. Primary System
I
B. Secondary Containment
I I
C. Other

\subsection{Codes and Standards}

\subsubsection{National Electric Code}

The design of the electrical and instrumentation portion of the system shall comply with the National Electric Code.

\subsubsection{ASME B\&PV Code}

The primary system shall be analyzed to the requirements of the ASME Code Section III, Class 2. The material allowable limits shall be taken from the Nuclear Systems Materials Handbook (using minimums). This 
approach provides safety assurance while preventing excessive thickness of capsule walls which could result in erroneous experimental results. (Note that the design pressure is $50 \%$ greater than the maximum operating pressure, thus providing a factor of safety of at least 1.5.) 


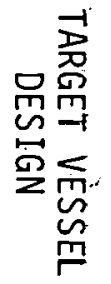




\section{TARGET VESSLL UESIGN OESCRIPTION}

\subsection{System Description}

The target system has been designed as an integrated unit which can be easily assembled and handled by personnel. A significant degree of safety has been designed into the system by means of the use of high strength materials and secondary containment boundaries for the tritium. In general, all the components used on the system are corrosion resistant. off-the-shelf components have been used wherever possible within the design curitraints.

There are two basic subsystems within the target system (Figure 4). These are the primary system and the secondary containment. The secondary containment acts as the mount and positioning mechanism for the target capsule. It can be positioned at any angle. In addition it provides a "leak tight" boundary to collect any tritium which may leak or permeate from the primary system boundary. The back flange of the secondary containment supports the power, instrumentation and cooling feed-throughs which support the primary system. The front of the containment (nose) is made of aluminum to allow muon and neutron penetration. The nose also contains an insulator which thermally isolates the target capsule from the secondary containment. The entire secondary containment is maintained at vacuum during the experiment so that a positive internal pressure cannot result if all the tritium/deuterium were released from the primary system. The vacuum is monitored by a remote gauge so that the experiment can be terminated if in-leakage is detected. The vacuum also provides thermal insulation.

The primary system is filled with deuterium and/or tritium at the LANL Tritium Handling System. The fill is made by means of the capsule capillary tube. Following the fill the capillary tube is crimped and welded by the LANL resistance weld system. The tube is then severed. The primary system is then interfaced to the secondary containment back flange by means of the $\mathrm{LN}_{2}$ inlet and outlet lines and the heater and thermocouple connectors. This assembly is then placed in the secondary containment and is secured by means of bolts at the back flange. 


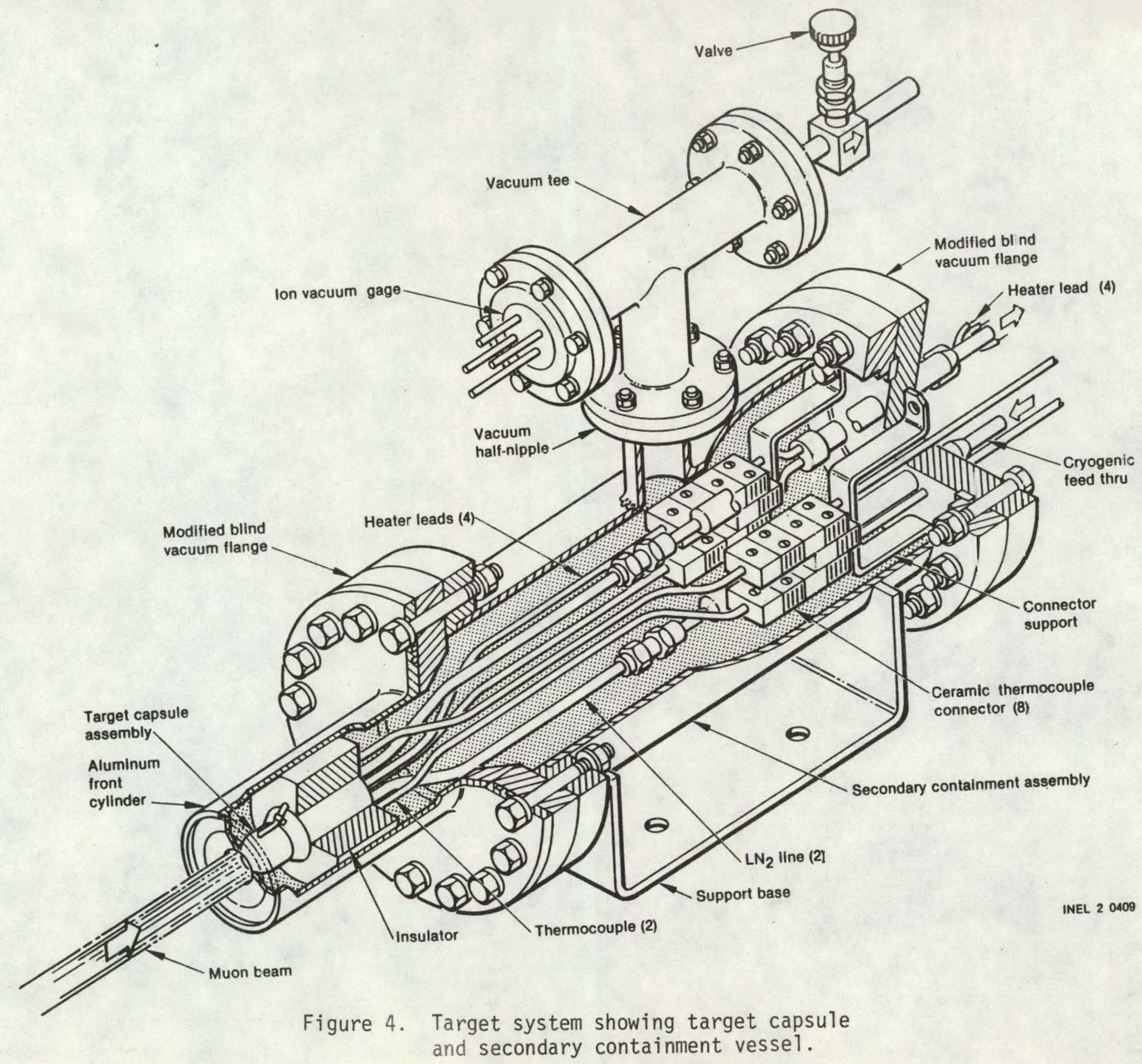


The capsule has been designed for a maximum design pressure of $45,000 \mathrm{psig}$ at $700 \mathrm{~K}$. The maximum operating pressure for the present capsule design is $30,000 \mathrm{psig}$ at $700 \mathrm{~K}$. The capsule will also be subjected to cryogenic temperatures $(80 \mathrm{~K})$ while subjected to pressures of approximately 7860 psig (see Appendix C).

A heater system and a cryogenic jacket are provided to attain the extremes in temperature. The capsule has thermocouples mounted near the capsule nose to monitor the temperature of the deuterium/tritium mixture.

\subsection{Secondary Containment}

The secondary containment consists of five (5) subassemblies. These are:
A. Back Flange
B. Main Body
C. Vacuum Attachment
D. Front Cylinder (Nose)
E. Insulator

Each of these subassemblies will be described in detail below.

\subsubsection{Back Flange Subassembly}

The back flange of the secondary containment acts as the feed-through flange for the instruments that support the primary system. This flange is a blank 6-inch vacuum flange (Varian Model \#954-5081). It is bolted to the body using a commercial screw and nut set (Varian Model \#953-5027). The flange is sealed to the body using an OFHC copper gasket (Varian Model \#953-5016). Two stainless steel sheathed thermocouples (Omega 
Model \#304-K-M0-125) pass through holes in the back flange. They are silver brazed (Easy Fio 45 or equal) to the back flange to hold them in place and effect a seal. A ceramic thermocouple connector (Omega Model \#UNOXCHAL-MF) is attached to each end of the thermocouple wire. The inner (internal to the secondary containment) connector is mounted to a stainless steel bracket which is mounted to the back flange. The bracket configuration is shown in Figure 4. It is made of 11 gage $304 \mathrm{SST}$ with a 3/8-inch thich 304 SST leg welded to it. The leg is drilled and tapped for attachment of the thermocouple connectors. The bracket is attached to the blind flange using two $5 / 16^{\prime \prime}$ by $1 / 2 "$ long socket head cap screws. The blind flange has tapped holes for these screws.

The back flange has a power penentration for the primary system (target capsule) heaters. This penetration is very similar to the thermocouple penetration. A four conductor (16 AWG), copper sheathed cable (General Cable Corporation Type MI-600 volt) is silver brazed in a 0.387 inch diameter hole in the back flange. The braze supports the cable and effects a vacuum seal. The vacuum end of the cable is sealed using on epoxy compound. The cable leads are attached to the heater leads using ceramic thermocouple connectors (Omega Model \#UNOX-UNCO-MF). These connectors are mounted in the same way as the previously discussed thermocouple connectors. The Type MI-600 volt cable is magnesium oxide insulated. It is UL listed, meets NEC Article 330 and the copper conductors are constructed to ASTM B4.

The back flange, also has two penetrations (inlet and outlet) for liquid nitrogen. (These penetrations may also be used for air cooling.) The penetrations are a tube-in-tube design with a sealed dead space between them. This design insulates the $L_{2}$-bearing tube from the back flange to preclude unwanted $\mathrm{LN}_{2}$ boil-off. The inner tube is 3/16-inch diameter and the outer tube is 1/2-inch diameter. Both tubes are 304 SST. The outer tube is silver brazed to the secondary containment back flange to support it and to seal it. The 3/16-inch diameter tube has a fitting (Swagelok Model \#SS-300-6-3TSW) welded to it. This fitting interfaces the $\mathrm{LN}_{2}$ feed-throughs to the target capsule nitrogen lines. The feed-throughs provide axial support and alignment for the target capsule. 


\subsubsection{Main Body Subassembly}

The main body of the secondary containment is a commercial vacuum nipple (Varian Model \#962-5039). The ends of the nipple are standard 6 -inch vacuum flanges and the center is a 4-inch diameter SST tube. The front end of the nipple has a modified vacuum blind flange (Varian Model \#954-5081) bolted to it. An OFHC copper gasket (Varian Model \#953-5016) seals the blind flange to the nipple. The flange is modified to accept bolting of the secondary containment front cylinder (nose) to it. It is also center-bored to the inside diameter of the nose so that the target capsule may pass through it. A 14 gage, 304 SST, u-shaped piece is welded to the bottom of the nipple to provide support for the secondary containment. This support has holes in it for mounting to a support table.

\subsubsection{Vacuum Attachment Subassembly}

The vacuum attachment subassembly provides the fittings, valve and tubing required to pull a vacuum on the secondary containment. A $1-1 / 2$-inch hole is bored in the top-center of the secondary containment nipple. A standard 2-3/4-inch vacuum half nipple (Varian Model \#952-5079) is welded to the nipple at that point. A standard vacuum 2-3/4-inch tee (Varian Model \#952-5051) is bolted to the half-nipple using a screw and nut set (Varian Model \#953-5020). An OFHC copper gasket (Varian Model \#953-5014) is used for the seal. One end of the tee provides the connection for a vacuum system. This end is closed using a standard 2-3/4 blind vacuum flange (Varian Model \#954-5077) with a screw and nut set (Varian Model \#953-5020) and OFHC copper gasket (Varian Model \#953-5014). The blind flange has a $3 / 8$-inch hole drilled in the center of it with a 3/8-inch 304 SST tube welded in the hole. This tube is welded to a valve (Nupro Model \#SS-GBW-TSW) which provides for vacuum isolation and attachment to the vacuum system. The opposite end of the vacuum tee provides for mounting an ion gauge (Varian Model \#971-5009) to monitor the vacuum with in the secondary containment. The gauge is attached using the same screw and nut set and gasket mentioned above. 


\subsubsection{Front Cylinder (Nose) Subassembly}

The nose of the secondary containment is constructed of T-6061 aluminum. Aluminum is used to reduce scattering effects on the muon beam and on neutrons produced in the fusion reaction. The nose is a right circular cylinder with an 1/2-inch thick aluminum flange weld to one end and a flat plate welded to the other. The flange has a common bolt circle with the main body 6 -inch vacuum flange. This reduces the cost of the main body adapter flange and provides sixteen $5 / 16-24$ by 2-1/2-inch long bolts (Varian Model \#953-5049) to allow adequate compression of the double gasket seals. Metallic seals are used to seal the flange to the body because elevated temperatures are expected in the area and because elastomers do not perform well in the presence of tritium. The seals are copper plated stainless steel c-seals with a helical internal wire wrap. They are manufactured by the Helicoflex Company and are widely. used in the fusion industry. The cylindrical portion of the nose is made from 2-inch diameter T-6061 aluminum tube. An aluminum plate is welded to the front end of the tube. This plate is bored part way through to provide a thin wall for the muons to pass thru. The bore diameter is 0.375-inches and the wall thickness is 0.042 -inches.

\subsubsection{Insulator Subassembly}

The insulator is the interface between the secondary containment front cylinder and the target capsule. It serves two basic purposes. First, it provides radial support for the target capsule and second, it acts as a. thermal insulator for the target capsule. It is anticipated that Owens Corning "Macor" $\left(\mathrm{Al}_{2} \mathrm{O}_{3}\right)$ machinable ceramic will be used. Figure 4 shows that the insulator will cover the back portion of the capsule only. This amount of coverage is thought to be adequate for thermal purposes. A detailed thermal and stress model will be generated for the target capsule. If the model indicates the need for additional insulation the insulator may have to be extended toward the capsule tip. The capsule outside diameter and the front cylinder inside diameter are both highly 
polished to provide "reflectivc" insulation. In addition, the secondary containment's internal environment is a vacuum. The inside diameter of the insulator has axial slots to provide egress for the target capsule thermocouple leads.

\subsection{Primary System}

The primary system (Figure 5) consists of five basic components. These are:
^. Target Capsule
B. Capillary Tube Subassembly
C. Liquid Nitrogen Tubes
D. Heaters
E. Thermocouples

Each of these components is described in detail below. (The system described below was designed for 45,000 psig pressure, anticipating a maximum operating pressure of 30,000 psig.

\subsubsection{Target Capsule}

The target capsule (Figure 5) is the heart of the primary system. It provides the controlled volume for the deuterium/tritium target mixture. The target capsule is required to handle design temperatures from $70 \mathrm{~K}$ to $700 \mathrm{~K}$ and pressures from atmospheric to $45,000 \mathrm{psig}$ (design) while at the higher temperature. These requirements necessitated the need for the use of a high strength, high temperature, non-corrosive material that has adequate ductility at cryogenic temperatures. The alloy chosen was ARMCO A-286 (ASME-SA453 Grade 660) which has a yield strength of 84,000 psi at 


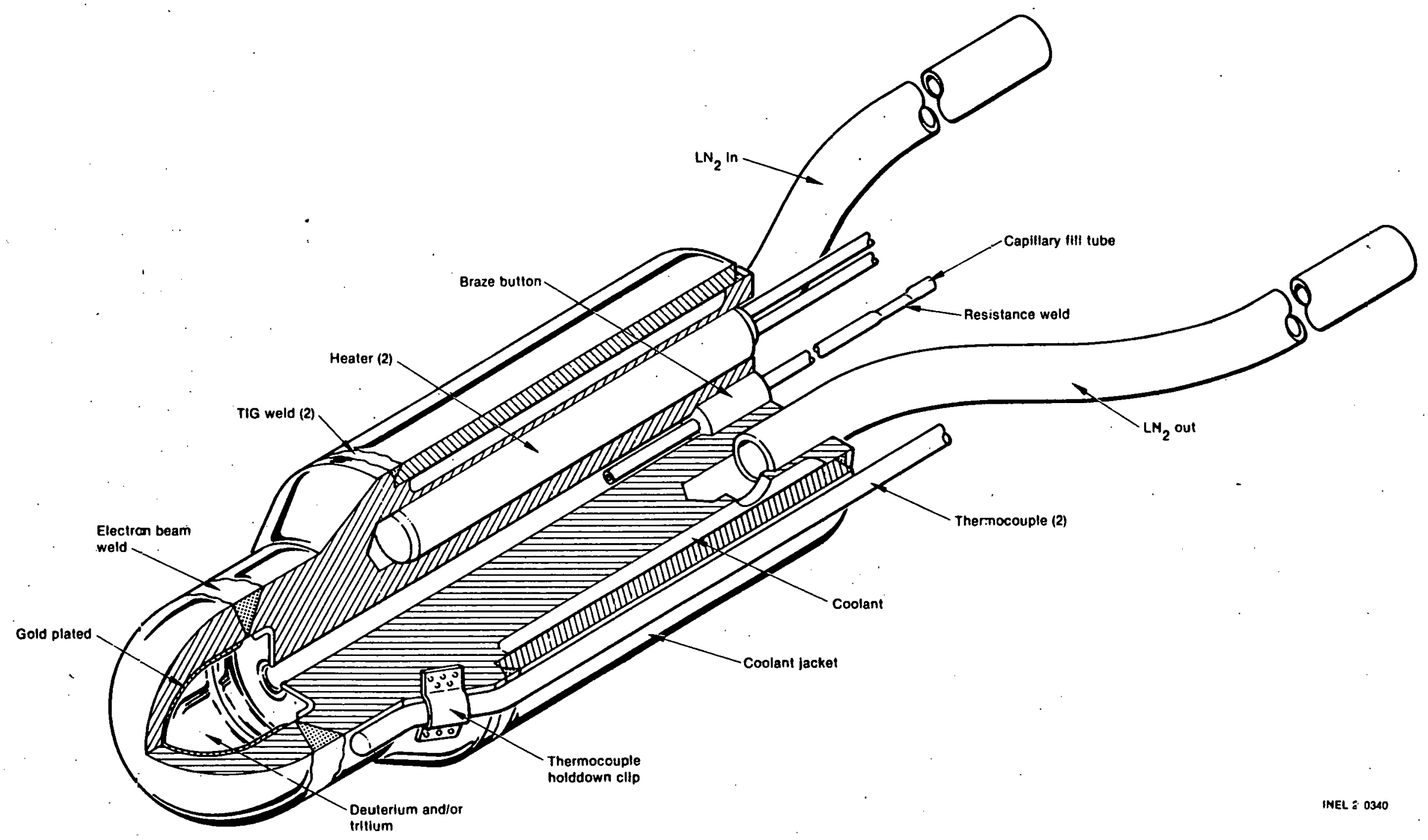

Figure 5. Target capsule detail 
$700 \mathrm{~K}$. A-286 is an age hardenable stainless steel commonly used as a bolt material. Further information on the choice of this alloy is given in the following section (3.3.2).

The thickness of the spherical end and the capsule side walls was based on equations taken from the ASME Boiler and Pressure Vessel code, Section III, Class 2, Page 65 of NC-300. The formulas are as follows:

Sphere $\ln \left(\frac{R+t}{R}\right)=\frac{0.5 P}{S}$

Cylinder $\ln \left(\frac{R+t_{t}}{R}\right)=\frac{P}{S}$

$$
\text { For } P>0.4 S
$$

$$
\begin{aligned}
& R=\text { inside radius } \\
& t=\text { wall thickness } \\
& P=\text { internal pressure } \\
& S=y i e l d \text { strength }
\end{aligned}
$$

The hemispherical end analysis was conservative because it was assumed that the hemisphere was of constant thickness. However the hemisphere edges are really much thicker than the sides. The cylinder analys is was also somewhat conservative because the length to diameter ratio of the capsule is much less than 10. However, the present analysis method is not adequate for final design purposes. A detailed thermal and stress analysis (probably finite element because of thermal cycling requirements) will be performed on the final capsule design. These analyses will form a part of the safety analysis.

The target capsule is made in three pieces. These are the spherical head, body and the cooling jacket. The head is not a true hemisphere because the side walls are considerably thicker (0.150 inches) than the front wall (0.062 inches). The spherical head and body cavity are plated with 0.002 -inches of gold on the inner surface. The plating is polished to 
reduce surface irregularities and micro-cracks. The head is electron beam welded to the body per Military Specification Mil W-46132. Electron beam welding will result in the highest quality weld with the least heat affect on the gold plating.

The configuration of the target capsule body can best be understood by reviewing Figure 5 and Figure 6 . The body is a right circular cylinder which interfaces with the head on the front end, the cooling jacket radially and the heaters, cooling tubes and capillary tube subassembly on the back end. The body is drilled ( 0.125 inch dia.) through the center tn provide for filling with deuterium/tritium. The cooling jacket is TIG welded to the body to provide the annulus for the liquid nitrogen.

Figure 6 contains a significant number of notes which relate to the target capsule manufacturing process. The process is very critical to the attainment of a quality target capsule.

\subsubsection{Selection of Materials for the Target Vessel}

A number of factors enter into the selection of materials suitable for the high-pressure target vessel: response to radiation, strength, fabricability, hydrogen permeability and solubility, and hydrogen embrittlement.

Radiation damage to the target vessel is of little concern in this experiment. Each target vessel will be used for 23 experimental runs, of about 5 hours each, and subjected to actual muon exposure for about half of each run. Thus, muon irradiation per vessel is only:

3 runs $\times 2.5 \mathrm{hrs} / \mathrm{run} \times 1000 \mu / \mathrm{s} \times 3600 \mathrm{~s} / \mathrm{hr}=10^{7}$ muons

The muon beam irradiates an area of approximately $1 \mathrm{~cm}^{2}$ (beam spot $\sim 6 \mathrm{~mm}$ diameter FWHM). An exposure of $10^{7} \mu / \mathrm{cm}^{2}$ is roughly 10 orders of magnitude smaller than that which might deleteriously effect the beam entry window. Neutron irradiation due to muon catalysis will similarly have no significant impact on the target vessels: 


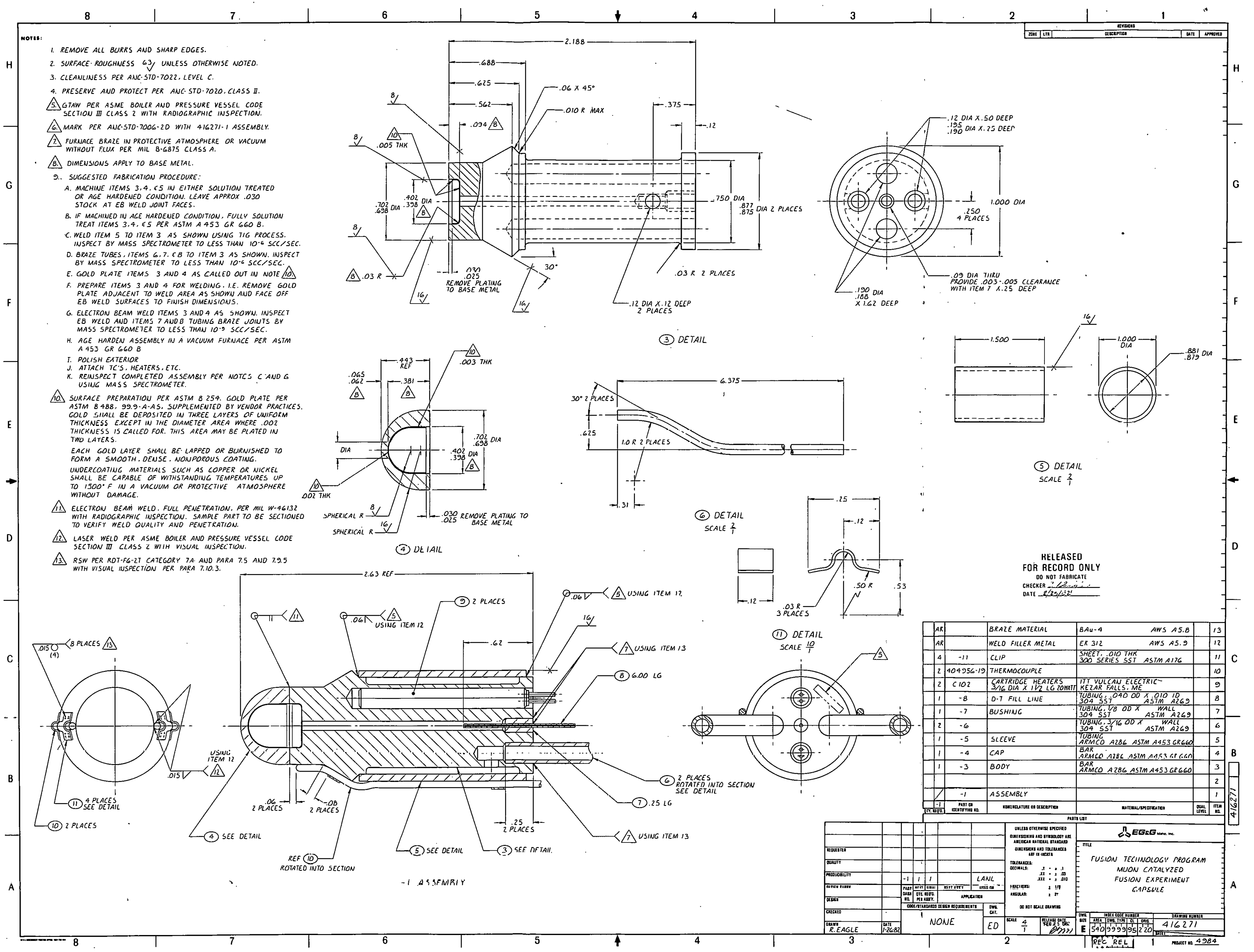


$\sim 100$ neutrons $/ \mu \times 10^{7} \mu=10^{9}$ neutrons over $\sim 5.5 \mathrm{~cm}^{2}$

The walls of the target vessel exposed to the muon beam must be kept as thin as possible to optimize muon stops in the target gas (see Section 2.1). This requires the selection of high-strength vessel materials (Section 3.3.1). Table 2 displays the physical properties of a number of high-strength structural alloys taken from a number of sources. 13-17 Other alloys could be included in this survey, but we have attempted to include representative materials from the major classes of high-temperature, high-strength alloys.

Safety considerations demand that tritium permeation through the target vesse 1 and tritium build-up in target vessel walls be minimized. Hydrogen permeabilities and solubilities in a number of candidate materials are juxtaposed in Figures 7 and $8 .^{18}$ Note that we have added curves for gold to these plots using the relations:

Solubility $=S_{0} \exp \left(-Q_{S} / R T\right)$

and

Permeability $\left.=S_{0} D_{0} \exp \left[-\left(Q_{S}+Q_{d}\right) / R T\right)\right]$

where

$$
\begin{aligned}
T & =\text { temperature }(K), \\
R & =\begin{array}{l}
\text { gas constant, and } S_{O}, D_{0}, Q_{S} \text { and } Q_{D} \text { are given in } \\
\text { Appendix } D .
\end{array}
\end{aligned}
$$

Comparison of the data in Figures 7 \& 8 shows that metals in which hydrogen is most soluble also exhibit the largest permeability to hydrogen. Clearly, to reduce loss of tritium through target walls and hydrogen build-up in thè walls, materials from the lower halves of these figures should be selected. 
TABLE 2. PYHSICAL PROPERTIES OF REFERENCE STRUCTURAL ALLOYS

\begin{tabular}{|c|c|c|c|c|}
\hline $\begin{array}{l}\text { Melting } \\
\text { Temperature } \\
\left({ }^{\circ} \mathrm{C}\right)\end{array}$ & $\begin{array}{l}\text { Density } \\
\left(\mathrm{g} / \mathrm{cm}^{3}\right)\end{array}$ & $\begin{array}{l}\text { Thermal } \\
\text { Expansion } \\
\text { at } 400^{\circ} \mathrm{C} \\
\left(10^{-6} /{ }^{\circ} \mathrm{C}\right)\end{array}$ & $\begin{array}{l}\text { Yield } \\
\text { Strength* } \\
\text { at } 700 \mathrm{~K} \\
(\mathrm{MPa})\end{array}$ & $\begin{array}{l}\text { Specific } \\
\text { Heat at } \\
200^{\circ} \mathrm{C} \\
\left(\mathrm{J} / \mathrm{Kg}^{\circ} \mathrm{C}\right)\end{array}$ \\
\hline
\end{tabular}

Austenitic

Stainless Steels

$\begin{array}{llllll}\text { Type } 304 & 1400 & 8.0 & 17.3 & 116 & 500 \\ \text { Type 316 } & 1400 & 8.0 & 17.8 & 120 & 510 \\ \text { Armco A-286 } & 1400 & 7.91 & 17.3 & 560 & 460\end{array}$

Ferritic Steels

$$
\text { HT-9 }
$$

1420

7.8

12

320

560

Nickel Alloys

$\begin{array}{llllll}\text { Inconel } 625 & 1400 & 8.4 & 13.3 & 400 & 440 \\ \text { Inconel } 718 & 1300 & 8.2 & 14.1 & 900 & 435\end{array}$

Titanium Alloys

$$
T i-6242
$$

1650

4.5

9.5

590

510

Vanadium Alloys

$$
V-15 \mathrm{Cr}-5 \mathrm{Ti}
$$

1900

6.1

10

490

500

Niobium Alloys

$$
\text { FS-85 }
$$

2470

10.6

6.7

290

220

* Divide by 6.9 to convert to Ksi. 


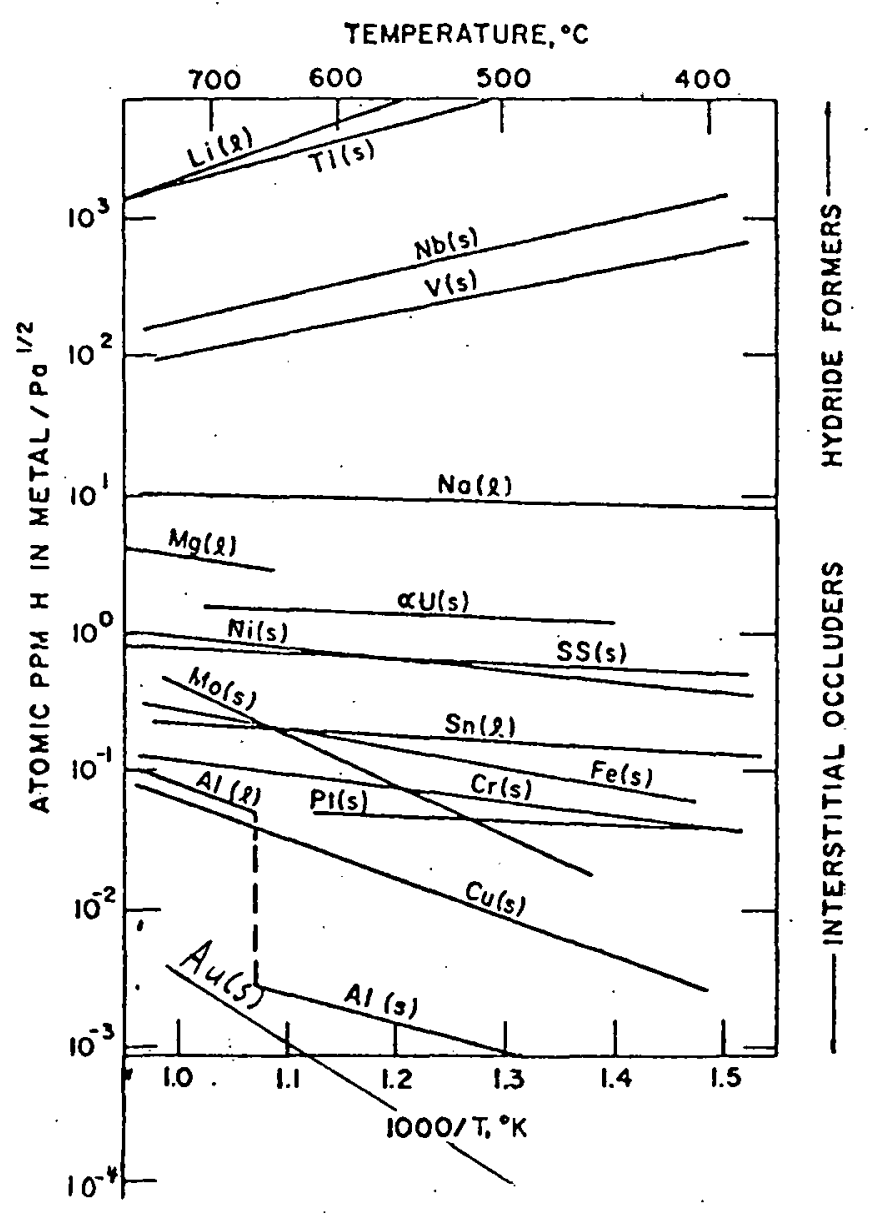

Figure 7. Hydrogen solubility (Sieverts constant) as a function of temperature for selected metals and alloys.

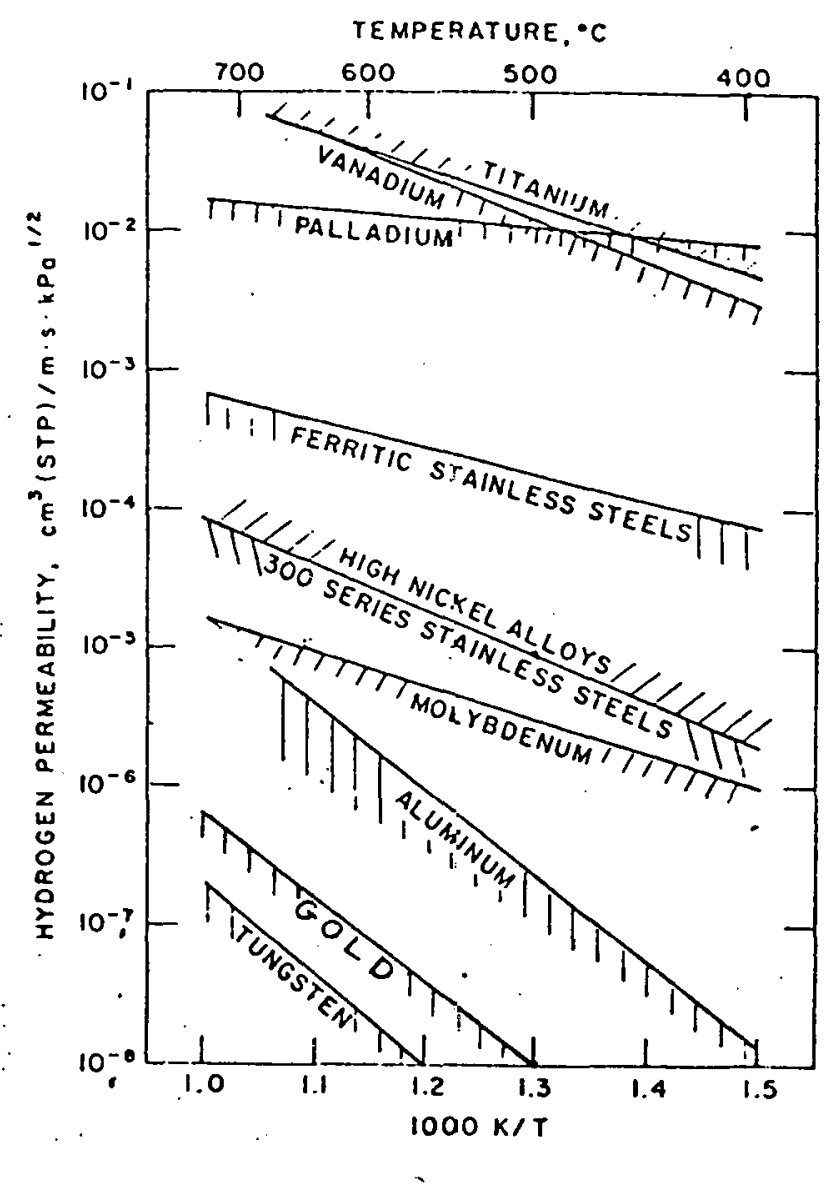

Figure 8. Hydrogen permeability as a function of temperature for selected metals and alloys. 
Infortunately, titanium, vanadium and niobium readily form hydrides. The resulting high hydrogen solubilities and permeabilities render alloys of these metals unsuitable for our purposes. ${ }^{19}$ Use of high-nickel alloys and ferritic steels has been discouraged because of hydrogen-embrittlement problems. ${ }^{19,20}$. However, certain austenitic stainless steels have desirable strength, fabricability and hydrogen-resistant properties, particularly when a layer of a low-permeability materlal such as gold is plated onto the stainless steer. 19,21

Calculations for hydrogen permeation and wall loading have been performed using the code TMAP (see Appendix D) for a stainless steel vesse 1 with and without gold plating. In either case, tritium loss is negligible ( 5 microcuries) over the course of an experimental run. (An evacuated secondary containment vessel captures any tritium which manages to permeate the target walls).

However, tritium build-up in the vessel material is a more serious problem. Without a gold permeation barrier inside the target chamber, the tritium inventory reaches about 6 curies $/ \mathrm{cm}^{3}$ in the case of a $100 \%$ tritium target, or about 2000 PPM hydrogen in the metal. A layer of gold 50 microns thick inside the vessel reduces this loading by three orders of magnitude (see Appendix $D$ ). This is necessary to inhibit hydrogen embrittlement of the target vessel, and constitutes one of the reasons for plating the insideof the target chambers with gold (see also section 3.2). Embrittlement due to hydrogen may become significant for hydrogen concentrations greater than $\sim 1 \mathrm{ppm} .{ }^{19}$ The gold plating is sufficient to allow the vessel to be heated to $700 \mathrm{~K}$ for $210^{3}$ seconds for data-taking. Tritium build-up at lower temperatures is negligible (at $600 \mathrm{~K}$, hydrogen loading reaches $1 \mathrm{ppm}$ after $210^{4}$ seconds. Since very little hydrogen is contained in the metals ( 23 millicuries in steel, 6 microcuries in gold following first run), vacuum distillation between runs is neither needed or recommended. 


\subsubsection{Gold Plating the Target Chamber Interior}

The inside surface of the target chamber is to be plated with 2 mils $(50 \mu \mathrm{m})$ of gold. This is done for several reasons:

1. A thin layer of gold is effective in reducing deuterium-tritium permeation through the walls of the target vessel to a negligible level (see Appendix $D$ ). This is important since the radioactive gas is to be contained at elevated temperatures (up to $700^{\circ} \mathrm{K}$ ) and pressures (up to $30 \mathrm{Ksi}$ ). Besides posing a potential hazard, loss of hydrogen isotopes would reduce the density of the target gas thereby diminishing the accuracy of experimental results.

2. Gold should seal imperfections on the inner surface of the stainless steel vessel, particularly at the weld joint. This will inhibit dislocation transport of hydrogen which is known to significantly lower the stress necessary to initiate fracture in metals. ${ }^{18}$ Thus, gold plating will increase the longevity and safety of the stainless-steel vessels.

3. A gold layer will help maintain the purity of the target gas. Even a small admixture $(\sim 0.01 \%)$ of $Z>2$ elements (such as $\mathrm{N}_{2}, \mathrm{CO}_{2}, \mathrm{O}_{2}$ ) can lead to a nearly complete transfer of muons to these gases, since: 22

$\lambda_{p \rightarrow z}=10^{10} z$

Since muon capture by high-Z gases would terminate the d-t fusion catalysis cycle under investigation, it is important to keep such containments below the $1 \mathrm{ppm}$ level. Owing to a low solubility constant and chemical reactivity, gold is ideal in helping maintain the purity of the deuterium-tritium target. Gold also inhibits the retention of $d-t$ gases in target walls (due to a very low solubility constant--see figure 7) which could otherwise affect a determination of the $d-t$ ratio for subsequent runs using a vessel. 
4. Finally, gold nuclei are effective in capturing muons, thus preventing muon decay so that the event signature is not satisfied in such cases (see Section 7). This is particularly important in eliminating cases where muons diffuse to vessel walls following a few d-t. ratalysis ryc.les. Figure 9 displays the range of muons in gold as a function of muon momentum. A gold layer two mils $(50 \mu \mathrm{m})$ thick is sufficient to stop muons with momenta up to $25 \mathrm{MeV} / \mathrm{c}$. This assures that muons in the high-momentum tail of the distribution of beam muons will almost certainly be captured in gold and prevented from generating spurious triggers.

Thus, gold plating the interior of the target chamber, although difficult, provides a number of benefits for the safety and accuracy of the experimental investigation of muon-catalyzed fusion.

\subsubsection{Capillary Tube Subassembly}

The capillary tube subassembly consists of two items. These are a capillary tube and a braze button. The button is brazed to the capillary tube per MIL B-6875 Class A.using braze filler metal BAu -4 (AWS A5.8). The braze button is made from ARMCO A-286 and the capillary tube is made from ARMCO Alloy Nitronic 50. Nitronic 50 is a medium strength $\left(y_{s}=\right.$ 60,000 psi) stainless steel that is weldable and requires no annealing after the weld process. LANL has routinely resistance welded annealed 304 SST capillary tubes with internal pressures up to 24,000 psig at room temperature. However, 304 SST does not have the strength required to withstand the design conditions of $45,000 \mathrm{psig}$ at $700 \mathrm{~K}$. Therefore Nitronic 50 was selected and will require qualifing the capillary tube resistance seal weld.

The capillary tube is 6-inches long and has an outside diameter of 0.040-inches and an inside diameter of 0.010-inches. The braze button is 0.25 -inches long and has an outside diameter of 0.125 inches. The inside diameter will be match machined to the capillary tube outside diameter to 


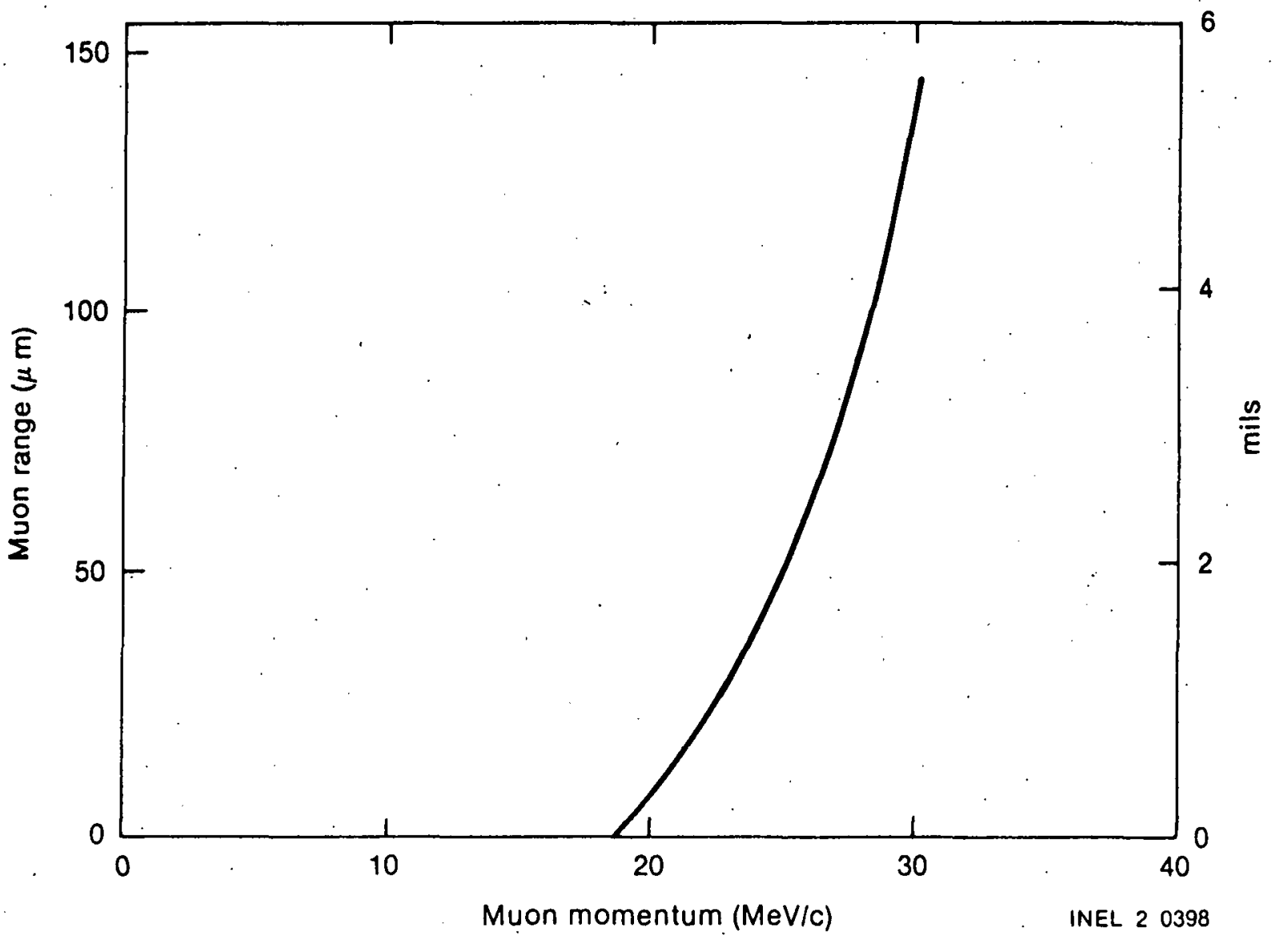

Figure 9. Muon range in gold. 
provide the proper braze clearance. The capillary tube subassembly is brazed to the target capsule body per MIL-B-6875 Class A using BAu -4 filler metal (AWS A5.8).

\subsubsection{Liquid Nitrogen Tubes}

Liquid nitrogen is provided to the target capsule cooling jacket by means of inlet and outlet 3/16-inch 304 SST tubes. These tubes are brazed to the back of the capsule body per MIL-B-6875 Class A using BAu -4 filler metal (AWS A5.8). Counter-sunk holes are provided in the body to accomodate the tubes and braze clearances. These tubes attach to the secondary containment $\mathrm{LN}_{2}$ feed thrus by means of a compression fitting (Swage lok \#SS-300-6-3TSW).

The $\mathrm{LN}_{2}$ tubes provide axial support for the target capsule. The tubes are bent radially away from the capillary tube so that room is provided for the resistance welder jaws.

\subsubsection{Heaters}

Two cartridge heaters are provided in the target capsule body to heat the body from cryogenic temperatures $(80 \mathrm{~K})$ to $700 \mathrm{~K}$. The heaters are inserted in holes which are match drilled to the diameter of the given heater. This should improve the thermal contact area and provide for better heating.

The cartridge heaters (ITT Vulcan Electric Model \#C102) are 3/16 inch in diameter and 1-1/2-inches long. They have a 20 watt capacity and have a stainless steel sheath. The heater leads are insulated with a high temperature glass fabric. The leads are wired to ceramic thermocouple-type connecters (Omega Model \#UNOX-UNCO-MF). These connectors interface with similar connectors on the secondary containment back flange. 


\subsubsection{Ihermocouples}

Two thermocouples are attached to the outside of the target capsule to monitor the temperature of the deuterium/tritium mixture. The ends of the thermocouples are laser welded to the capsule body just behind the capsule head weld. The thermocouple leads are secured to the capsule body using stainless steel clips that are capacitance discharge welded to the body. The holddown clips are intended to preclude any lead movement that could stress the laser weld. The thermocouple leads are wired to ceramic thermocouple connectors (Omega Model \#UNOX-CHAL-MF) that plug into a similar connector on the secondary containment back flange.

Surplus nuclear grade chromel-alumel (Type K) thermocouples will be used. These thermocouples are available from a terminated project. They have a grounded junction and a 0.062-inch diameter SST sheath. Their configuration is outlined on EG\&G Drawing 404956 and they are the -19 assembly.

\subsection{Instrumentation and Control Equipment}

The instrumentation and control equipment is associated with monitoring the target capsule temperature, heating the target capsule and monitoring the secondary containment vacuum. One of the two thermocouples is routed to a digital temperature meter (Omega Model \#2160A-K) and the other is routed to the digital heater controller (Omega Model \#4002KF). This system provides for redundancy when monitoring the target capsule temperature. It also provides for good control of the capsule temperature. The Omega heater controller has dual set points that will aid in precluding an over-temperature (and pressure) situation.

The secondary containment vacuum monitoring equipment is used to determine if gas is leaking from the primary system or if there is in-leakage to the secondary containment from the atmosphere. The equipment used is an ion gauge element (Varian Model \#971-5009) and an ion gauge monitor (Varian Model \#843, available from surplus). 
The control and monitoring equipment outlined above will be housed in a small instrument rack. The rack will be located in an area remote from the experiment.

\section{$3.5 \quad$ Interfares}

The target system interfaces with several LANL systems and numerous LANL equipment items. These systems and items are listed below:
A. Tritium Handling System
B. Capillary Tube Weld System
C. LANL LN 2 Dewar
D. LANL Vacuum Pump (Leak Detector)
E. LAMPF Muon Beam
F. LAMPF Experiment Support Table
G. LAMPF Instrument Lead Trays

Each of these interfaces is briefly discussed below.

\subsubsection{Tritium Handling System}

The LANL Tritium Handling System is use to fill the target capsule with the deuterium/tritium mixture. The required fill temperatures and pressures are discussed in Section 5.3. This system interfaces to the target capsule at the capillary tube. This interface will be resolved during the final design process. 


\subsubsection{Capillary Tuhe Weld System}

The LANL capillary tube weld system is used to resistance seal weld the capillary tube closed after the fill. The interface occurs between the tube and the welder jaws. The weld process will be qualified for the Nitronic 50 tubing.

\subsubsection{LANL LN 2 Dewar}

LANL will supply a pressurized $L_{2}$ dewar that will interface with the secondary containment cryogenic feed thrus. The interface will he made using compression fittings. The dewar system will have a valve to regulate the $L_{2}$ flow.

\subsubsection{LANL Vacuum Pump (Leak Detector)}

LANL will provide a helium leak detector which will be used to pull a vacuum on the secondary containment and perform a helium leak check. The leak dectector will be capable of attaining a $10^{-6}$ torr vacuum. The . interface will be at the down stream side of the Nupro valve, and will be made using a compression fitting.

\subsubsection{LAMPF Muon Beam}

The LAMPF Muon beam will interface with the target system at the secondary containment front. cylinder window (the reduced thickness section portion of the cylinder front plate). The beam passes through the aluminum window, through the capsule hemispherical head, and then interacts with the deuterium/tritium mixture.

\subsubsection{LAMPF Experiment Support Table}

LANL will provide a table to mount the target system on and align the target to the muon beam. The interface will be between the target system support plate and the table. 
3.5.7 LAMPF Instrument Lead Trays

The instrument and power leads between the target capsule and the remote meters and controls will be routed through existing penetrations and trays. 


\section{TEST PLAN}

This plan oulines the testing that will be done on the primary system and secondary containment to verify proper function. In addition, it outlines the experimental. testing that will be performed (run conditions).

The plan covers component checkout (CC) tests, system operational (SO) tests and experimental run conditions.

\subsection{Component Checkout (CC) Testing}

CC testing encompasses simple checks to assure that components are functioning properly on an individual basis. This will avoid having a completely assembled system which must be disassembled to correct a basic malfunction. The CC tests are listed below.

\subsubsection{Thermocouples}

A11 thermocouples shall be tested for thermal response prior to and after installation on the system components. They shall also be continuity checked before and after installation.

\subsubsection{Heaters}

All heaters shall be tested for continuity before and after installation. The heaters shall be momentarily energized before and after installation to assure response to power.

\subsubsection{Resistance Weld}

The capillary tube resistance weld shall be qualified as outlined below using the LANL welding equipment:

A. Five capillary tubes shall be welded per the drawing requirements. They shail be visually inspected for integrity and then pressure tested to burst. The burst pressure shall exceed 45,000 psig. 
B. Five capillary tubes shall be welded per the drawing requirements while subjected to an internal pressure (hydrogen preferred but not required) of $\simeq 13250 \mathrm{psig}$. The tubes shall then be visually inspected for integrity and pressure tested to burst. The burst pressure shall exceed 45,000 psig.

c. The actual production welds shall appear identical (visually) to the test welds to be accepted.

\subsubsection{Welds and Brazes}

Welds and brazes shall be liquid penetrant inspected per the requirements of the ASME Code, Section III. In addition, any primary fluid containing welds or brazes shall be radiographed per the above requirements.

\subsubsection{Leak Testing}

The primary system (tritium containing system) shall be leak checked to the requirements of the ASME Code, Section III. The maximum acceptable total leak shall not exceed $1 \times 10^{-7} \mathrm{scc} / \mathrm{sec}$ helium.

The secondary containment (contains the primary system components) shall be leak checked to the requirements of the ASME Code, Section III. The maximum acceptable total leak shall not exceed $1 \times 10^{-6} \mathrm{scc} / \mathrm{sec}$ helium.

\subsubsection{Secondary Containment Instrument and Power Penetrations}

The secondary containment instrument and power penetration shall be checked for continuity before and after installation.

\subsubsection{Hydrostatic Test}

The primary system shall be hydrostatically (demineralized water) tested at 37,500 psig. The primary system shall be checked for deformation 
following the test. Following the test, the primary system shall he baked out for 4 hours at $400^{\circ} \mathrm{F}$ while under a vacuum to remove residual water.

\subsection{System Operations (SO) Testing}

The So testing is intended to verify the performance of the integrated primary system and secondary containment. The SO testing will also establish system setpoints. The SO tests are described below.

\subsubsection{Filling Demonstration}

The primary system shall be pressurized to $\simeq 14$ psia with nitrogen while cooled to $80 \mathrm{~K}( \pm 10 \mathrm{~K})$ using the cooling jacket. The nitrogen source shall maintain the pressure at $=14$ psia during the cooling process. After filling, the capillary tube shall be welded and severed. This test is intended to demonstrate the filling technique using nitrogen.

\subsubsection{Pressurization Test}

After the filling is complete per 4.1 above, the primary system shall be heated to $700^{\circ} \mathrm{F}$ in 30 minutes ( \pm 5 minutes) to pressurize the system and verify the heat-up rate. The primary system shall then be cooled to room temperature, removed from the secondary system, and inspected for deformation. This test shall be done with the primary system in the secondary containment and under vacuum. (This test will result in a 37,500 psig capsule internal pressure, see Appendix C).

\subsection{Experimental Conditions}

The purpose of the MCF experiment is to determine the efficiency of the muon catalyzed fusion reaction. The scope of this section will be limited to the mechanical system only. 


\subsubsection{Capsule Preparation}

The target capsules will be filled with twenty-five (25) different combinations of tritium/deuterium ratios and densities. Experimental runs will be made on each combination at various temperatures. The conditions for each run are summarized in Table 3.

Prior to filling the target capsules at various temperatures and pressures, they will be baked-out at $400^{\circ} \mathrm{F}$ for 4 hours while under a vacuum of $10^{-6}$ torr. The bake-out is intended to degas the capsules prior to fill so that the primary fluid is not contaminated. The primary fluid must have < IPPM N $\mathrm{N}_{2}, \mathrm{O}_{2}$ and $\mathrm{CO}_{2}$ total, as these contaminants hinder the fusion process (see Section 3.3.3).

The fills will be done using the LANL Tritium Handling System (SK-WX-5-173). After filling, the capsule capillary tube will be resistance welded shut and severed. The welding will be done using the LANL resistance weld system described in LANL report LA-3991-MS.

\subsubsection{Capsule Handling and Installation}

After the capsules have been filled and seal welded, one will be placed in the capsule holder located in the secondary containment. The capsule will be locked in place and the thermocouple leads will be attached to the secondary containment feed-through connector. The secondary containment clossure flange will then be bolted in place. A helium leak detector will then be piped to the secondary containment vacuum line. A $10^{-6}$ torr vacuum will then be pulled on the secondary containment and it will be helium leak checked to $1 \times 10^{-6} \mathrm{scc} / \mathrm{sec}$ helium. Following the leak check, the vacuum line will be valved off, separated and capped.

The assembly will then be moved to the muon beam area and mounted on an existing support table. The secondary containment/capsule will then be aligned to the muon beam port. Power and instrument leads will then be 
tARLE 3. TARGET CAPSULE EXPERIMENTAL CONDITIONS

\begin{tabular}{|c|c|c|c|c|c|c|c|c|}
\hline $\begin{array}{l}\text { Run } \\
\text { Number }\end{array}$ & $\begin{array}{l}\mathrm{LH}_{2} \text { Dens ity } \\
(x) \\
\end{array}$ & $\begin{array}{c}\text { Run Temperatures } \\
(\mathrm{K})\end{array}$ & $\begin{array}{c}2 H(D) \\
(\%) \\
\end{array}$ & $\begin{array}{l}{ }^{3} H(T) \\
(X) \\
\end{array}$ & $\begin{array}{l}\mathrm{He} \\
(\underline{x})\end{array}$ & $\begin{array}{l}\text { Fill Pressure } \\
\text { (psig) } \\
\end{array}$ & Fill & $\begin{array}{l}\text { Temperature } \\
\text { (K) }\end{array}$ \\
\hline 1 & 70 & $\begin{array}{l}80,140,200,300 \\
400,500,600,700\end{array}$ & 100 & 0 & 0 & 13910 & & 293 \\
\hline 2 & 0 & 293 & 0 & 0 & 0 & Vacuum & & 293 \\
\hline 3 & 70 & $\begin{array}{l}80,140,200,300, \\
400,500,600,700\end{array}$ & 95 & 5 & 0 & 13910 & & 293 \\
\hline 4 & 70 & $\begin{array}{l}80,140,200,300, \\
400,500,600,700\end{array}$ & 90 & 100 & 0 & 13910 & & 293 \\
\hline 5 & 70 & $\begin{array}{l}80,140,200,300 \\
400,500,600,700\end{array}$ & 70 & 30 & 0 & 13910 & & 293 \\
\hline 6 & 70 & $\begin{array}{l}80,140,200,300, \\
400,500,600,700\end{array}$ & 50 & 30 & 0 & 13910 & & 293 \\
\hline 7 & 70 & $\begin{array}{l}80,140,200,300, \\
400,500,600,700\end{array}$ & 30 & 70 & 0 & 13910 & & 293 \\
\hline 8 & 70 & $\begin{array}{l}80,140,200,300 \\
400,500,600,700\end{array}$ & 10 & 90 & 0 & 13910 & & 293 \\
\hline 9 & 70 & $\begin{array}{l}80,140,200,300 \\
400,500,600,700\end{array}$ & 5 & 95 & 0 & 13910 & & 293 \\
\hline 10 & 70 & $\begin{array}{l}80,140,200,300 \\
400,500,600,700\end{array}$ & 0 & 100 & 0 & 13910 & & 293 \\
\hline 11 & 70 & $\begin{array}{l}80,140,200,300 \\
400,500,600,700\end{array}$ & TBD & TBO & 0 & 13910 & & 293 \\
\hline 12 & 70 & $\begin{array}{l}80,140,200,300 \\
400,500,600,700\end{array}$ & TBD & TBD & 0 & 13910 & & 293 \\
\hline 13 & 70 & $\begin{array}{l}80,140,200,300 \\
400,500,600,700\end{array}$ & TBO & TBD & 0 & 13910 & & 293 \\
\hline 14 & 100 & $80,140,200,270,330$ & 95 & 5 & 0 & 7860 & & 80 \\
\hline 15 & 100 & $80,140,200,270,330$ & 50 & 50 & 0 & 7860 & & 80 \\
\hline 16 & 100 & $.80,140,200,270,330$ & 5 & 95 & 0 & 7860 & & 80 \\
\hline 17 & 100 & $80,140,200,270,330$ & TBO & TBD & 0 & 7860 & & 80 \\
\hline 18 & 100 & $80,140,200,270,330$ & TBD & TBO & 0 & 7860 & & 80 \\
\hline
\end{tabular}


TABLE 3. (cont inued)

\begin{tabular}{|c|c|c|c|c|c|c|c|}
\hline $\begin{array}{l}\text { Run } \\
\text { Number }\end{array}$ & $\begin{array}{l}\mathrm{LH}_{2} \text { Density } \\
(\%) \\
\end{array}$ & $\begin{array}{l}\text { Run Temperatures } \\
(\mathrm{K})\end{array}$ & $\begin{array}{l}2 \mathrm{H}(\mathrm{O}) \\
(\%) \\
\end{array}$ & $\begin{array}{c}3 H(T) \\
(x) \\
\end{array}$ & $\begin{array}{l}\mathrm{He} \\
(\%)\end{array}$ & $\begin{array}{l}\text { Fill Pressure } \\
\text { (psig) }\end{array}$ & $\begin{array}{c}\text { Fill Temperature } \\
(K)\end{array}$ \\
\hline 19 & 40 & $\begin{array}{l}80,140,200,300 \\
400,500,600,700\end{array}$ & 95 & 5 & 0 & 6240 & 293 \\
\hline 20 & 40 & $\begin{array}{l}80,140,200,300 \\
400,500,600,700\end{array}$ & 50 & 50 & 0 & 6240 & 293 \\
\hline 21 & 40 & $\begin{array}{l}80,140,200,300 \\
400,500,600,700\end{array}$ & 5 & 95 & 0 & 6240 & 293 \\
\hline 22 & 40 & $\begin{array}{l}80,140,200,300 \\
400,500,600,700\end{array}$ & TBD & TBD & TBD & 6240 & 293 \\
\hline 23 & 70 & $\begin{array}{l}80,140,200,300 \\
400,500,600,700\end{array}$ & 49.75 & 49.75 & .5 & 13910 & 293 \\
\hline 24 & 70 & $\begin{array}{l}80,140,200,300 \\
400,500,600,700\end{array}$ & 49 & 49 & 2 & 13910 & 293 \\
\hline 25 & 70 & $\begin{array}{l}80,140,200,300 \\
400,500,600,700\end{array}$ & 45 & 45 & 10 & 13910 & 293 \\
\hline
\end{tabular}


attached to the assembly as required. The liquid nitrogen Dewar will have been filled with $\mathrm{LN}_{2}$ in preparation for cooling the capsule. The vacuum gauge will be checked to assure no in-leakage to the secondary containment.

\subsubsection{Experiment Sequence}

Table 3 lists twenty-five different experimental runs which will be made over the given range of temperatures. The capsule will be cooled to the lowest run temperature and stabilized thermally. The first muon exposure will be made at this temperature, the data will be recorded, and the temperature of the capsule will then be elevated to the next higher temperature. This sequence will be repeated until the highest temperature shot is reached. The capsule heaters will then be de-energized and the capsule will be cooled to room temperature. Provision is made for forced air cooling by means of the nitrogen jacket if required. The cool-down rate shall not exceed $100^{\circ} \mathrm{F}$ per minute.

After the cool-down, the experimental assembly (primary and secondary) will be removed from the facility and replaced by the next assembiy. The above sequence will then be repeated.

\subsubsection{Post Experiment Handling}

Following the experimental run, the secondary containment/primary system assembly will be returned to the fill station where the capsuie will be removed and placed in the capsule storage rack. A new capsule will then be taken from the storage rack and the sequence established in 4.3 .2 and 4.3.3 will be repeated. The used capsules will be checked for deformation following each run to assure suitability for refill. 


\section{SAFETY CONSIDERATIONS}

This section identifies the safety considerations for the muon catalyzed fusion experiment target system. Safety considerations will be addressed from the point of capsule fill to experiment operation at LAMPF. The safety of the LANL Fill System or the LAMPF beam will not be addressed here. Four safety considerations have been ident ified for the MCFE mechanical system. These are:

1. Tritium Release

2. Electrical Safety

3. Primary System Breach

4. Thermal Safety

Each of these considerations will be addressed separately in the following paragraphs.

\subsection{Tritium Release}

Tritium release will only be addressed for the target system assembly (primary system assembled in the secondary containment). LANL-supplied systems and equipment will not be addressed. The tritium is initially contained solely within the primary system. The primary system is installed in the secondary containment and the secondary containment is maintained at vacuum. The primary system (tritium containing) does not penetrate the secondary containment. A vacuum gauge is attached to the secondary containment to monitor significant in-leakage from the atmosphere or the primary system.

As the experiment proceeds, tritium will tend to permeate from the primary system to the secondary containment vacuum. This permeatation. will be inhibited by means of gold plating on the inside of capsule to less than 5 microcuries (Appendix $D$ ). The secondary containment will be sealed to 
$1 \times 10^{-6}$ scc/sec helium. Therefore, with the negative pressure differential on the secondary containment and the leak tightness of the containment, tritium is not expected to leak from the containment. If leakage were to occur while the assembly is in place at the LAMPF facility, a ventilation hood would collect it resulting in proper ventilation of the experiment area.

It can be concluded that there are multiple barriers and mechanisms to prevent personnel exposure to tritium from the target system. Thus, the design incorporates adequate personnel tritium exposure safety margins.

\subsection{Electrical Safety}

The target system contains the following electrical components:

1. Two Cartridge Heaters ( $\approx 20$ watts each)

2. 115V Heater Controller

3. $115 \mathrm{~V}$ Temperature Indicator

The electrical subsystem will be designed and installed per the requirements of the National Electric Code (NEC). Design and installation to the NEC will assure adequate personnel safety.

\subsection{Primary System Breach}

A breach of the primary system would result in tritium release to the secondary containment. The consequences of this release were addressed above. The breach would be a longitudinal crack in the capsule circular section or a radial crack in the capsule nose. These areas are required to be as thin as practical to reduce muon or neutron shielding. A breach would result in a release of energy which would result in a net force on the capsule. The capsule reaction force will be transferred to the mount. The final design analysis will address the strength of the mount to assure that it is adequate to prevent the secondary containment from being damaged. 


\subsection{Thermal Safety}

The primary system will be heated to as high as $700 \mathrm{~K}$ and cooled to as low as $80 \mathrm{~K}$. These extremes in temperature could result in personnel injury if skin were to come in contact with the metal. The primary system is contained within a secondary containment which precludes people from touching the tubing or capsule. There will be liquid nitrogen lines leading to and from the primary system. These lines will penetrate the secondary containment wall. The inlet line will lead from a dewar to the primary system. This 1 ine will be insulated to prevent contact by personnel. The outlet line will vent nitrogen gas that is boiled-off while cooling the primary system. This line will be insulated to protect personnel. The vented gas will be directed upward to preclude personnel contact. The system has been adequately designed to preclude personnel injustry from thermal hazards. 


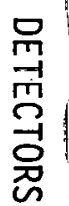




\section{PARTICLE DETECTORS}

Particle detection requirements are given in Reference 1. The arrangement of detectors for muons (M1, M2), electrons (E1, E2), and neutrons (N1, N2) is shown schematically in Figure 10. The handling of signals from the detectors is presented in the following section.

Counters M1 and M2 define the incoming muon beam. Muon-decay electrons are detected by counters El and E2 placed in front of the neutron detectors. Veto counters (e.g., for beam halo particles) may be added depending on charged particle backgrounds. Charged particle detectors will be made from $1 / 8^{\prime \prime}$ thick plastic scintillator of type Pilot $B$. These detectors will be insensitive to neutrons due to their thinness and elevated bias settings.

Several factors enter into the choice of neutron detector materials and geometries. One desires a scintillator material which will provide for the optimum detection of neutrons. As explained in Appendix $E$, the Monte Carlo program GRACE has been used to predict neutron-detection efficiencies for two scintillator materials commonly used for neutron detection, Pilot $F$ and NE213. Figure E-1 shows that Pilot $F$ is approximately $10 \%$ more efficient in detecting neutrons than NE213 (for the same thickness and bias). However, NE213 is superior in that it allows for pulse shape discrimination against background gamma rays and electrons. In principle, such neutron detectors could also serve as muon-decay electron detectors.

Optimal geometric detection efficiencies are also desirable. The Monte Carlo program SOLANG has been used to. predict solid angles subtended by right cylindrical detectors and their errors (see Appendix $B$ ). The arrangement of detectors shown in Figure 10 covers $68 \%$ of $4 \pi$, relative to the extended source of neutrons from the target. More complicated geometries may permit higher geometrical efficiencies. For example, Figure 11 displays an arrangement of particle detectors which "wrap around" the target. Approximately $88 \%$ of $4 \pi$ is covered in this case ( $152 \mathrm{~mm}$ diameter scintillators with a $42 \mathrm{~mm}$ diameter hole to accommodate the 


\section{Detectors}

Figure 10. Arrangment of particle detectors. PM tubes for charged particle detectors extend out of the plane of the paper.

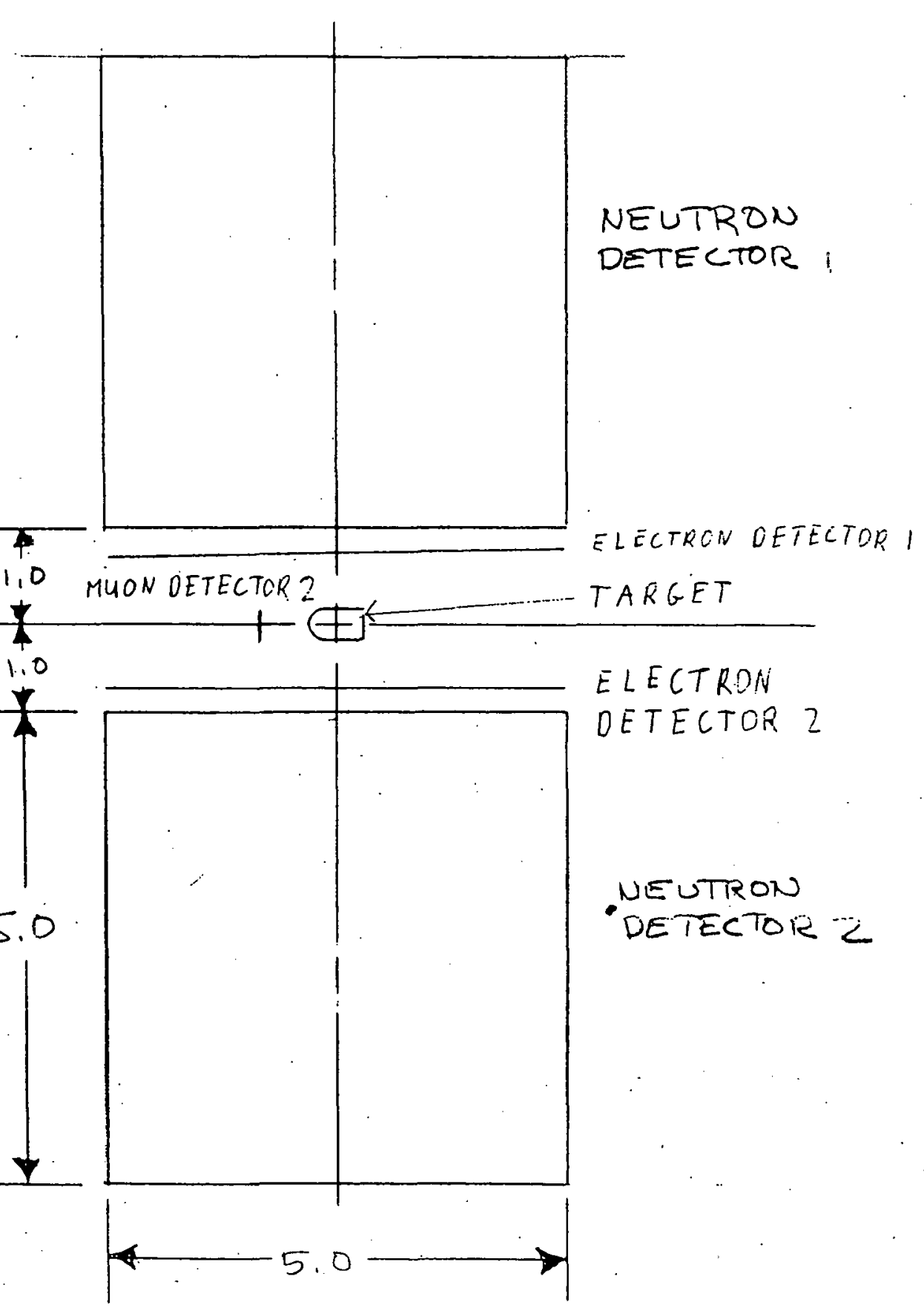




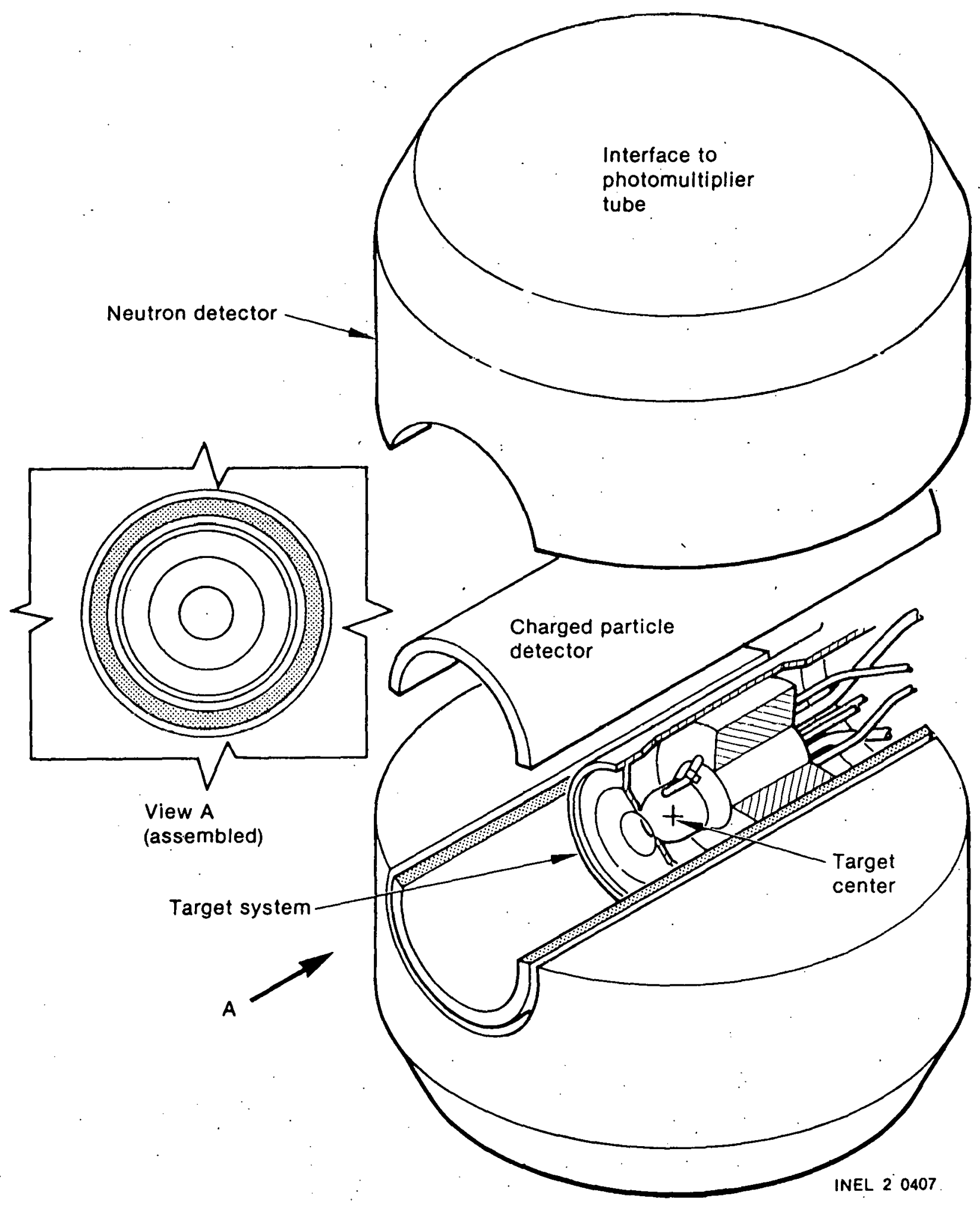

Figure 11. Alternative arrangement of particle detectors. 
target and muon beam). However, calibrating or calculating the overall neutron-detection efficiencies and errors is much simpler for right-cylindrical detectors. Indeed, we are currently combining the GRACE and SOLANG codes to do just that. Furthermore, cylindrical geometries permit simpler detector fabrication (encapsulated NE213 detectors can be purchased off-the-sheif).

We plan, then, to use two 5" $(127 \mathrm{~mm})$ diameter by $5^{\prime \prime}$ long encapsulated NE213 scintillators attached to 5" photo-multiplier tubes as neutron detectors arranged as shown in Figure 10 for the following reasons:

1. Discrimination against gamma rays and electrons is possible;

2. Simple geometry facilitates determining neutron detection efficiency and its error accurately;

3. Neutron detection efficiency is adequate (roughly 15\%, combining scintillator and geometrical efficiencies);

4. Encapsulated NE213 scintillators of reasonable sizes can be purchased off-the-shelf. 


\section{FAST FIECTRONICS}

Our experiment requires detection of a muon arriving at the target, followed by detection of one or more $14 \mathrm{MeV}$ neutrons; each valid event concludes with detection of the electron from muon decay.

The basic event logic, as shown in Figure 12, is a triple coincidence. If a muon arrives at the target while the computer is not BUSY and in proper time sequence with the proton. BEAM, the MU gate generator goes high for five microseconds. The first neutron pulse after MU goes high sets the $N$ flip-flop high. The triple coincidence requirement is fulfilled if an electron (E) is detected before MU falls low.

We wish to reject any event where two or more muons have stopped in the target during the same 5 microsecond period. Each MU STOP signal from the muon telescope sets high an extendable 5 microsecond gate, called IMU. Signal IMU in effect arms an AND gate; if another MU STOP comes before IMU falls, $2 M U$ is generated to reject the event.

The neutron detectors are to be fabricated with NE213 liquid scintillator, in order to perform pulse shape discrimination. The detector logic is drawn in Figure 13. The anode output of each detector's PM tube is followed by a pulse shape discriminator (PSD). The discriminator neutron (e.g. NT) outputs are $O R^{\prime} d$ together, to generate $N$ for the triple coincidence. They are also AND'd to form NCOINC. This last signal indicates the neutron counters have fired in coincidence; the event will be rejected if NCOINC is high. The PSD electron outputs are simply OR'd together to form signal E. E completes the triple coincidence.

Figure 14 illustrates the ADC/TDC logic for one neutron detector. When MU goes high, all the TDC clocks start running, and the circuit opens for business. Each successive neutron pulse $N 1$ causes a separate output of the logic router to go high. The logic router outputs perform two functions: they stop a TDC channel and gate open an ADC. 
Figure 12.

\section{Event Logic}
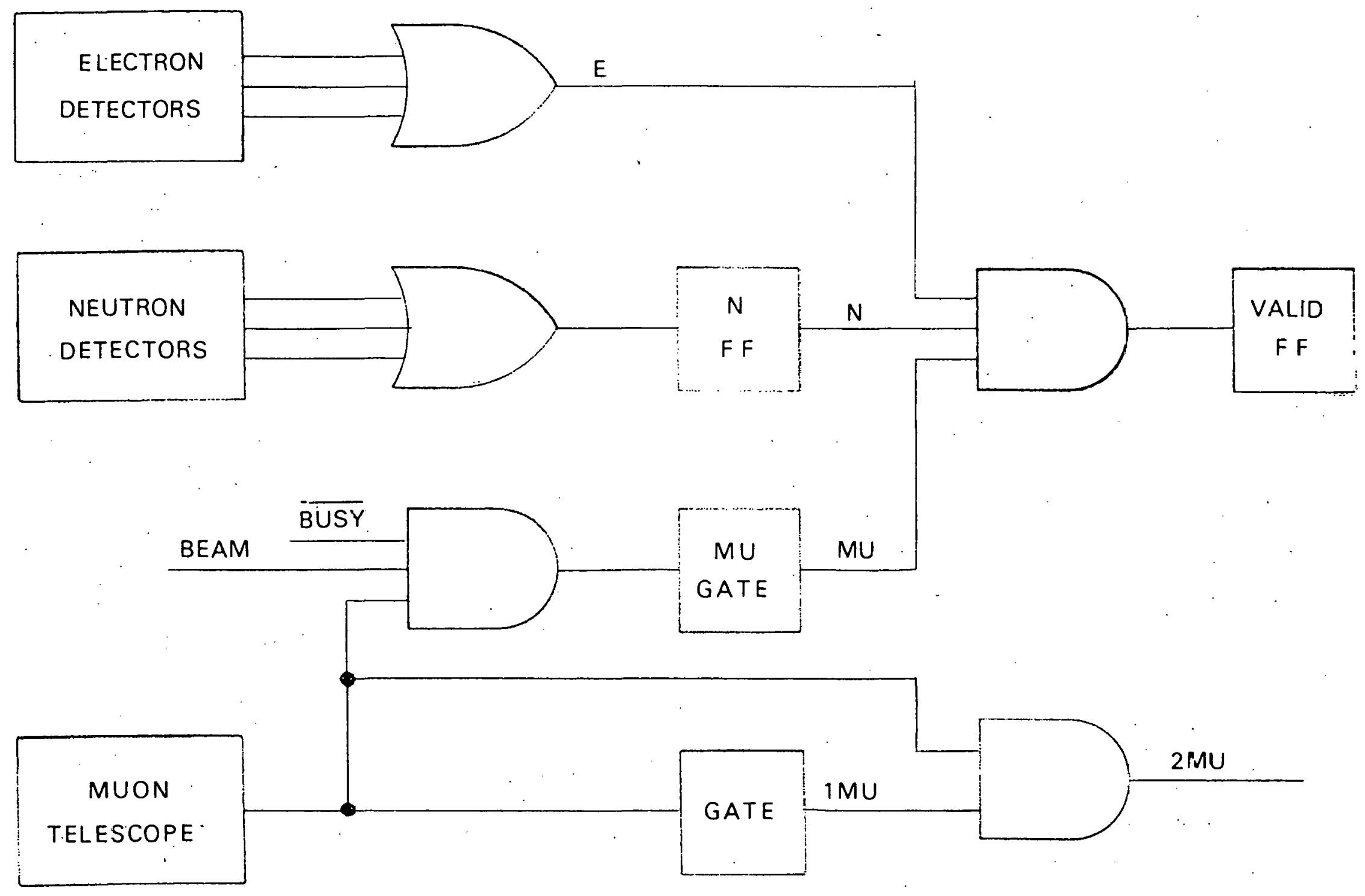
Figure 13.

\section{Detector Logic}

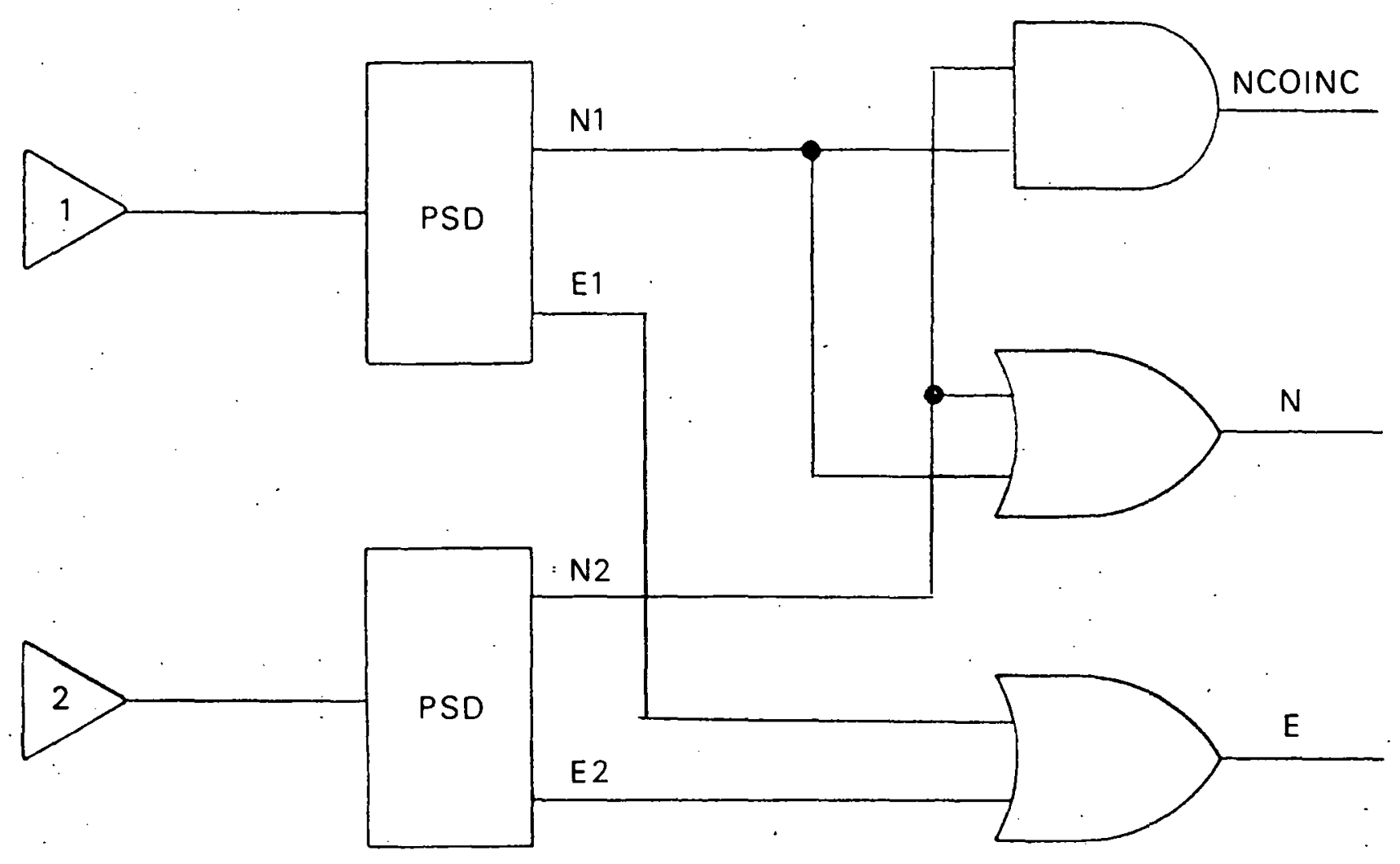


Figure 14.

\section{ADC/TDC Logic}

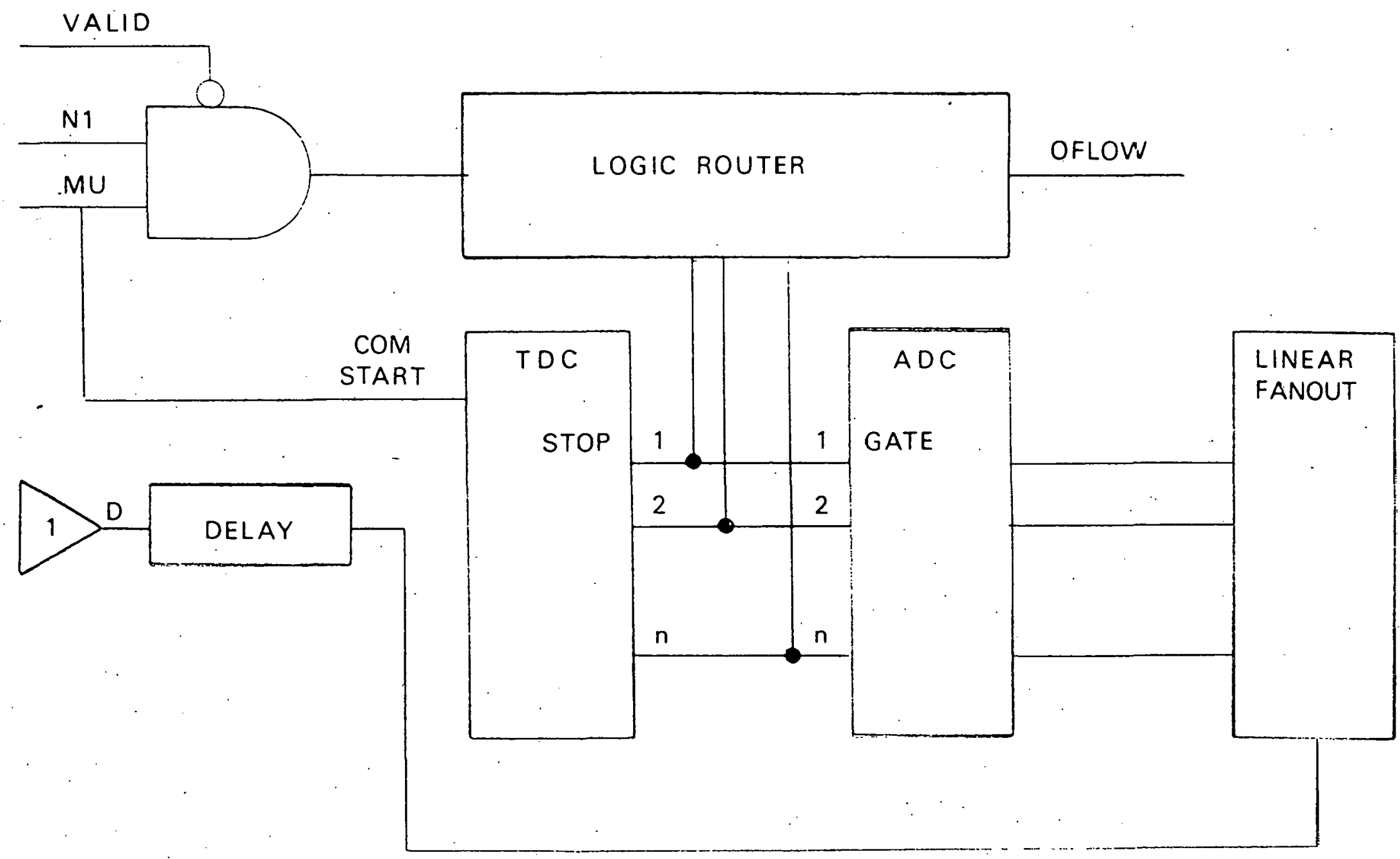


Dynode pulses from the PM tube dre delayed, then passed to a linear fanout. Finally they go to the ADC's. The first neutron pulse is recorded by $A D C 1$, the second by $A D C 2$, etc. Similarly, the time distribution of the neutrons is recorded by use of TOCl for the first neutron, TDC2 for the second, and TDCn for the nith.

The logic router is basically a string of flip-flops. The first two stages are shown in Figure 15. Each successive input pulse changes the state of one flip-flop and arms the next in series. The last stage generates a pulse called OFLOW, indicating that the number of neutron pulses has exceeded the available ADC and TDC channels.

Internally the logic router will be constructed with ECL logic for fast operation. Level shifters are provided at the input and output in order to match NIM fast logic levels.

The reset logic, shown in Figure 16, clears the ADC's, TDC's, flip-flops, and gates. The reset logic operates after the computer processes an event or the logic detects an invalid event. Four signals can cause a RESET:

DONE Computer is finished recording an event

NCOINC Coincident pulses in neutron detectors

TIMEOUT Triple coincidence not satisfied in 5 microseconds

2MU Two muons in target.

In particular, RESET is applied to the front panel CLEAR inputs of the $A D C$ 's and TDC's resetting them in $1-2$ microseconds.

After a valid event occurs, a computer interrupt is sought by applying VALID to a CAMAC input register (see Figure 17). The computer replies by raising the BUSY signal; when done recording the event it signals DONE. The latter two signals come from a CAMAC output register. 
Figure 15.

\section{Logic Router}

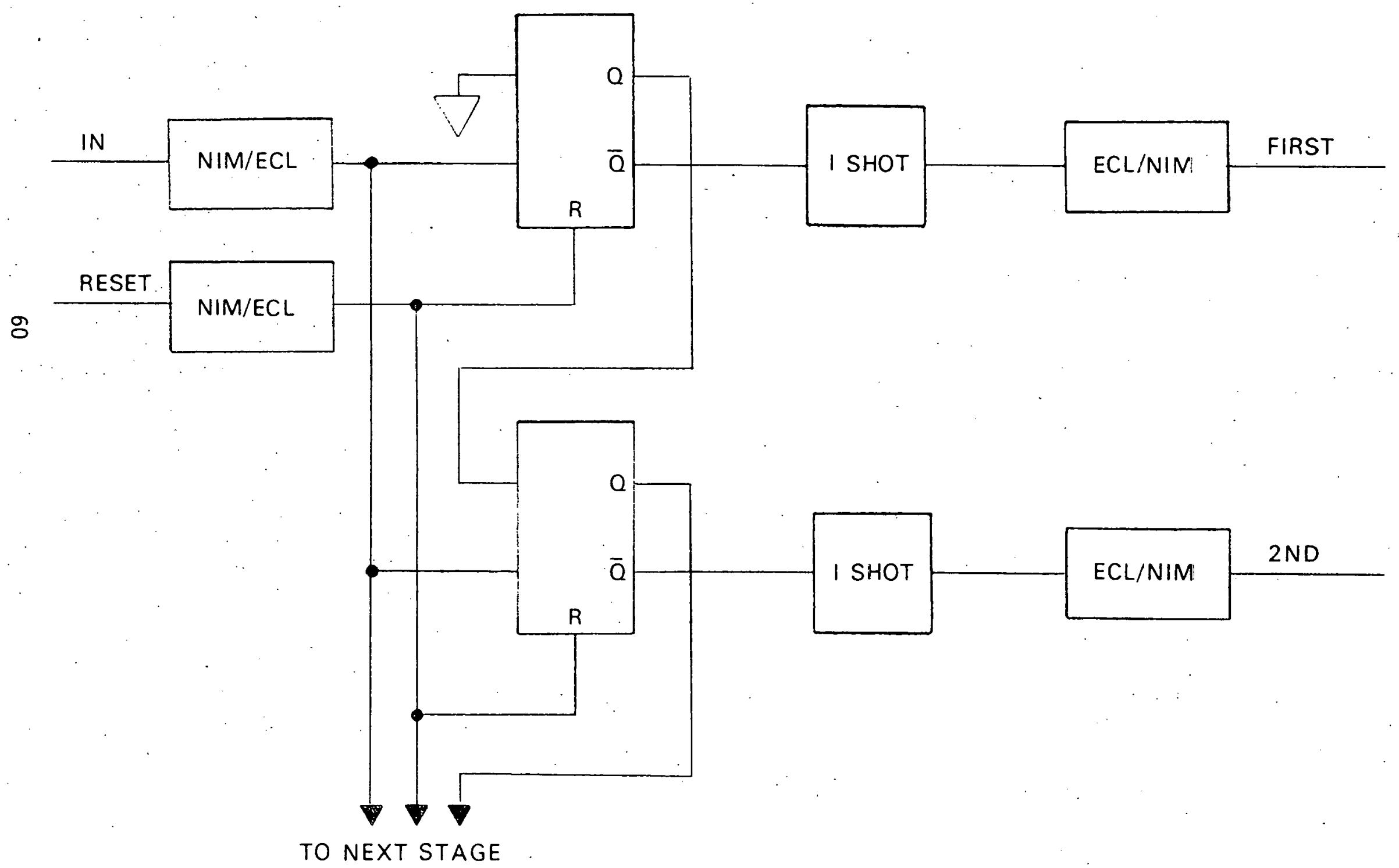


Figure 16.

\section{Reset Logic}

임

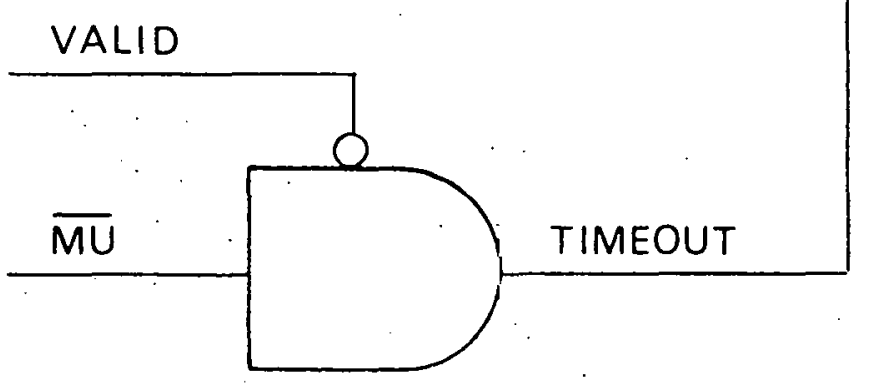


Figure 17.

\section{CAMAC I/O}

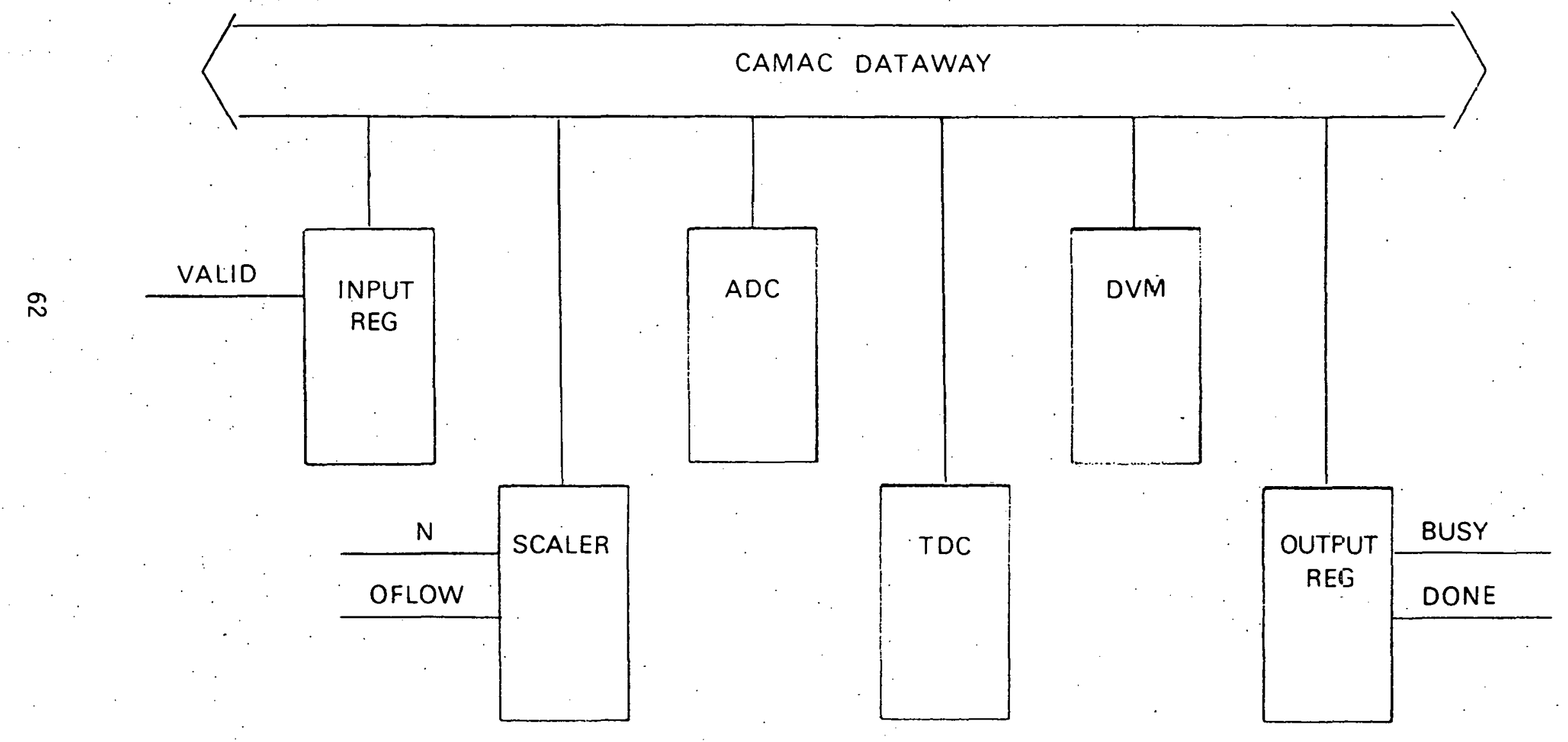


Figure 17 also shows that several signals, including $N$ and OFLOW, will be monitored with CAMAC scalers.

A summary of the logic signals for this experiment can be found in Table 4 .

Aill of the required electronics, save PSU's and logic routers, is built up from the standard NIM and CAMAC modules. A list of the necessary gear is presented in Table 5 . 
TABLE 4. LOGIC SIGNALS

\begin{tabular}{|c|c|c|}
\hline Name & Figure & Definition. \\
\hline BEAM & 12 & Proton puise delivered to pion production target \\
\hline BUSY & 12,17 & Computer busy \\
\hline DONE & 16,17 & - Computer done with event \\
\hline$E$ & 12,13 & E1 or E2 \\
\hline El & 12,13 & Electron detector 1 fired \\
\hline MU & $12,13,14,17$ & $\begin{array}{l}\text { Muön arrived al taryel; cumpuler not busy and } \\
\text { beam present }\end{array}$ \\
\hline MU STOP & 12 & Muon arrived at target \\
\hline N & 12,13 & $\mathrm{~N} 1$ or $\mathrm{N} 2$ \\
\hline N1 & 13,14 & Neutron detector 1 fired \\
\hline NCOINC & 13,16 & Two neutron detectors fired in coincidence \\
\hline IMU & 12 & At least one muon in target \\
\hline FLOW & 14 & $\begin{array}{l}\text { More neutron pulses than } A D C \text { channels to handle } \\
\text { them. }\end{array}$ \\
\hline RESET & 16 & Reset $A O C^{\prime} s, T D C^{\prime} s$, gates and flip-flops \\
\hline $2 M U$ & 12,16 & At least two muons in target \\
\hline VALIO & $12,15,16,17$ & $\begin{array}{l}\text { Valid event: triple coincidence requirement } \\
\text { satisfied }\end{array}$ \\
\hline
\end{tabular}


TABLE 5. ELECTRONIC MODULES

\begin{tabular}{|c|c|c|c|}
\hline Quantity & MFR & Mode 1 & Item \\
\hline 1 & Power Designs & HV 1570 & HVPS \\
\hline 4 & Lecroy & 222 & Dual Gate \& Delay \\
\hline 2 & $"$ & $2249 S G$ & CAMAC ADC (Separate Gates) \\
\hline 3 & $"$ & $2228 A$ & CAMAC TDC ( $5 \mu$ sec Range) \\
\hline 1 & $"$ & $2249 A$ & CAMAC ADC \\
\hline 2 & $"$ & 2251 & CAMAC Scaler \\
\hline 7 & $"$ & $365 A L$ & Logic Unit \\
\hline 1 & Ortec & $\mathrm{DB} 463$ & Delay \\
\hline 2 & Lecroy, & 128 & Linear Fanout \\
\hline 2 & $"$ & 429 & Logic Fanout \\
\hline 1 & Kinetic Sys. & -- & Multichannel DVM \\
\hline 2 & EG\&G Idaho & -- & PSD \\
\hline 2 & EG\&G Idaho & -- & Logic Router \\
\hline 1 & Ortec & IR026 & CAMAC Input Register \\
\hline 1 & Ortec & ND027 & CAMAC Output Register \\
\hline 1 & Std. Eng. & 1410 & CAMAC Crate \\
\hline 2 & Any & -- & NIM Bin, $6 \mathrm{~V}$ \\
\hline 1 & Kinetic Sys. & 3290 & Dataway Display \\
\hline
\end{tabular}




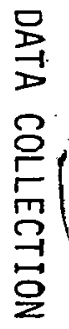


The on-line computer system will consist of the following pieces of hardware (or equivalents):

1. DEC PDP-11/45 with RSX-110 operating system

2. Dual disk drive unit

3. Two 9-track tape drive units

4. Tektronix 4000 series graphics storage scope

5. Teletype control console

6. Printronix graphics/line printer

7. CAMAC interface

The data acquisition program will provide the following services:

1) At the beginning of a run:

(a) request from terminal the following header information:

1)) Run number

2) Deuterium concentration

3) Tritium concentration

4) Helium concentration

5) Target gas density

b) Read the thermocouple

c) Write a header block to tape, consisting of the information in a) and b) along with the time and date 
2) For each event:

a) Read the ADC's, TDC's and the total number of neutrons detected for the event

b) Add the number of neutrons to the histogram of the number of neutrons per event

c) Buffer this data for eventual write to tape

d) Provide DONE signal to electronics.

3) Periodically

a) Read the following scalars and update run totals

1) $\mathrm{N} 1, \mathrm{~N} 2$

2) $\mathrm{E} 1, \mathrm{E} 2$

3) MU STOP

4) MU

5) $2 \mathrm{MU}$

6). $M 1$

7) $M 2$

b) Read in current DVM channel number and channel reading, and advance the channel. (The DVM will be used to monitor photomultiplier tube voltages, vessel thermocouple readings, secondary vessel vacuum, and beam magnets. Out-of-range readings will cause the computer to alert the experimenters of the problem and halt data-taking.) 
4) At the end of a run

a) Make final reading of scalars in $3 a$ )

b) Write out trailer record consisting of information in header block, the totals from $3 a$ ) and the averages from $3 b$ )

Background programs will be written in FORTRAN to accumulate statistics and histograms. Ratios of scaled logic signals (e.g. $\left.\left(\mathrm{N}_{1}+\mathrm{N}_{2}\right) / \mathrm{Ml} \cdot \mathrm{M} 2\right)$. will be calculated and displayed during data-taking to on-line analysis of data and comparisons with expected values. Sample histograms are shown in Figure 18. The bottom histogram shows the expected (Poisson) distribution of detected neutrons for average neutron count $=12$. (Taking into account predicted neutron detection efficiencies, this histogram would imply $\left.n_{\mu}=70.\right)$ Such histograms will allow experimenters to continuously monitor counter and logic operation along with some experimental results.

In addition to on-line computer logging and analysis of data, a set of written logs will be kept. All experimental conditions will be logged, including descriptions of beam tuning, counter efficiency tests, fast electronics as actually implemented, and on-line software. In addition, records will be maintained to keep track of gas bottle pressures, beam magnet settings, mass spectrometer analyses of target gas compositions, changes in logic modules, random observations, and so on. 

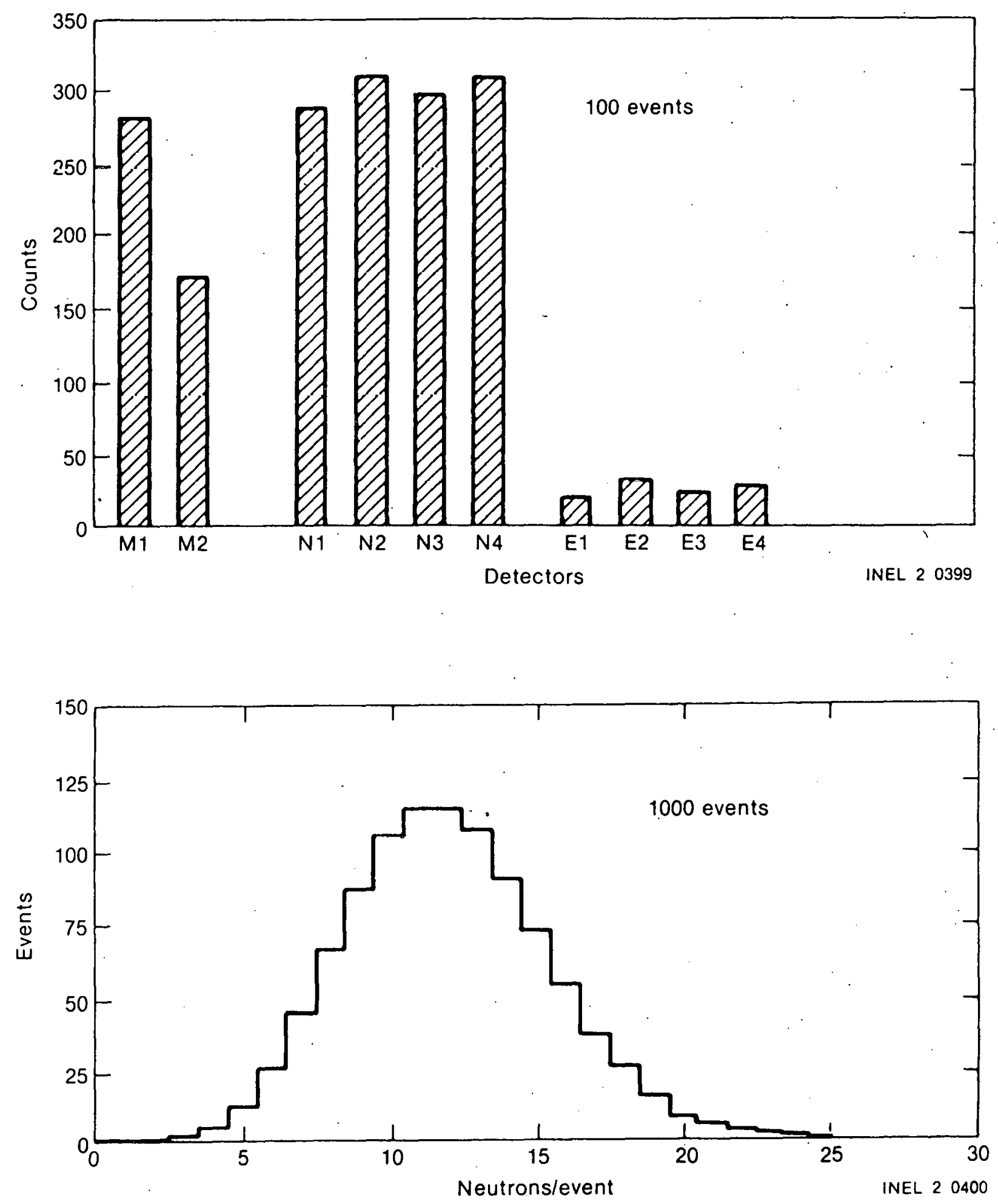

Figure 18. Examples of diagnostic and raw-results histograms which can be generated during data-taking. 
$0 \%$ 
APPENDIX A

\section{PROGRAM SIMUT}

SIMUT is a computer program written to simulate targets which could be used in the muon catalysis experiment. Changes in momentum and scattering angle of the muon beam are calculated as the beam passes through a target entry window into a hydrogenic $(d-t)$ target. Range and projected RMS scatter of the beam in the target are calculated for muons which successfully pass through the window.

SIMUT was written in Fortran 5 by $S$. E. Jones and currentiy runs on the CYBER-176 system at the INEL. A listing of SIMUT is given on subsequent pages (Figure $A-1$ ).

The following parameters may be varied to simulate experimental conditions:

- Muon beam momentum

- Target window thickness

- Target window material

- Plating material (and its thickness) on vessel interior

o Density of fluid d-t target.

Tables for values of $\mathrm{dE} / \mathrm{dx}$ of muons in metals (copper and lead) and muon range in hydrogen were extracted from the particle properties handbook. Material densities $(\rho)$ and characteristic radiation lengths $\left(L_{R}\right)$ were also used. Changes in momentum $(P)$ for incremental steps $(\Delta x)$ through. the target window were calculated using:

$\Delta P=\rho \sqrt{1+(105.66 / P)^{2}} d E / d x \Delta x$ 
Figure A-1. Listing of simulation program SIMUT.

PROGRAM SIMUT ( INPUT, OUTPUT, TAPEG=OUTFUT)

$c$
$C$
$C$
$C$
$C$
$C$
$C$
$C$

PROGRAM TO CALCULATE CHANGE OF MUON BEAM MOMENTLM

AND INCREASE OF SCATTERING ANGLE

AS BEAM PASSES THROUGH TRRGET ENTRY WINDOW

S.E. JOHES 1,82 VERSIOH QUER MOD OQR

DIMENSION DPDX(70), DEDX(70), RNGE (35), RNGH(35)

DIMENSION DEDXAU( 35 ), DPDXAU( 35 )

$C$
$C$

ASSUME WINDOW IS MADE OF SSTEEL RZB6, FLATEI) WITH STFALI CM (FF GCRI

DATA RO /7.9/, RADLEN /1.76/, WTMU /105.65946/, STPSIZ/6.01/

DATA ROAU $/ 19.3 /$, RADLAU $/ 0.35 /$, STPAU $/ 0.005 /$

DATA DEDXAU $77 * 100 ., 40 ., 36 ., 31,, 28,, 25 ., 22 ., 20 ., 18.5,17 .$,

$+\quad 16 ., 14.5,13.5,12.5,11.7,11 ., 10.4,9.8,9.2,8.8,8.4,7.8$,

$+7.4,7.0,6 \cdot 7,6.4,6 \cdot 2,5.9,5 \cdot 6 /$

DATA DEDX/7*100. ,56. ,50. , 45. , 40. , 36. , 32. , 29. , 26. , 24. ,21. 5, 261. , 19.

$+\quad, 17.5,16.5,15.5,14.5,13.5,13.0,12.5,11.7,11.0,16.5,18.01,9.6$,

$+\quad 9.0,8.6,8.2,7.9,7.6,7.4,7.2,6.8,6.6,6.4,6.2,6.0,5.7,5.55$,

$+\quad 5.4,5.25,5.1,5 ., 4.8,4.7,4.6,4.55,4.5,4.4,4.3,4.2,4.1,4 ., 3.9$,

$+\quad 3.85,3.8,3.75,3.7,3.6,3.5,3.45,3.4,3.35,3.3$,

C

C

RANGE IN LHR IN MM, $P=8$ TO 35 MEV $/ C$

DATA RNGH $7 * 0 ., 0.06, .14, .2, .3, .4, .52, .7, .9,1.2,1.4,1.8,2.2,2.5$,

$+\quad 3.0,3.4,4 \cdot 0,5 \cdot 0,5.8,6.7,7.5,8.7,10 ., 11 ., 12.5,14 ., 16 ., 18 ., 26.1$

C

C GENERATE DP/DX ARRAY BASED ON IE/IXX (FOR STEEL)

C

10

DO 10 IP $=8,70$

$P=$ FLOAT (IP)

$\mathrm{DPDX}(\mathrm{IP})=\mathrm{DEDX}(\mathrm{IP}) * \mathrm{RO} *(\operatorname{SQRT}(1+($ WTMU/P) $* * \overrightarrow{\mathrm{C}}))$

C GENERATE DP/DX FRRAY BASED ON IJE/IDX (FOR GOLD)

$\mathrm{C}$

DO 11 IP $=8,35$

$P=$ FLOAT (IP)

DPDXAU(IP) $=$ DEDXAU(IP) $*$ RORU * (SQRT $(1+($ WTMU/P) $* * 2))$

11 CONTINUE

c

CALCULATE RANGE IN D-T MIXTURE AT FHI $=0.4$

C

12

DO $12 \mathrm{~J}=8,35$

$$
\operatorname{RNGE}(J)=\operatorname{RNGH}(J) / 0.4
$$

$\mathrm{C}$

C CYCLE FOR THICKNESSES 0.8 MM - 2.4 MY BY $0.2 \mathrm{MM}$

$\mathrm{C}$

DO 100 ITHICK $=8,24,2$ 


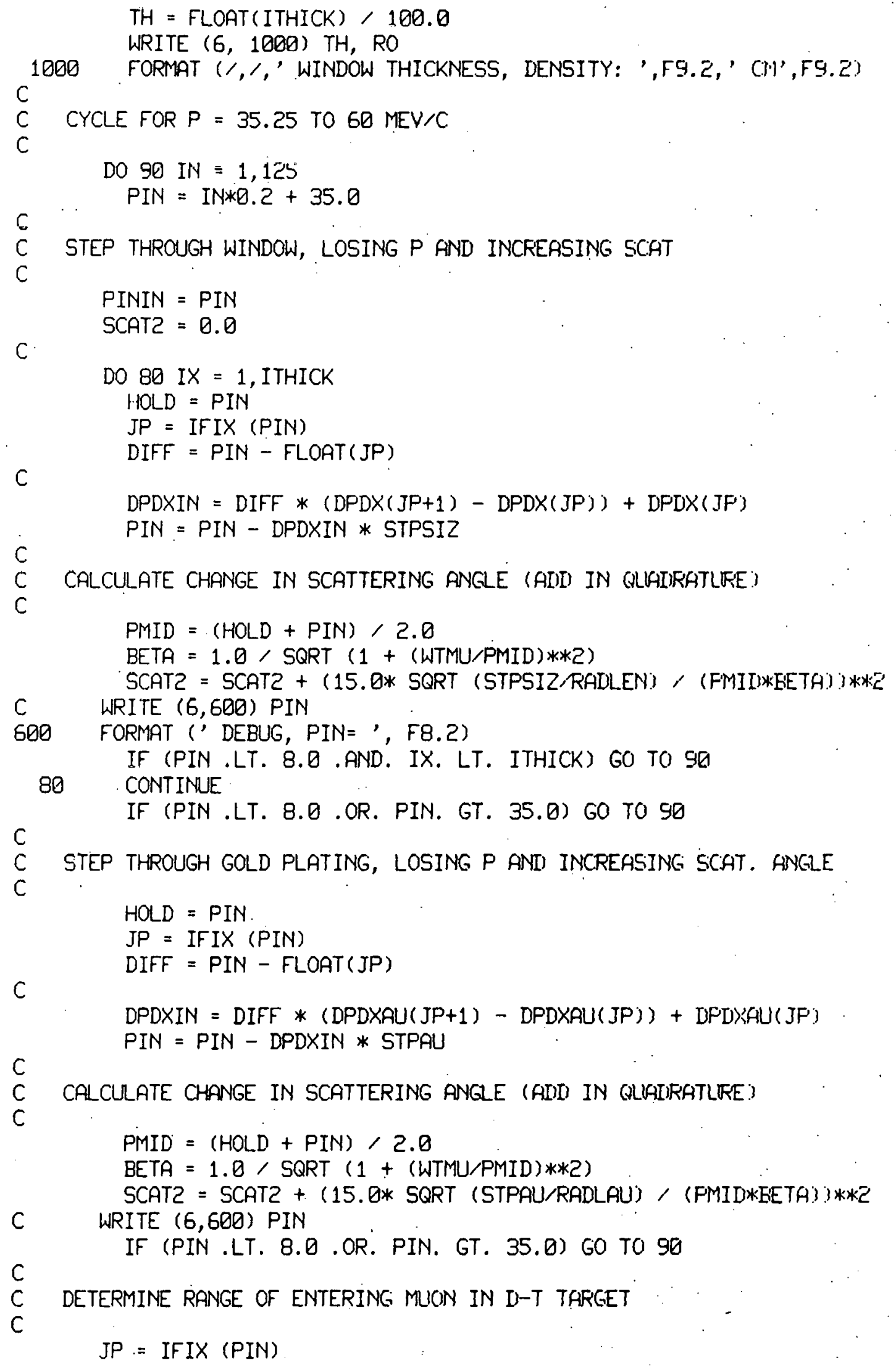




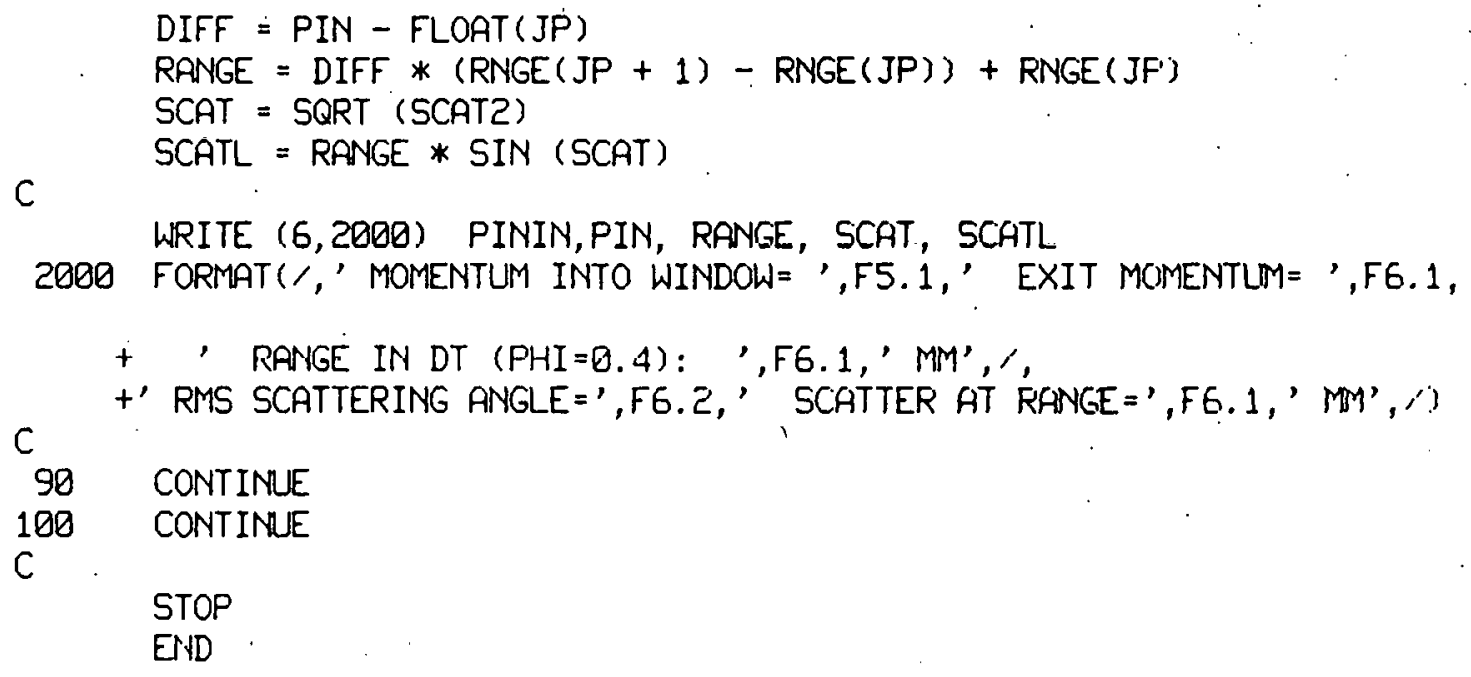


Changes in scattering angle were calculated using:

$\theta \underset{\text { plane }}{\text { rms }}=\left(15 / P *_{\beta}\right)\left(\Delta x / L_{R}\right)^{1 / 2}$

where

$$
B=\left[1+(105.66 / P *)^{2}\right]-1 / 2
$$

and

$$
P *=\dot{P}-\Delta P / 2
$$

Incremental changes in scattering angle are added in quadrature. Finally, calculations of muon range in hydrogen assume that:

$$
\text { range } \propto 1 / \text { density }(\phi)
$$

SIMUT has been used to predict incident beam momenta and acceptable momentum bites for various experimental conditions. We define as acceptable a momentum bite for which $70 \%$ of incident muons stop in the $\mathrm{d}-\mathrm{t}$ target. The remainder stop more or less equally in the front window, rear wall and sides of the target vessel (due to scattering). The optimum length of the target vessel can also be determined, i.e., the length where high-momentum muons stop equally in the rear wall and sides of the vessel. Results are shown in Table $A-1$ assuming a $1 \mathrm{~cm}$-diameter target chamber. (Salient results are plotted in Figure 9, Section 3.3.3). The program also shows that 2 mils of gold plating on the inside of muon entry window have minor impact on acceptable momentum bites. The need for gold plating is explained elsewhere (see Section 3.3.3). 
TABLE A-1. ACCEPTABLE MUON BEAM MOMENTUM BITES AS PREDICTED BY PROGRAM SIMUT

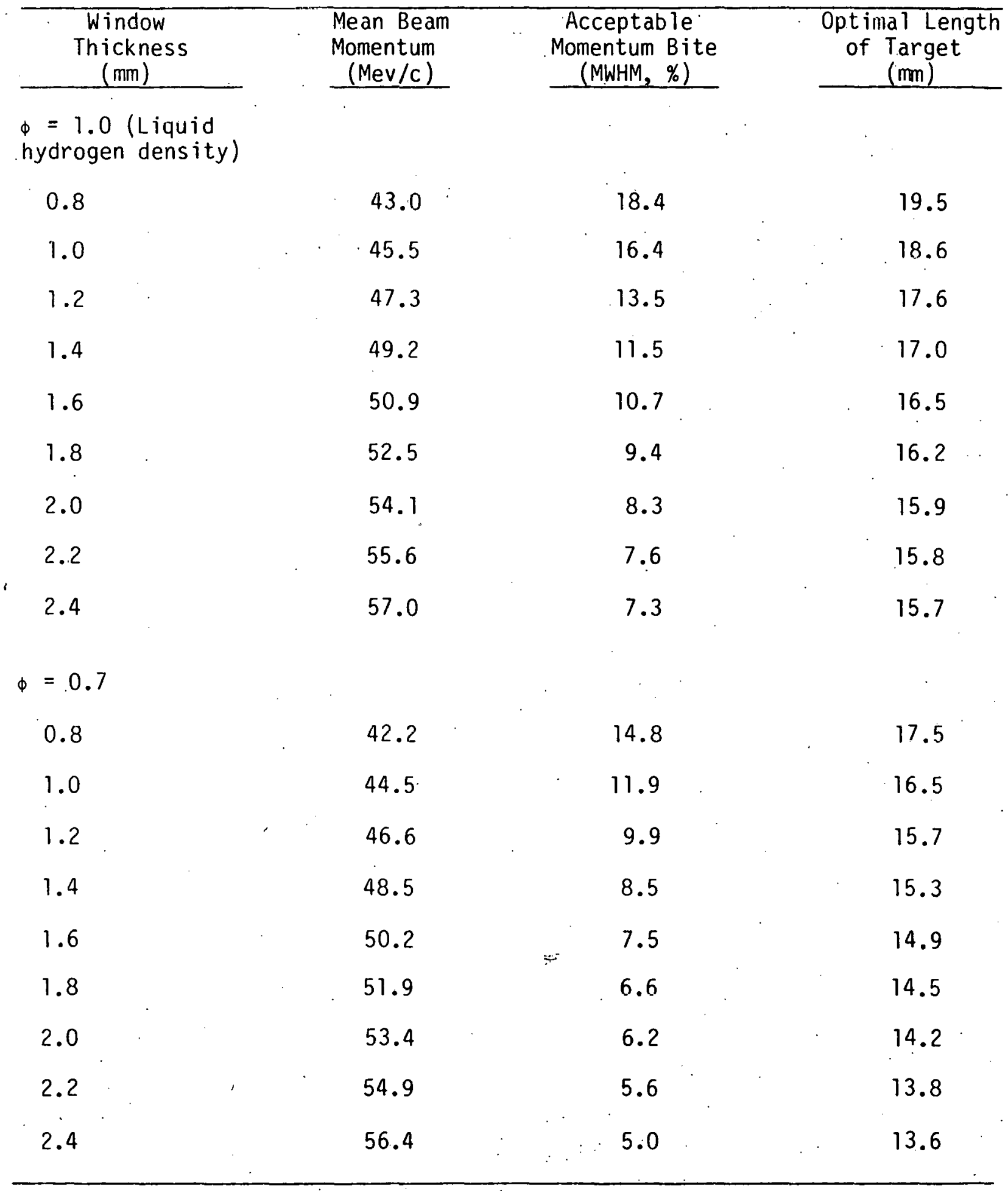


TABLE A-1. (continued)

\begin{tabular}{lccc}
\hline $\begin{array}{c}\text { Window } \\
\text { Thickness } \\
(\mathrm{mm})\end{array}$ & $\begin{array}{c}\text { Mean Beam } \\
\text { Momentum } \\
(\text { Mev/c) }\end{array}$ & $\begin{array}{c}\text { Acceptable } \\
\text { Momentum Bite } \\
(\text { MWHM, \% })\end{array}$ & $\begin{array}{c}\text { Optimal Length } \\
\text { of Target } \\
(\mathrm{mm})\end{array}$ \\
\hline $\begin{array}{l}0.4 \\
0.8\end{array}$ & 40.9 & 8.6 & 13.5 \\
1.0 & 43.4 & 7.1 & 12.9 \\
1.2 & 45.6 & 5.7 & 12.5 \\
1.4 & 47.6 & 5.0 & 12.2 \\
1.6 & 49.5 & 4.5 & 11.9 \\
1.8 & 51.2 & 3.7 & 11.6 \\
2.0 & 52.8 & 3.6 & 11.3 \\
2.2 & 54.3 & 3.3 & 11.0 \\
2.4 & 55.9 & 3.0 & 10.8 \\
\hline
\end{tabular}


APPENDIX B

COMPUTER CODE SOLANG: MONTE CARLO CALCULATION OF AVERAGE SOLID ANGLE SUBTENOED BY CYLINDRICAL DETECTORS

The target in this experiment is bullet-shaped (section 2.1), resulting in an extended neutron source of unusual geometry. We wish to calculate the geometrical efficiency of neutron detectors which could be used in this experiment for detecting neutrons emitted isotropically from our extended source. A Monte Carlo code called SOLANG (Solid Angle) is used for this purpose. The code was originally written for an IBM computer by Lucian Wielopolski, ${ }^{-1}$ for point and disk sources and a single right circular cylindrical detector. The code was adapted to the INEL CDC-CYBER system by $S$. E. Jones. In the process, computer memory requirements were reduced by an order of magnitude. Predictions of the revised code agreed well with values reported by Wielopolski. Also the neutron source was modelled assuming a uniform (random) distribution of point sources inside a bullet-shaped volume, and capabilities for multiple detectors were added The resulting SOLANG code is 1 isted on subsequent pages (Figure $B-1$ ).

SOLANG is used to predict average solid angles $(\Omega)$ and their errors subtended by right circular cylindrical detectors in various arrangements around the target vessel. Conditions and results are displayed in Figure B-2. The average solid angle and its statistical error (based on 1000 throws of the Monte (arlo) are displayed as percentage of $4 \pi$. covered by each detector assembly. An upper limit (U.L.) to the error is determined by looking at worst cases, i.e., neutron point sources at extreme positions in the target volume. Note that symmetrical arrangement of detectors is important in reducing the upper-limit error, as is keeping the target small and detectors as close to it as possible. Planned future improvements include utilization of SIMUT. (Appendix A) to better determine the distribution of neutron origins in the target. (Most muons will stop near the nose of the target.) SOLANG will also be coupled with GRACE (Appendix E) to predict overall neutron detection efficiency, folding together geometrical and scintillator efficiencies. 
Figure B-1. Listing of Monte Carlo program SOLANG

PROGRAM SQLANG (INPUT, OUTPUT, TAPE5=INFUT, TAFEG=CUTFUT'?

C SOLANG CALCLLATES THE AVERAGE SOLID ANGL SLETENIEII E' FICHT

C CIRCULAR CYLIDRICAL DETECTOR(S) FROM POINT (S) (F AERITEAEY

C POSITION AND STANDARD ERROR OF THAT SCLID ANOLE.

C AUTHORS: L. WIELOPOLSKI AND S.E. JONES

C VERSION 2 MOD 2 MARCH 1982

PARAMETER (NTHRO=1000)

DATA IFLAG / 1 ,

C INITIALIZE VARIABLES

C HO $=$ HEIGHT OF TARGET MIDPOINT ABOVE IETECTOR

$\mathrm{C} \quad \mathrm{R}=$ RADIUS OF TARGET (CYLINDRICALLYY SYMMETRIC)

C TARGL $=$ LENGTH OF TRRGET

C DL = LENGTH OF DETECTOR

C RO = RADIUS OF DETECTOR

HO $=21.0$

$R=5.0$

TARGL $=15.0$

$\mathrm{DL}=101.6$

$\mathrm{RO}=63.5$

$P I=3.1415926$

SUM $=0.0$

SUMSQ $=0.0$

$\mathrm{PLL}=0.0$

KOUNT $=0$

77 CONTINUE

C POINT SELECTION

$33 \quad Y=$ TARGL $*$ RANF ( ) - TARGL $/ 2.0$

$X=2.0 * R * \operatorname{RANF}()-\mathrm{R}$

$Z=2.0 * \mathrm{R} * \mathrm{RANF}()-\mathrm{R}$

IF (Y.GE. (R - TARGL/2.0) ) THEN

C CYLINDRICAL PORTION OF TARGET

IF ( (X**2 + Z**2).LT. R**2 ) GOTO 44

GOTO 33

- ELSE

C HEMI-SPHERICAL PORTION OF TARGET

$Y S=Y+5$.

IF ( (X**2 + YS**2 + Z**2) .LT. R**2) GOTO 44

GOTO 33

ENDIF 
C CALCULATE HEIGHT OF SOURCE ABOVE IETECTIR,

C AND DISTANCE OF SOURCE TO DETECTUR AXIS

$$
\begin{aligned}
& H=H O+Z \\
& P=S Q R T(X * * 2+Y * * 2)
\end{aligned}
$$

C CALCLLATE SOLID ANGLE SUBTENDED FOR THIS FOINT SCLRECE

66

$$
\text { KOUNT }=\text { K.OUNT }+1
$$

CONTINUE

IFLAG = -IFLAG

IF (P.GT.RO) GO TO 2

TMIN $=0.0$

TMAX $=\operatorname{ATAN}((\mathrm{RO}+\mathrm{P}) / \mathrm{H})$

$T C R I=\operatorname{ATAN}((R O-P) / H)$

$X F=$ RANF( )

TETA $=A \operatorname{COS}(\operatorname{COS}($ TMIN $)-X F *(\operatorname{COS}($ TMIN $)-\operatorname{COS}($ TMAX $)))$

$T T=\operatorname{TAN}(T E T A)$

$W 1=(\operatorname{Cos}($ TMIN $)-\cos ($ TMAX $)) / 2.0$

IF (TETA.GT.TCRI) GOTO 1

$W 2=1.0$

GOTO ?

$1 \mathrm{ALMX}=\operatorname{ACOS}((\mathrm{P} * \mathrm{P}+\mathrm{H} * H * T T * T T-R O * R 0) /(2.8 * H * T T * P))$

$W 2=A L M X / P I$

GOTO $?$

2 ALMX $=\operatorname{ASIN}(R O / P)$

ALMN $=-$ ALMX

$X F=\operatorname{RANF}()$

ALPHA $=$ ALMX* $(2.0 * X F-1.0)$

$W 1=$ ALMX/PI

$S I=\operatorname{SIN}(A L P H A)$

$X L=P * \operatorname{COS}(\mathrm{ALPHA})-S Q R T(R O * R O-P * P * S I * S I)$

IF $(H) \cdot 5,4,3$

$3 X L L=P * C O \bar{S}(A L P H A)+5 Q R T(R O * R O-P * P * S I * S I)$

TMAX $=$ ATAN $(X L L / H)$

GOTO 6

$4 \quad$ TMAX $=P I / 2.0$

GOTO 6

$5 \quad \operatorname{TMAX}=P .1 / 2.0+A T A N(-H / X L)$

$6 \quad \operatorname{TMIN}=\operatorname{ATAN}(X \mathrm{~L} /(\mathrm{H}+\mathrm{DL}))$

$W 2=(\cos ($ TMIN $)-\cos ($ TMAX $)) / 2.0$

$7 W T=W 1 * W 2$

$A L L=A L L+W T$

IF ( IFLAG .LT. Q) THEN

$H=H O-Z$.

GOTO 66

ENDIF

SUMSQ $=$ SUMSQ + RLL**2

$S U M=S U M+$ ALL

$A L L=0.0$

8 IF (KOUNT .LT. NTHRO) GOTO 77

C CALCLLATE AVERAGE SOLID ANGLE AND ITS ERRIR; FRINT CRT FESLRTS 


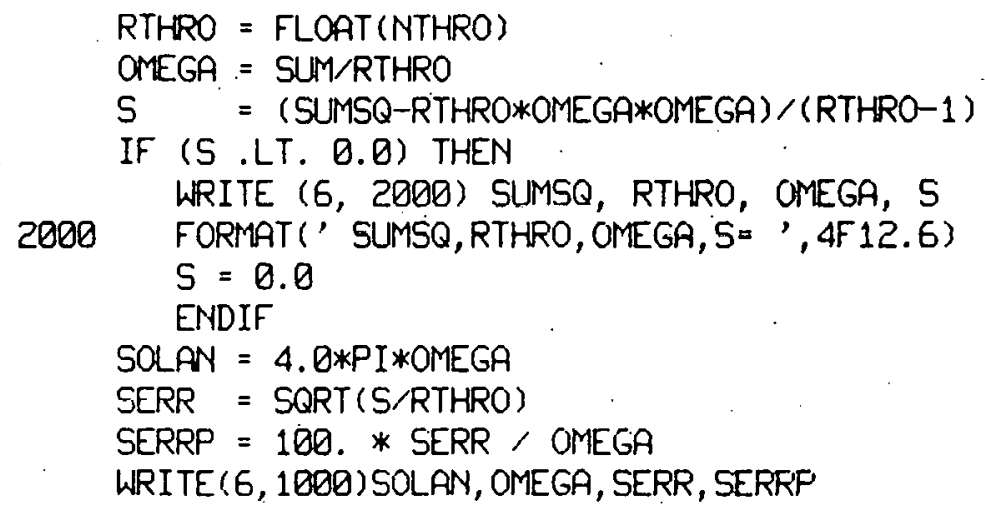

1000 FORMAT(' 1 SOLID ANGLE=',F10.5, ',' FRACTION OF $4 F I=', F 10.5$, \& $\quad$,' RELATIVE ERROR = ,F10.5, ,' ERROR \%=',F16.5)

STOP

END 

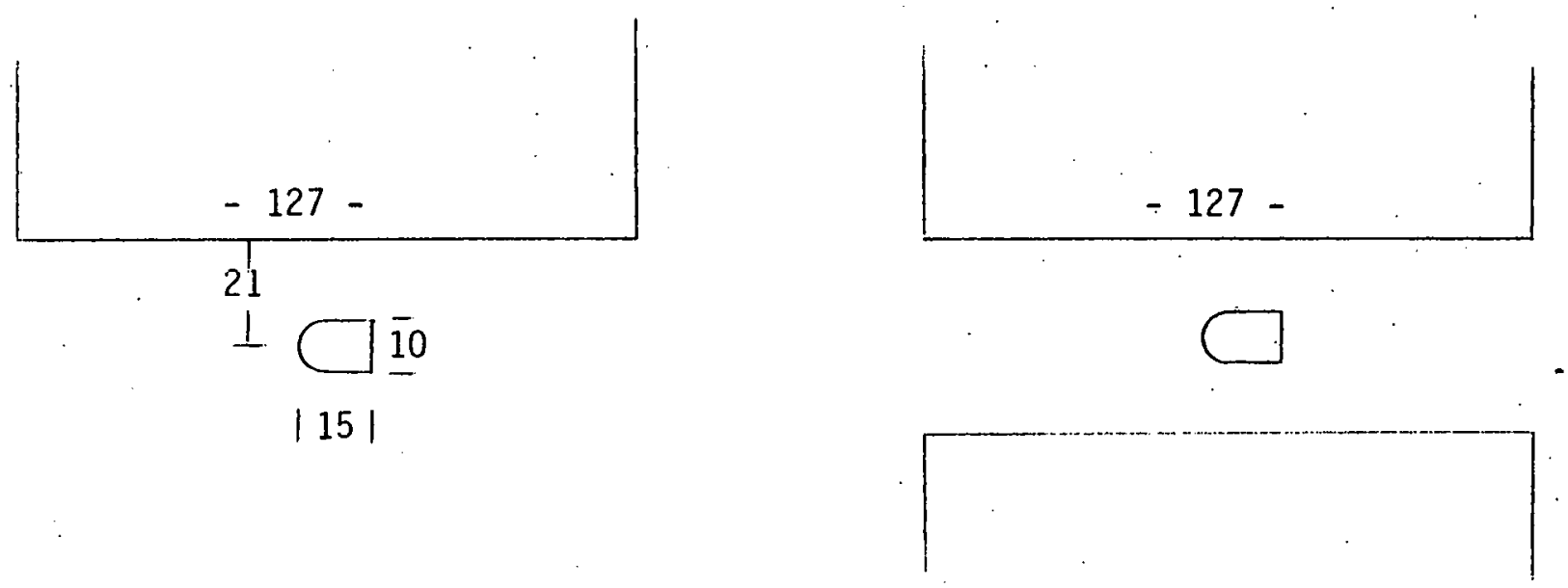
a) $\Omega=34.4 \pm 0.1 \%$
U.L. $=10.4 \%$
b) $\Omega=68.2+0.2 \%$
U.L. $=0.3 \%$

- 203.2 -
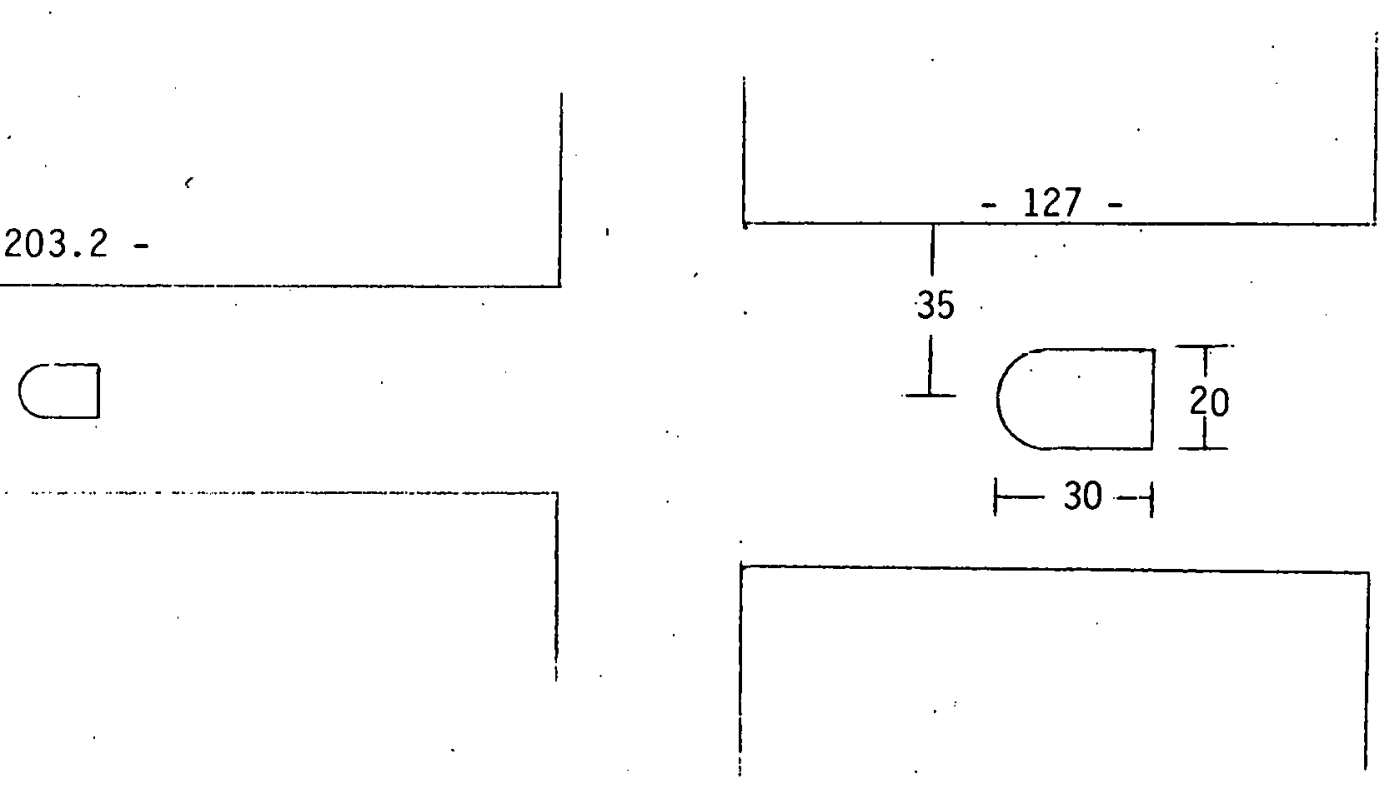
c) $\Omega=79.5 \pm 0.2 \%$
U.L. $=0.1 \%$

d) $\begin{aligned} & \Omega=51.3 \pm 0.3 \% \\ & \text { U.L. }=2.1 \%\end{aligned}$

Figure B-2. Average solid angles and errors for extended neutron source and right circular cylindrical detectors arranged as shown (half-scale). All dimensions are in millimeters. 
PRESSURE-VOLUME-TEMPERATURE RELATIONS FOR HIGH-DENSITY DEUTERIUM-TRITIUM TARGETS

Equations of state for fluid $\mathrm{D}_{2}$ and $\mathrm{T}_{2}$ at various temperatures are given and used in this section. Relationships between pressure $(P)$, volume (V) and temperature (T) for deuterium and tritium are needed to predict operating pressures to be contained by target vessels at elevated temperatures, and to determine pressures which must be used to fill the vessels with $\mathrm{D}_{2}-\mathrm{T}_{2}$ mixtures at desired densities at moderate temperatures.

The state properties of real gases can be expressed by the virial equation:

$P V / R T=1+B / V+C / V^{2}+D / V^{3}+\ldots .$,

where

$B, C, D$, . . are the second, third, fourth, etc. virial coefficients and are functions of temperature.

Values of these coefficients for deuterium and tritium for various temperatures $^{\mathrm{C}-1}$ are assembled in Table $\mathrm{C}-1$. Using these coefficients in Equation $\mathrm{C}-1$, we observe that compressibility factors (PV/RT) for tritium are within $\sim 2 \%$ of those calculated for deuterium at various temperatures.

A general equation of state for tritium valid in the region $2<P<20 K b a r$ and $75<T<300 \mathrm{~K}$ has also been obtained ${ }^{\text {: }}$ :

$$
\begin{aligned}
V= & \left(34.342+0.00026515 T+14.317 \mathrm{~T}^{-1 / 2}\right) \mathrm{P}^{-1 / 3} \\
& +(-27.506+0.017580 \mathrm{~T}) \mathrm{P}^{-2 / 3} \\
& +\left(24.268+0.050145 T-280.19 T^{-1 / 2}+1161.1 \mathrm{~T}^{-1}\right) \mathrm{P}^{-1} \mathrm{~cm}^{3} / \mathrm{mol}^{-1}
\end{aligned}
$$


TABLE C-1. SECOND, THIRD, AND FOURTH VIRIAL COEFFICIENTS FOR DEUTERIUM AND TRITIUM AT VARIOUS TEMPERATURES

\begin{tabular}{|c|c|c|c|c|c|c|}
\hline \multirow[b]{2}{*}{$\begin{array}{r}T \\
(K) \\
\end{array}$} & \multicolumn{3}{|c|}{ Deuterium $_{2}$} & \multicolumn{3}{|c|}{ Tritium $_{2}$} \\
\hline & $\left(\mathrm{cm}^{3} / \mathrm{mol}\right)$ & $\begin{array}{c}\mathrm{C} \\
\left(\mathrm{cm}^{6} / \mathrm{mol}^{2}\right) \\
\end{array}$ & $\left(\mathrm{cm}^{9} / \mathrm{mol}^{3}\right)$ & $\left(\mathrm{cm}^{3} / \mathrm{mol}\right)$ & $\left(\mathrm{cm}^{6} / \mathrm{mol} 1^{2}\right)$ & $\left(\mathrm{cm}^{9} / \mathrm{mo}^{3}\right)$ \\
\hline 75 & -- & -- & -- & $-20 a$ & $520^{a}$ & 32395 \\
\hline 100 & -4.03 & 520 & 23750 & -4.68 & 500 & 22610 \\
\hline 150 & 5.94 & 460 & 14305 & 5.70 & 435 & 13620 \\
\hline 200 & 10.30 & 420 & 9985 & 10.10 & 405 & 9505 \\
\hline 250 & 12.58 & 395 & $7555^{\circ}$ & 12.38 & 385 & 7190 \\
\hline 300 & 13.94 & 385 & 6015 & $14.57^{b}$ & $290^{b}$ & $6400^{b}$ \\
\hline $\begin{array}{l}\text { a. } \\
\text { b. }\end{array}$ & $\begin{array}{l}\text { xtropolate } \\
\text { ee Ref. C- }\end{array}$ & $\begin{array}{l}\text { d to } 75 \mathrm{~K} f r \\
1, \text { Equation }\end{array}$ & $\begin{array}{l}\text { n values at } \\
\text { 3). }\end{array}$ & higher temp & atures. & \\
\hline
\end{tabular}


Calculations based on these above equations are represented in Table $\mathrm{C}-2$ and Figure $\mathrm{C}-1$, which should be particularly useful for the conditions planned for this experiment. Note that we define $\phi$ to be hydrogen density relative to that of liquid hydrogen:

$$
\phi=\rho / \rho^{\star}
$$

where $\rho^{*}=4.25 \times 10^{22}$ nuclei $/ \mathrm{cm}^{3}$

$$
=0.353 \mathrm{~mole} / \mathrm{cm}^{3} \text {. }
$$

We should point out that the vessel will expand by $\Delta V / V \sim 3 \%$ as the temperature increases to $700^{\circ} \mathrm{K}$, decreasing the density by a corresponding amount. Thus,

$\phi=\phi(T)=\dot{\phi}_{f i 11} \frac{V_{f i 11}}{V(T)}$

so that actual densities can be calculated at specific temperatures at which data are taken. $V(T)$ will be determined from thermal and stress analyses of the target vessel.

Figure $\mathrm{C}-1$ shows data for $\mathrm{P} / \mathrm{vs} \mathrm{T}$ for $\mathrm{H}_{2}$ up to $600^{\circ} \mathrm{K}$ and 1678 atmospheres. ${ }^{C-2}$ From the data we observe that $P$ : varies linearly with $T$ to a good approximation for $T>300 \mathrm{~K}$. This gives us confidence in linearly extrapolating results of equations $\mathrm{C}-1$ and $\mathrm{C}-2$ to $\mathrm{T}=700 \mathrm{~K}$. Design and maximum operating pressures (45Ksi and $30 \mathrm{Ksi}$ respectively) are also shown on the graph. Finally, we have also plotted P/vs $T$ for nitrogen ${ }^{\mathrm{C}-3}$ at liquid nitrogen density $(0.81 \mathrm{~g} / \mathrm{cc})$, showing that nitrogen may be of use in testing vessels to elevated pressures ( $245 \mathrm{Ksi}$ ) at moderate temperatures ( $2300 \mathrm{~K})$. 
TABLE C-2. CALCULATED COMPRESSIBILITY FACTORS FOR T2

\begin{tabular}{lccc}
\hline Phi & $\frac{V\left(\mathrm{~cm}^{3} / \mathrm{mole}\right)}{1.0}$ & 28.34 & $\frac{P V / R T(\text { at } T=75 \mathrm{~K})}{\mathrm{PV} / R T(\text { at } T=300 \mathrm{~K})}$ \\
0.7 & 40.49 & 2.36 & 2.16 \\
0.67 & 42.52 & 1.31 & 1.63 \\
0.4 & 70.85 & 1.24 & 1.59 \\
\hline
\end{tabular}




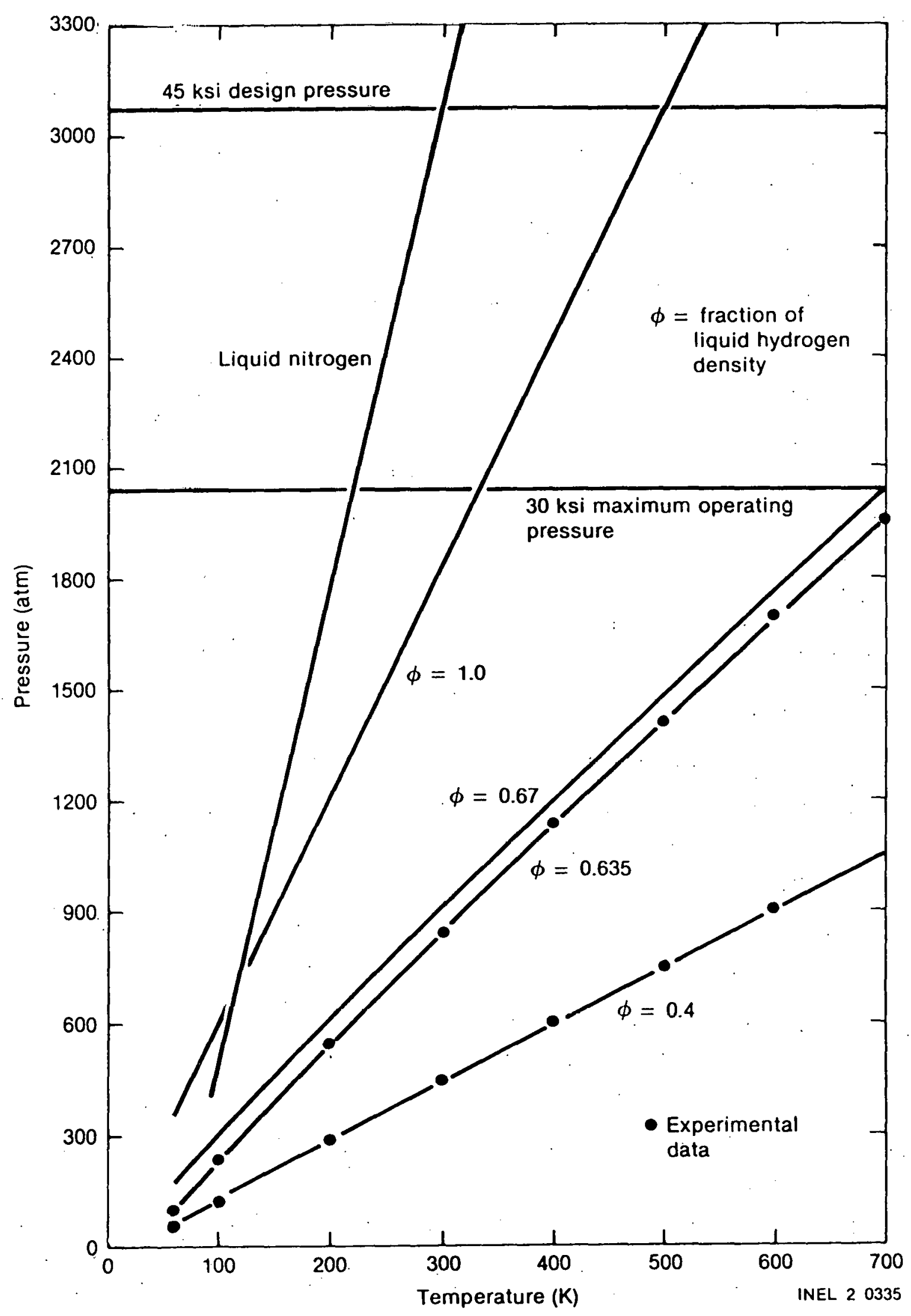

Figure C-1. Approximate pressure curves for high-density hydrogen and nitrogen gases. 
A COMPARISON OF TEMPERATURE SCALES

\begin{tabular}{|c|c|c|c|}
\hline K & ${ }^{\circ} \mathrm{C}$ & ${ }^{O} F$ & Kemarks \\
\hline $\begin{array}{r}0 \\
21 \\
70 \\
77 \\
273 \\
293 \\
373 \\
600 \\
700 \\
1336\end{array}$ & $\begin{array}{r}-273.2 \\
-252 \\
-223 \\
-223 \\
0 \\
20 \\
100 \\
327 \\
427 \\
1063\end{array}$ & $\begin{array}{r}-459.7 \\
-423 \\
-369 \\
-321 \\
32 \\
68 \\
212 \\
621 \\
800 \\
1945\end{array}$ & $\begin{array}{l}\text { Absolute zero } \\
\text { LH2 boils at } 760 \mathrm{mmHg} \\
\text { Lower limit, this experiment } \\
\text { LN2 boils at } 760 \mathrm{mmHg} \\
\text { Ice melts. } \\
\text { Room temperature } \\
\text { Water boils at } 760 \mathrm{mmHg} \\
\text { Lead melts } \\
\text { Upper limit, this experiment } \\
\text { Gold melts }\end{array}$ \\
\hline
\end{tabular}




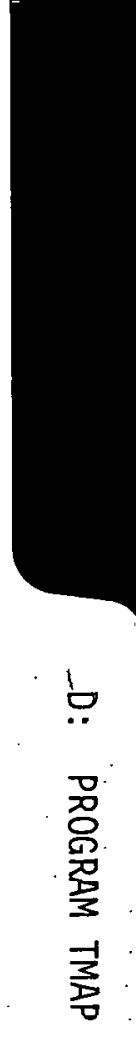




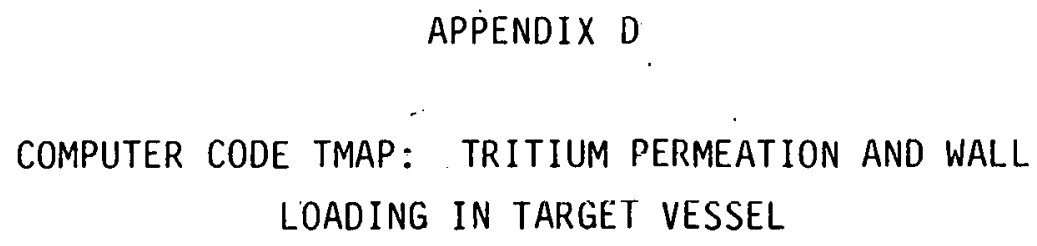

A computer program developed by the Fusion Reactor Safety Research Program at the Idaho National Engineering Laboratory has been modified to determine hygrogen permeation and wall loading in the target vessel proposed for this research. The Tritium Migration Analysis Program (TMAP) was written by D. F. Holl and and B. J. Merrill of EG\&G Idaho, Inc. D-1 TMAP solves differential equations for hydrogen movement through surfaces and in bulk materials, and includes equations for chemicil reactions.

In order to model conditions appropriate to this experiment, TMAP has been modified by its authors and S. E. Jones as follows. Diffusivities and solubilities for gold and stainless steel as shown in Table $D-1$ were incorporated into TMAP.

TABLE D-1. HYDROGEN DIFFUSIVITY (D) AND SOLUBILITY (S) CONSTANTS USED IN MODIFIED VERSION OF TMAP.

\begin{tabular}{|c|c|c|c|c|c|}
\hline & $\begin{array}{r}D_{0} \\
2\end{array}$ & ${ }^{Q_{D}}$ & $\frac{\mathrm{cm}^{3}(\mathrm{STP})}{3}$ & $Q_{S}$ & \\
\hline tainless & $\frac{\left(\mathrm{cm}^{2} / \mathrm{s}\right)}{0.12}$ & $\frac{(\mathrm{eV} / \mathrm{atom})}{0.61}$ & $\frac{\mathrm{cm}^{3} \text { atom }}{1.3}$ & $\frac{(\mathrm{eV} / \text { atom })}{0.06}$ & $\frac{\text { References }}{D-2, D-3}$ \\
\hline Gold & $5.6 \times 10^{-4}$ & 0.245 & 103.57 & 0.945 & $D-4$ \\
\hline
\end{tabular}

We note here that these data for gold are not well known. Thus, we make conservative assumptions regarding the effectiveness of gold plating as a tritium barrier, but insist on experimental tests of a target vesse 1 using pressurized hydrogen at elevated temperatures ( $2700 \mathrm{~K}$ ) prior to the experimental data-taking.

The variation of pressure of the deuterium-tritium mixture in the vessel as a function of temperature was calculated (see Appendix. C) and used in. TMAP. 
Changes in the hydrogen molecule recombination coefficient of steel and gold surfaces as a function of temperature were estimated (see Ref. D-5). Variations in the solubility constant (S) with absolute temperature $(T)$ were explicitly calculated using the relation:

$S=S_{0} \exp \left(-Q_{S} / R T\right)$

where $R$ is the Boltzmann constant $P$ is the pressure (atm) and $S_{0}$ and $Q_{S}$ are enumerated in Table $D-1$.

Permeation rates in TMAP are calculated in hydrogen molecules $/ \mathrm{cm}^{2} / \mathrm{sec}$, and wall inventories are expressed in hydrogen atoms $/ \mathrm{cm}^{3}$. These results were converted to the common unit of radioactivity, assuming all the hydrogen in the target to be tritium:

$$
\begin{aligned}
R & =\lambda N \\
& =1.8 \times 10^{-9} \mathrm{~s}^{-1} \times 1 \text { curie } / 3.7 \times 10^{10} \mathrm{~s}^{-1} \\
& =4.84 \times 10^{-20} \mathrm{Ci} / \text { atom } \\
& =9.67 \times 10^{-20} \mathrm{Ci} / \mathrm{molecule} \\
& =9765 \mathrm{Ci} / \mathrm{gm}
\end{aligned}
$$

Tritium permeation rates through steel (2mm thick, approximate thickness of the hemispherical end cap enter target vessel) and a thin gold layer are shown in Figure $\mathrm{D}-1$, as functions of time and temperature, at tritium density $=70 \%$ that of liquid hydrogen. Note that hydrogen permeation reaches steady-state values for gold (steel) in approximately 3 seconds ( 1.5 hours). The loss of tritium due to permeation is seen to be less than 5 microcuries over the course of an experimental run with or without the gold plating, an insignificant amount. 
Figure D-1.

\section{TRITIUM PERMEATION RATE THROUGH GOLD AND STEEL AS PREDICTED BY TMAP}

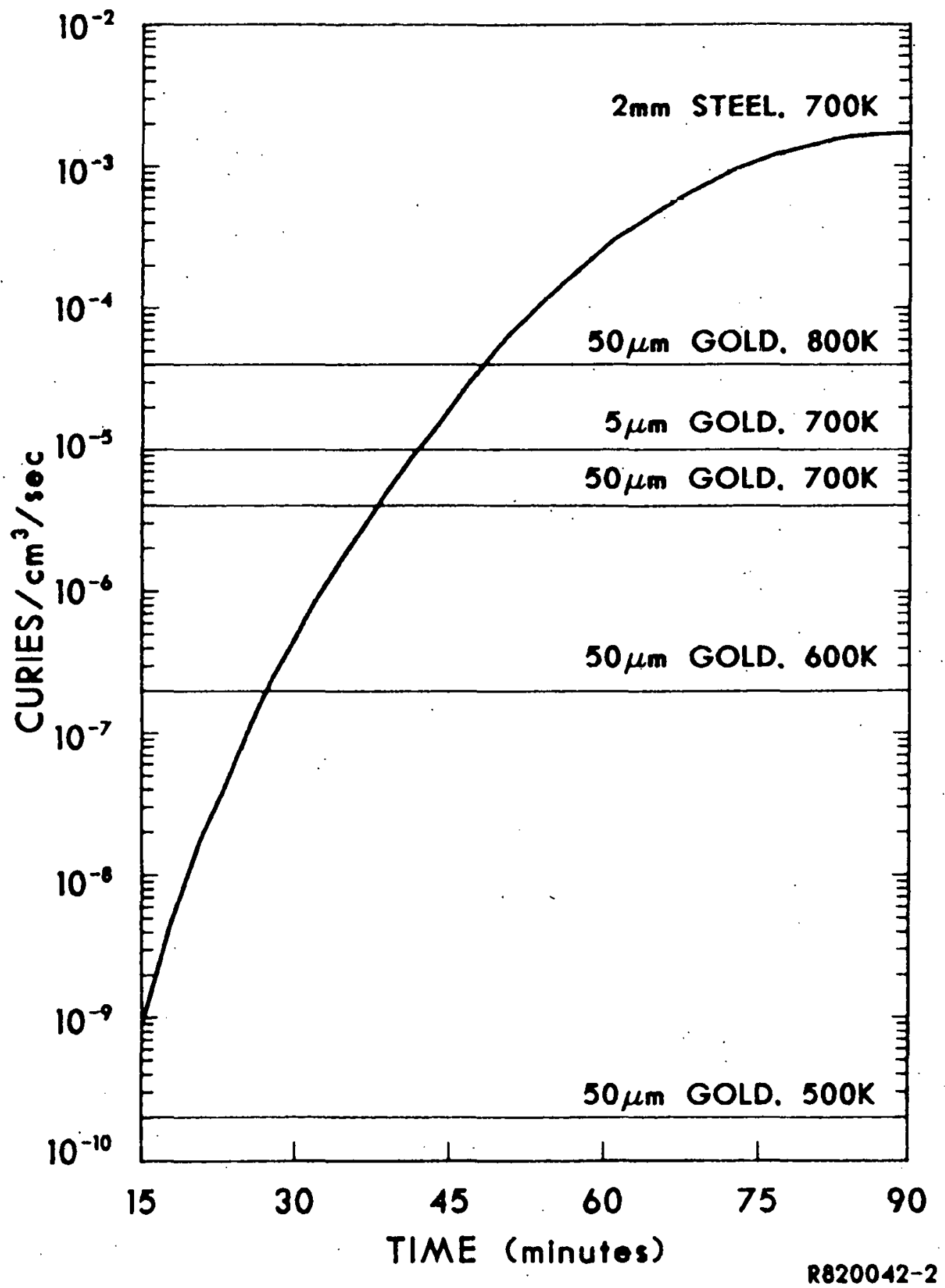


Tritium loading in the stainless steel target vessel walls (maximum thickness, $3.8 \mathrm{~mm}$ ) is shown in Figure $\mathrm{D}-2$ for a hydrogen target at $700 \mathrm{~K}$, with hydrogen density of $70 \%$ that of liquid hydrogen. TMAP demonstrates that tritium build-up increases as the square root of pressure, but exponentially with temperature, for a gold layer, so it is the temperature rather than the density of the hydrogenic target that drives tritium build-up. 18 on the other hand, tritium inventory in steel without gold plating is fairly insensitive to temperature changes, and is of order $10^{3} \mathrm{ppm} H$ in the steel after $\sim 10$ minutes. Since 1 ppm hydrogen in stainless steel is sufficient to embrittle it, stainless steel without gold plating would certainly become brittle in this experiment. Therefore, a gold layer is needed to provide a hydrogen permeation barrier. Gold plating 50 microns thick allows the target vessel to be used for about 15 minutes at $700 \mathrm{~K}$ before hydrogen concentration reaches $1 \mathrm{ppm}$ in the steel. This assumes that all of the hydrogen permeating the gold barrier stops in the steel.

TMAP is being modified still further to model the gold-steel interface, so that the hydrogen inventory in the steel can be determined as a function of distance from the gold barrier, and time. It is expected that results of this modelling may, at worst, require that the maximum target temperature be lowered to $\sim 650 \mathrm{~K}$, to insure that the vessel does not become brittle due to hydrogen. 
Figure D-2.

\section{TRITIUM WALL LOADING IN STAINLESS STEEL TARGET VESSEL AT $700 \mathrm{~K}$ AS PREDICTED BY TMAP}

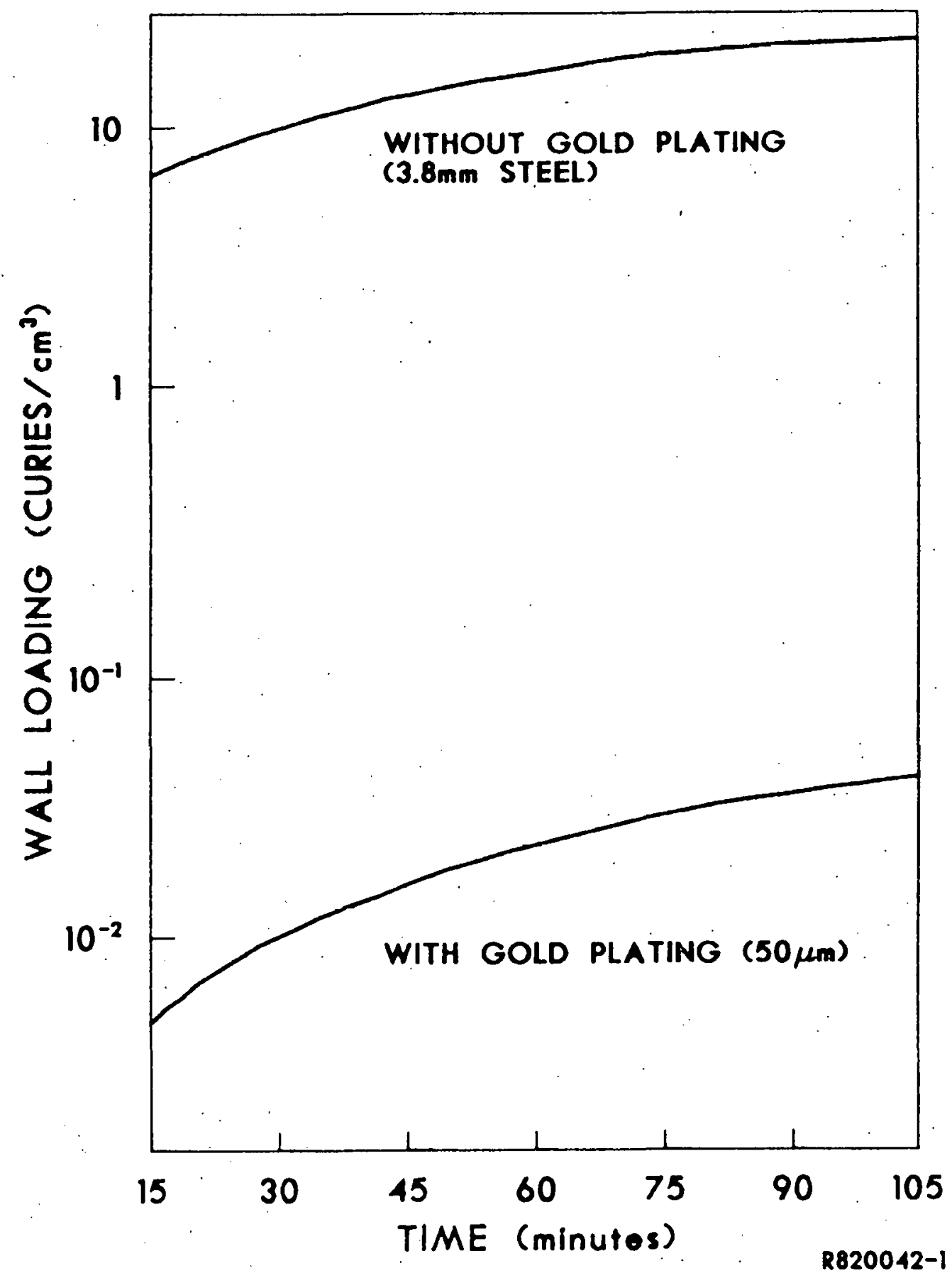




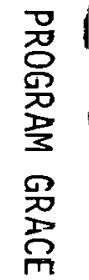


APPENDIX E

COMPUTER PROGRAM GRACE

A FORTRAN IV program is used to calculate neutron detection efficiencies in organic scintillators using Monte Carlo methods. The proqram was originally written by Noel Stanton. ${ }^{-1}$ It has been adapted to run on the dual CYBER-176 computer system of the INEL by Gus Caffrey and Steven $E$. Jones.

In organic scintillators, neutron detection results from ionization produced by charged particles (protons, alpha particles, nuclear fragments) which result from neutron interactions with carbon and hydrogen nuclei. The program calculates pulse height spectra due to light output of the scintillator which results from ionization.

The light output of an organic scintillatior is not linear in energy loss for slowly-moving heavy charged particles. This effect (called saturation) must be simulated for each type of particle, and may depend on scintillator type. GRACE assumes plastic scintillation material. However, we use the program to estimate neutron detection efficiencies in NE213 liquid scintillator, although we expect it's saturation properties to vary somewhat from those of plastic scintillators.

The unit of light output used in GRACE is MeV electron equivalent:

MeVee $\equiv$ Kinetic energy of a stopping electron in MeV which produces the same amount of light as the stopping heavy charged particle in question.

For instance, a stopping $4 \mathrm{MeV}$ proton will produce about 1.4 MeVee of light output in a plastic scintillator. 
GRACE accepts the following inputs:

1. Size and shape of counter (retangular or cylindrical)

2. Scintillator density and ratio of hydrogen to carbon atoms

3. Incoming neutron energy

4. Light collection thresholds (in MeVee).

Neutron detection efficiency is determined by Monte Carlo methods to about $15 \% .^{E-1}$ Recoil energies and directions of individual ncutrons are also calculated. This will allow us to fold in the geometrical acceptance of detectors to calculate overall neutron detector efficiency (see Section 6). GRACE is used to predict neutron detection efficiencies for. Pilot $F$ and NE213 scintillators as a function of thickness as shown in Figure E-1: These results allow us to assess the effects of scintillator choice and detector geometries on neutron detection efficiencies (see Section 6). 

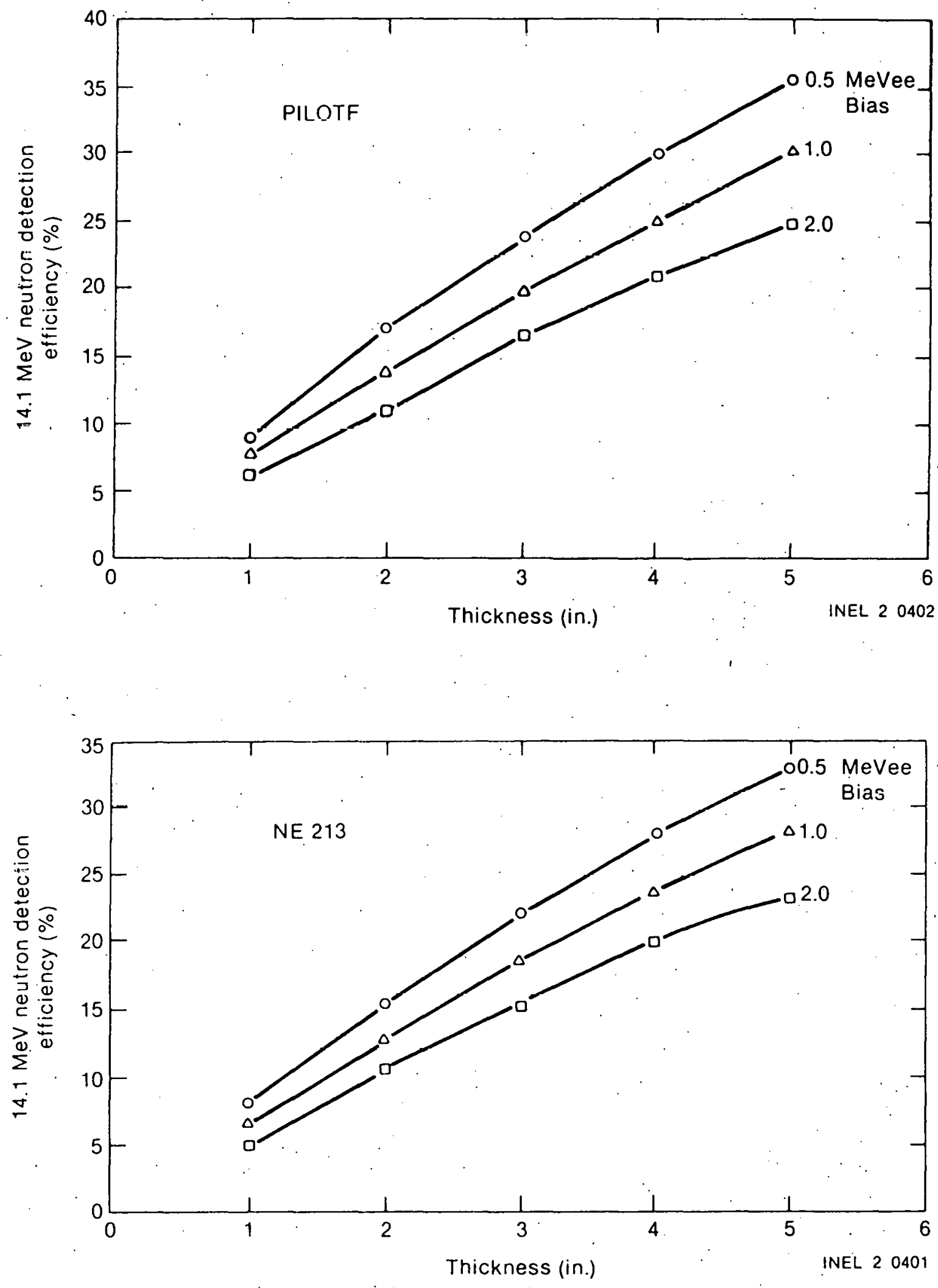

Figure E-1. Neutron detection efficiencies for Pilot $F$ and NE213 scintillator materials. 


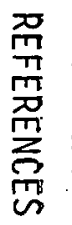




\section{REFERENCES}

1. S. E. Jones, "Measurement of the Efficiency of Muon-Catalyzed Fusion," Proposal Submitted to the Department of Energy, EG\&G Idaho, Inc., 23 December 1981.

2. Yu. V. Petrov, "Muon Catalys is for Energy Production by Nuclear Fusion," Nature, 285:466-468 (12 June 1980).

3. J. Rafelski, "Hydrogenic Meso-Molecules and Muon Catalyzed Fusion," CERN Preprint Ref. TH. 2674-CERN (8 June 1979).

4. J. D. Jackson, "Catalys is of Nuclear Reactions Between Hydrogen Isotopes by $\mu$ - Mesons," Physical Review, 106:330-339 (15 Apri 1 1957).

5. S. S. Gershtein and L. J. Ponomarev, "Meso-molecular Processes Induced by $\mu-$ and $\pi$ - Mesons," In Muon Physics, Vol. III, 142-233. V. W. Hughes and C. S. Wu.eds., New York: Academic. Press, 1975.

6. L. Bracci and G. Fiorentini, "Some Aspects of the Muon Catalysis of d-t Fusion," Nuclear Physics A364:383-407 (6, 13 July 1981).

7. H. Takahashi, "Energy Production Due to the $\mu$-Catalyzed DT Fusion in a Mixture of Deuterium and Tritium," Paper Presented at ANS 1981 Winter Meeting, San Francisco, Nov. 29 - Dec. 4, 1981.

8. S. E. Jones and E. S. Marwil, Unpublished Study of Optimum Deuterium Tritium Concentrations for Muon Catalysis, Idaho National Engineering Laboratory, (1979).

9. S. S. Gerstein, and L.P. Ponomarev, " $\mu$ - Meson Catalys is of Nuclear Fusion in a Mixture of Deuterium \& Tritium," Physics Letters, 72B: 80-82 (5 December 1977).

10. V. M. Bystritsky, et al., "Experimental Detection and Investigation of Muon-Catalyzed Fusion of Deuterium and Tritium," Physics Letters B, 94B:476-479 (25 August 1998).

11. Telephone Conversation, S. E. Jones with K. M. Crowe (University of California at Berkeley), 22 0ctober 1981.

12. S. S: Gershtein, et al, "Kinetics of Muon Catalysis Processes in a Mixture of Deuterium and Tritium," Sov. Physics JETP 51:1053-1058 (June 1980).

13. Nuclear Systems Materials Handbook, Part I, Group I, Section 7.

14. B. J. Merrill (EG\&G Idaho, Inc.) Memo to S. E. Jones, 6 Oct. 1980.

15. C. T. Lynch, ed., CRC Handbook of Materials Science, Vol. II, Cleveland, Ohio: CRC Press, Inc., 1975. 
16. Huntington Alloys Bulletin Regarding Inconel Alloy 718, 1978.

17. Armco Product Data Bulletin Number SA-1C Regarding Armco A-286 Stainless Steel.

18. V. A. Maroni and E. H. Von Deventer, "Materials Considerations in Tritium Handling Systems," Journal of Nuclear Materials, 85:257 (1979).

19. Telephone Conversation,. S. E. Jones with Gene Downs (Mound Facility, 10 March 1981. Mr Downs points out that little is known about the effects on hydrogen build-up in vanadium and titanium alloys on their strengths. However, since austenitic stainless steels have suitable properties, he recommends one of these for high-pressure vessels containing hydrogen isotopes.

20. R. P. Wurstner (Mound Facility) Letter to S. E. Jones Dated 20 November 1981.

21. Telephone Conversation, S. E. Jones with Thomas Flannigan (Mound Facility), 4 November 1981.

22. S. S. Gershtein and L. J. Ponomarev, "Meso-molecular Processes Induced by $\mu^{-}$and $\pi^{-}$Mesons,". In Muon Physics, Vol. III. 1.42-233.

V. W. Hughes and C. S. Wu eds., New York: Academic Press, 1975.

A-1. C. Bricman et al., "Review of Particle Properties," Phys. Lett. 75B: i-250, (Apri1 1978).

B-1. L: Wielopolski, "The Monte Carlo Calculation of the Average Solid Angle Subtended by a Right Circular Cylinder From Distributed Sources," Nuclear Instruments and Methods, 143:577-581, 1977.

C-1. R. L. Mills, D. H. Liebenberg, J. C. Bronson, "Equation of State of Fluid $T_{2}$ deduced from $P-V-T$ and Ultrasonic-velocity Measurements on $\mathrm{H}_{2}$ and $\mathrm{O}_{2}$ to 20Kbar," J. App 1. Phys. 49 (11):550-5506, November 1978.

C-2. J. Research N.B.S., 41:379.

C-3. J. S. Kunk le, S. D. Wilson, R. A. Cota, Compressed Gas Handbook, NASA SP-3045, 1969.

D-1. D. F. Holland and B. J. Merrill, "Analysis of Tritium Migration and Deposition in Fusion Reactor Systems," EGG-M-10281, Paper presented at the 9th Symposium on Engineering Problems of Fusion Research, 26-29 Octuber 1981.

D-2. J. L. Cecchi, "Tritium Permeation and Wali Loading in the TFTR Vacuum Vesse1," J. Vac. Sci. Technol., 16:58 (1979). 
D-3. Conversation, S. E. Jones with D. F. Holland, 3 March 1982.

D-4. Telephone Conversation, S. E. Jones with K. L. Wilson, 22 February 1982.

D-5. M. I. Baskes, "A Calculation of the Surface Recombination Rate Constant for Hydrogen Isotopes on Metals," J. Noel. Mat1s., 92:318 (1980).

E-1. N. R. Stanton, "Monte Carlo Program for Calculating Neutron Detection Efficiencies in Plastic Scintillator," Ohio State Univ. Research Foundation, C00-1545-92, Feb. 1971. 